Reprod. Nutr. Dévelop., 1987, 27 (2 A), 327-398.

\title{
Revue bibliographique : \\ Variations quantitatives et métabolisme des lipides dans les tissus adipeux et le foie au cours du cycle gestation-lactation
}

\section{2e partie (1) : chez la brebis et la vache}

Y. CHILLIARD

Laboratoire de la Lactation, I.N.R.A., Theix, 63122 Ceyrat, France.

Summary. Literature survey : body composition and lipid metabolism in adipose tissues and liver during pregnancy and lactation. 2. In the ewe and the cow.

This comprehensive review describes changes in body lipids, energy balance and metabolic pathways and endocrine regulations in the adipose tissues and liver of ewes and cows during pregnancy and lactation. These profiles are discussed in relation to litter size, food intake and diet composition. The interactions between teleophoretic mechanisms (that direct nutrients to the gravid uterus or to the mammary gland) and homeostatic mechanisms (that ensure maintenance of the mother organism) have been emphasized.

\section{Préambule}

\section{Particularités nutritionnelles des ruminants (cf. I.N.R.A., 1978)}

Par rapport à la ratte, qui a fait l'objet de la première partie de cette revue bibliographique (Chilliard, 1986), les ruminants présentent des particularités digestives qui conditionnent largement, par la nature des nutriments absorbés, l'orientation de leur métabolisme. En effet, les aliments qu'ils ingèrent, riches en parois végétales, séjournent pendant 15 à $48 \mathrm{~h}$ dans le rumen-réseau (dont le contenu est de 60 à $100 \mathrm{I}$ chez le bovin adulte), où ils subissent une dégradation plus ou moins complète sous l'action des enzymes sécrétées par les micro-organismes qui y pullulent $\left(10^{10}\right.$ par $\left.\mathrm{ml}\right)$.

Les acides gras volatils (acétique, propionique, butyrique principalement) produits au cours de ces dégradations représentent de 50 à $70 \%$ de l'énergie absorbée. Le reste de l'énergie (glucose, 3 à $15 \%$; acides aminés, 15 à $25 \%$ et lipides 5 à $15 \%$ ) est absorbé au niveau intestinal. Les acides aminés et les acides gras

(1) Première partie : chez la ratte, voir Reprod. Nutr. Dévelop., 19:86, 26, 1057-1103. 


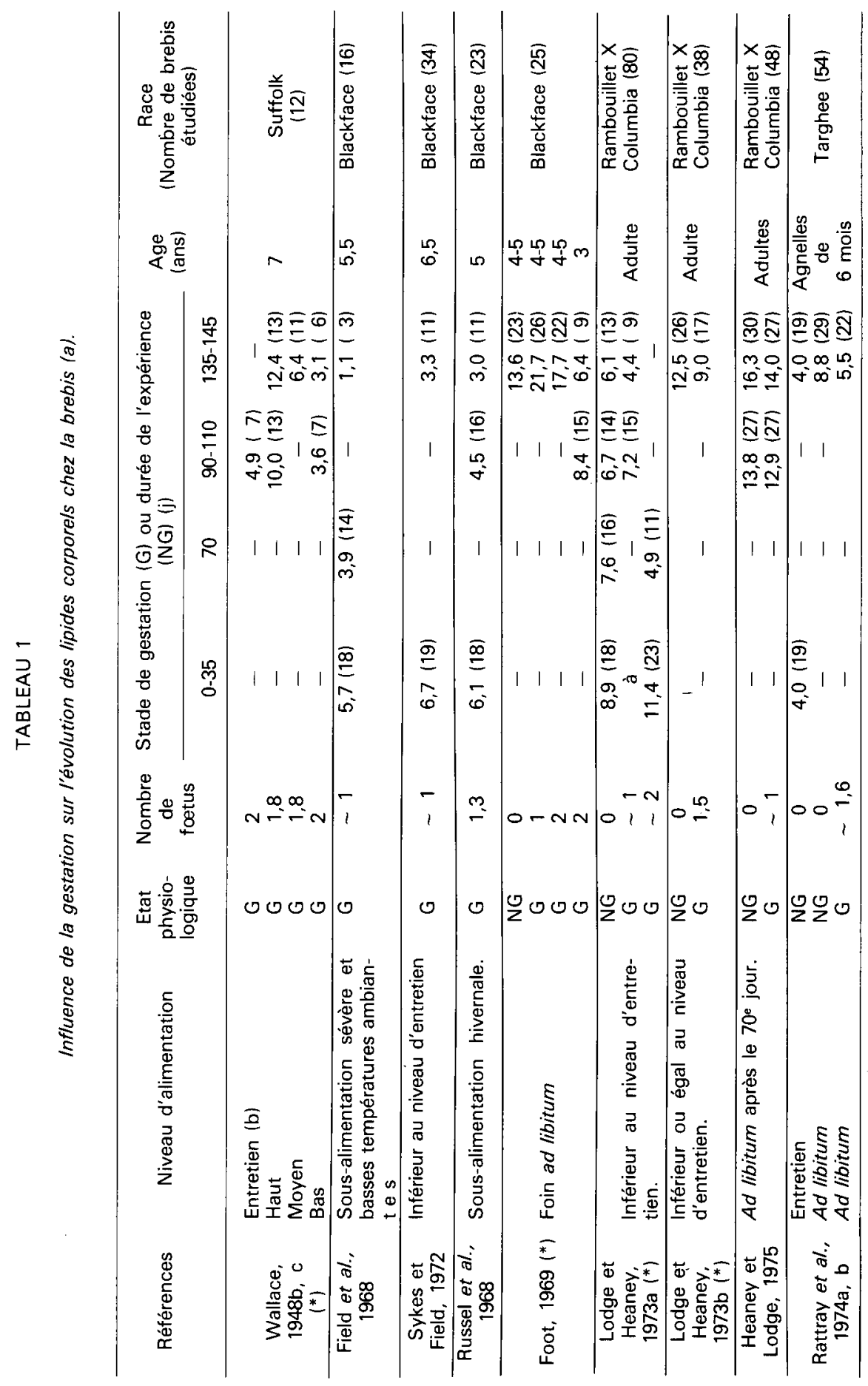




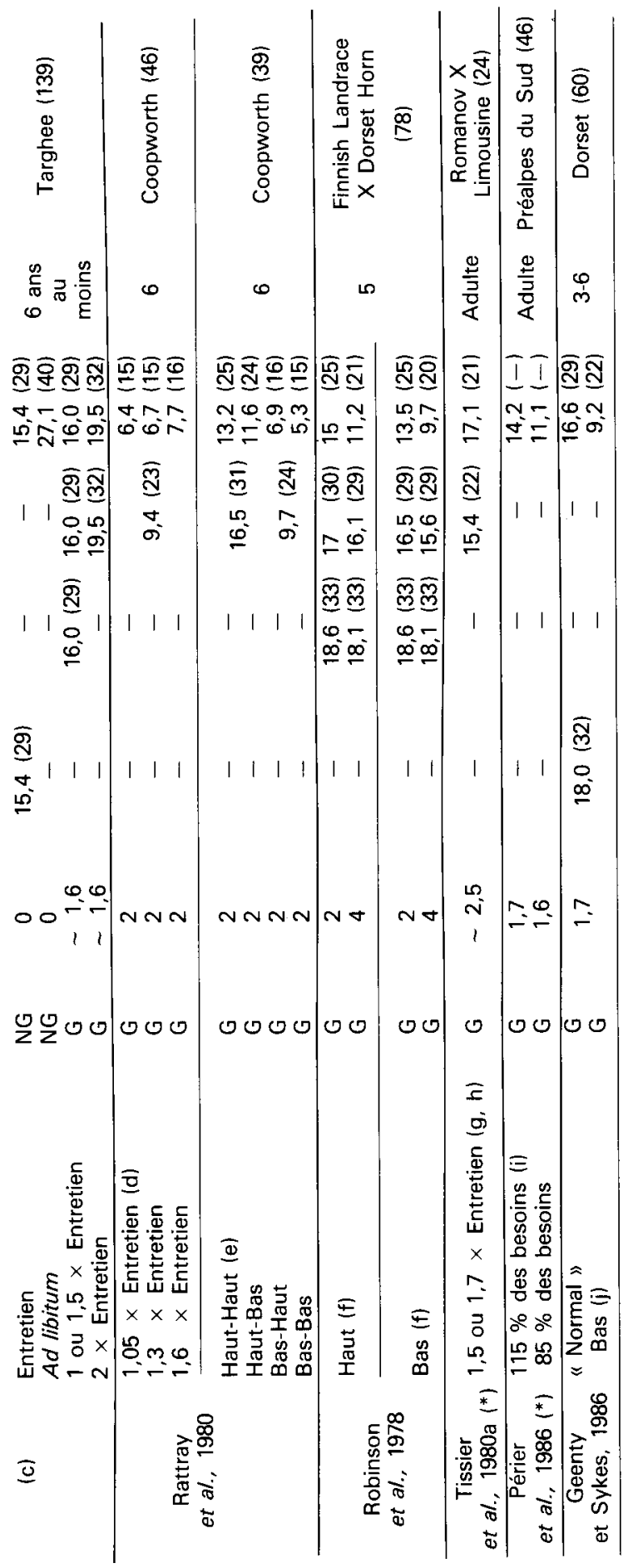

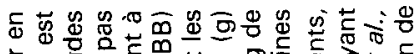

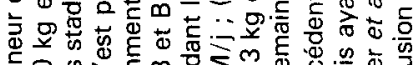

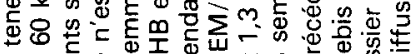

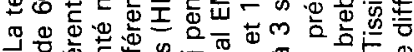

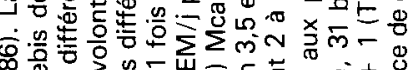

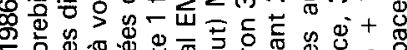

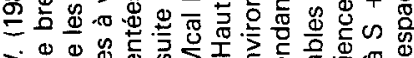

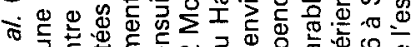

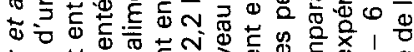

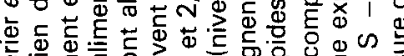

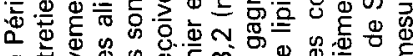
음

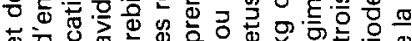

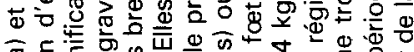

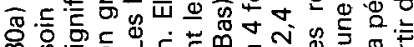

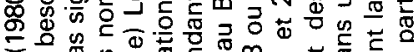
$=0 \%$

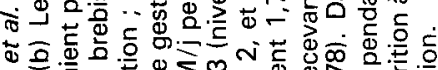

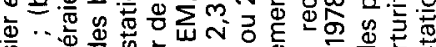

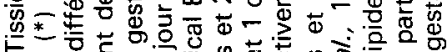
䒠

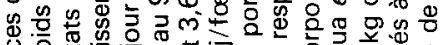

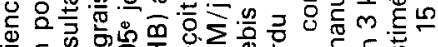

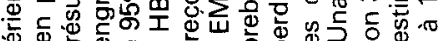

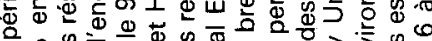

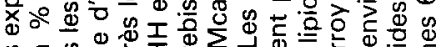

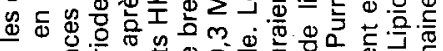

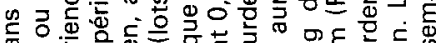

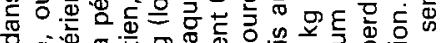

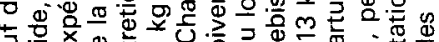

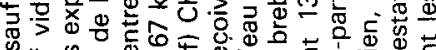
ڤ.

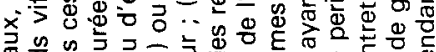

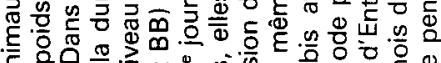

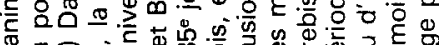

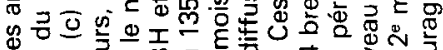

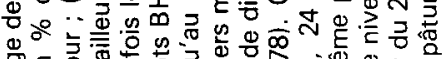
兽

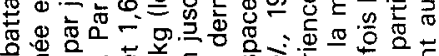

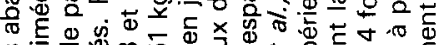

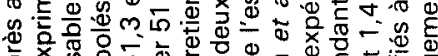

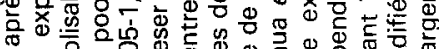

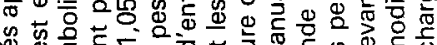

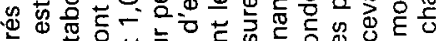

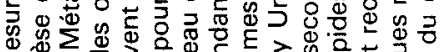

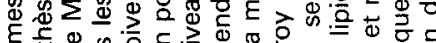

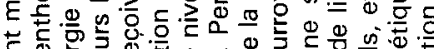

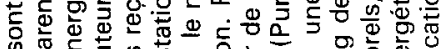

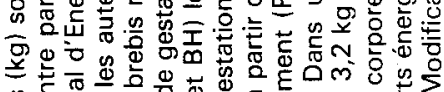

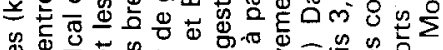

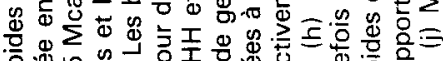

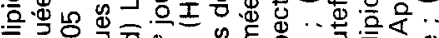

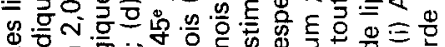
9. ब의

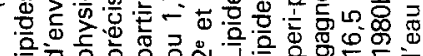


arrivant dans l'intestin diffèrent, en quantité et en proportions, de ceux que l'animal ingère, en raison d'une part des dégradations et des transformations que subissent les protéines et les lipides alimentaires, et d'autre part des synthèses protéiques et lipidiques effectuées par la microflore du rumen. Les acides gras alimentaires sont largement hydrogénés en acide stéarique et en acides gras monoinsaturés de structure trans. Les lipides microbiens sont riches en acides gras ramifiés ou à nombre impair de carbone.

Le long temps de séjour des aliments dans le rumen, et sa vidange continue, se traduisent par une certaine permanence de l'absorption des nutriments au cours du nycthémère, augmentant le temps nécessaire pour atteindre un état de jeun véritable. Ce phénomène, combiné à la faible teneur en lipides du régime et à I'hydrogénation importante des acides gras, explique la pauvreté du plasma de ruminant en lipoprotéines de très basse densité (VLDL) et en chylomicrons (Raphaël et al., 1973 ; Bickerstaffe et al., 1974 ; Harrison et al., 1974 ; Leat et Harrison, 1975). Celle-ci résulte en outre du catabolisme très rapide des VLDL et surtout des chylomicrons (Puppione, 1978 ; Ferreri et Elbein, 1982).

Le propionate produit dans le rumen est transformé en glucose dans le foie, ce qui compense la faible absorption de ce nutriment indispensable au métabolisme de l'animal. Cette néoglucogenèse permanente est permise par un rapport glucagon/insuline élevé, et une faible action du glucagon sur les tissus périphériques (Basset, 1975). Le métabolisme des lipides dans le foie de ruminant a été décrit par Rémésy et al. $(1984,1986)$. Nous rappellerons seulement ici que la lipogenèse de novo y est faible et qu'elle a surtout lieu dans les tissus adipeux à partir de l'acétate (Hanson et Ballard, 1967, 1968 ; Ballard et al., 1969, 1972 ; Hood et al., 1972 ; Ingle et al., 1972a, b ; Vézinhet, 1976 ; Liepa et al., 1978 ; Prior, 1978 ; Smith et Crouse, 1984). Cette caractéristique a été reliée à l'antagonisme existant entre néoglucogenèse et lipogenèse. II faut toutefois remarquer que la lipogenèse de novo hépatique est également faible chez certaines espèces

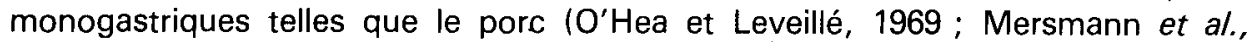
1973) qui ne sont pas dépendantes d'une néoglucogenèse permanente.

\section{Métabolisme des lipides dans les tissus adipeux et le foie chez la brebis.}

\section{Variations quantitatives des dépôts lipidiques et de l'énergie corporelle.}

\section{a) Gestation.}

Les résultats rassemblés dans le tableau 1 sont parfois difficiles à interpréter, car il n'existe pas toujours de témoins comparables (de même âge, de même format, de même état d'engraissement initial, et ayant subi le même traitement pendant la même période). Les tendances suivantes peuvent toutefois être soulignées : les brebis gravides sont généralement plus maigres en fin de gestation que celles qui ont reçu le même apport alimentaire sans être gravides (Lodge et Heaney, 1973a ; Rattray et al., 1974a ; Heaney et Lodge, 1975) mais l'inverse a pu être observé (Foot, 1969); les brebis portant 3 ou 4 foetus perdent plus de lipides (ou en déposent moins) que celles qui n'en portent qu'un ou deux (Robinson et 
al., 1978 ; Purroy Unanua et al., 1978) ; celles qui reçoivent une alimentation libérale peuvent soit mobiliser, soit déposer des lipides pendant le dernier tiers de la gestation (Wallace, 1948c ; Foot, 1969 ; Heaney et Lodge, 1975 ; Tissier et al., $1980 \mathrm{a}$, b) ; les quelques résultats concernant la première moitié de la gestation sont contradictoires; des brebis sous-alimentées peuvent mobiliser p/us de $50 \%$ de leurs réserves lipidiques pendant la gestation (Field et al., 1968 ; Russel et al., 1968 ; Sykes et Field, 1972 ; Robinson et al., 1978b ; Rattray et al., 1980 ; Geenty et Sykes, 1986).

A partir d'études calorimétriques mesurant la rétention globale d'énergie chez 4 brebis de race Mérinos portant un seul fœtus (Graham, 1964), et de mesures du contenu énergétique de l'utérus gravide, Langlands et Sutherlands (1968) ont pu calculer l'intensité du dépôt maternel à différents stades de gestation. Chez des brebis recevant $900 \mathrm{~g}$ d'aliment par jour, ce dépôt est positif (environ $40 \mathrm{~g}$ d'équivalent lipides par jour) pendant les 3 premiers mois de la gestation mais reste comparable à celui des témoins non gravides. Puis il diminue pour s'annuler pendant le dernier mois (en accord avec Corbett et al., 1982). Lorsque l'apport alimentaire est réduit à $600 \mathrm{~g}$ par jour, le dépôt est moins intense en début de gestation (en accord avec Eayres et al., 1985) et il y a mobilisation des lipides corporels pendant le dernier mois de gestation. Ce phénomène est en outre sous-estimé du fait du dépôt d'énergie qui a lieu simultanément dans la mamelle (environ 100 à $300 \mathrm{~g}$ de lipides jusqu'au $140^{\mathrm{e}}$ jour de gestation) (Lodge et Heaney, 1973b ; Rattray et al., 1974b ; Heaney et Lodge, 1975). Le poids de la mamelle avant la par-

TABLEAU 2

Contribution des tissus adipeux (TA) viscéraux à la mobilisation des lipides chez la brebis en gestation et en début de lactation.

\begin{tabular}{|c|c|c|c|c|c|c|c|}
\hline Période & $\begin{array}{l}\text { Stade } \\
\text { (Durée) }\end{array}$ & $\begin{array}{c}\text { Lipides } \\
\text { initiaux } \\
(\mathrm{kg})\end{array}$ & $\begin{array}{l}\text { Nombre de } \\
\text { foetus- } \\
\text { Niveau } \\
\text { alimentaire }\end{array}$ & $\begin{array}{l}\text { Variation } \\
\text { des lipides } \\
\text { corporels } \\
(\mathrm{kg})\end{array}$ & $\begin{array}{c}\text { dont TA } \\
\text { périrénal } \\
\mathrm{kg}(\%)\end{array}$ & $\begin{array}{c}\text { dont TA } \\
\text { épiploïque et } \\
\text { mésentérique } \\
\mathrm{kg}(\%)\end{array}$ & Références \\
\hline \multirow{4}{*}{ Gestation } & $\begin{array}{c}\text { Avant } 105 \mathrm{j} \\
(125 \mathrm{j})\end{array}$ & 6,1 & 1,3 - Bas & $-1,6$ & $-0,22(14)$ & $-0,15$ (9) & \multirow{2}{*}{$\begin{array}{c}\text { Russel et al., } \\
1968\end{array}$} \\
\hline & $\begin{array}{c}105-145 \mathrm{j} \\
(40 \mathrm{j})\end{array}$ & 4,5 & 1,3 - Bas & $-1,5$ & $-0,15(10)$ & $-0,34(22)$ & \\
\hline & $\begin{array}{c}74-116 \mathrm{j} \\
(42 \mathrm{j})\end{array}$ & $\begin{array}{l}18,6 \\
18,1\end{array}$ & $\begin{array}{l}2 \text { - Haut } \\
4 \text { - Bas }\end{array}$ & $\begin{array}{l}-1,4 \\
-3,5\end{array}$ & $\begin{array}{l}-0,24(17) \\
-0,41(12)\end{array}$ & $\begin{array}{l}-0,58(40) \\
-1,00(29)\end{array}$ & \multirow{2}{*}{$\begin{array}{l}\text { Robinson } \\
\text { et al., } 1978\end{array}$} \\
\hline & $\begin{array}{c}116-144 \mathrm{j} \\
(28 \mathrm{j})\end{array}$ & $\begin{array}{l}17,2 \\
14,6\end{array}$ & $\begin{array}{l}\text { 2- Haut } \\
4 \text { - Bas }\end{array}$ & $\begin{array}{l}-2,2 \\
-4,9\end{array}$ & $\begin{array}{l}-0,29(13) \\
-0,53(11)\end{array}$ & $\begin{array}{l}-0,64(29) \\
-1,23(25)\end{array}$ & \\
\hline \multirow{3}{*}{ Lactation } & \multirow{3}{*}{$\begin{array}{l}5-45 j \\
(40 \mathrm{j})\end{array}$} & 18 & Haut & $-4,8$ & \multicolumn{2}{|c|}{$-1,52(31)$} & $\begin{array}{c}\text { Cowan et al., } \\
1981\end{array}$ \\
\hline & & 20 & $\begin{array}{c}\text { Haut } \\
\text { Bas }\end{array}$ & $\begin{array}{l}-6,0 \\
-13,5\end{array}$ & \multicolumn{2}{|c|}{$\begin{array}{l}-1,26(21) \\
-3,31(25)\end{array}$} & \multirow{2}{*}{$\begin{array}{c}\text { Cowan et al. } \\
1980\end{array}$} \\
\hline & & 8 & $\begin{array}{c}\text { Haut } \\
\text { Bas }\end{array}$ & $\begin{array}{l}+0,4 \\
-5,1\end{array}$ & \multicolumn{2}{|c|}{$\begin{array}{l}-0,42(-) \\
-1,63(32)\end{array}$} & \\
\hline
\end{tabular}


turition est de $5,7 \mathrm{~kg}$ pour 4 fœtus et de $3,5 \mathrm{~kg}$ pour 2 fœetus. Plus de $70 \%$ de ce gain est réalisé pendant le dernier mois de gestation (Robinson et al., 1978).

La contribution de différents dépôts adipeux à la lipomobilisation au cours de la sous-alimentation de brebis gravides a été étudiée par Wallace (1948c), Russel et al. (1968) et Robinson et al. (1978). Pendant les 16 premières semaines de gestation, une perte de $1,6 \mathrm{~kg}$ de lipides résulte essentiellement de la mobilisation des tissus adipeux sous-cutanés, intermusculaires et périrénal. Pendant les 4 semaines qui précèdent la mise bas, la fonte lipidique $(1,5 \mathrm{~kg})$ s'accélère et l'ensemble des tissus adipeux sont mobilisés, y compris les lipides du squelette (Russel et al., 1968). Les tissus adipeux périrénal, épiplö̈que et mésentérique représentent de 25 à $55 \%$ des lipides mobilisés (tabl. 2). Chez des brebis en états d'engraissement variables, les dépôts adipeux sous-cutanés contribuent à la plus grande part des variations des lipides corporels (Russel et al., 1971), suggérant que les derniers tissus adipeux matures sont aussi les plus labiles. Ces résultats complètent et confirment ceux obtenus par Wallace (1948c).

Par ailleurs, la taille des adipocytes du tissu sous-cutané de brebis de race Finnoise $x$ Dorset tend à augmenter en début de gestation (jusqu'à $55-100$ jours) et à diminuer en fin de gestation (Vernon et al., 1981, 1985a). Ceci n'a toutefois pas été confirmé par Guesnet (1984) et lliou (1985) sur tissu omental de brebis moins prolifiques de race Préalpes du Sud.

\section{b) Lactation.}

Lorsqu'elles allaitent 2 agneaux, les brebis grasses a la parturition ou sousalimentées en lactation mobilisent plus de lipides (Fig. 1). Ces deux effets tendent
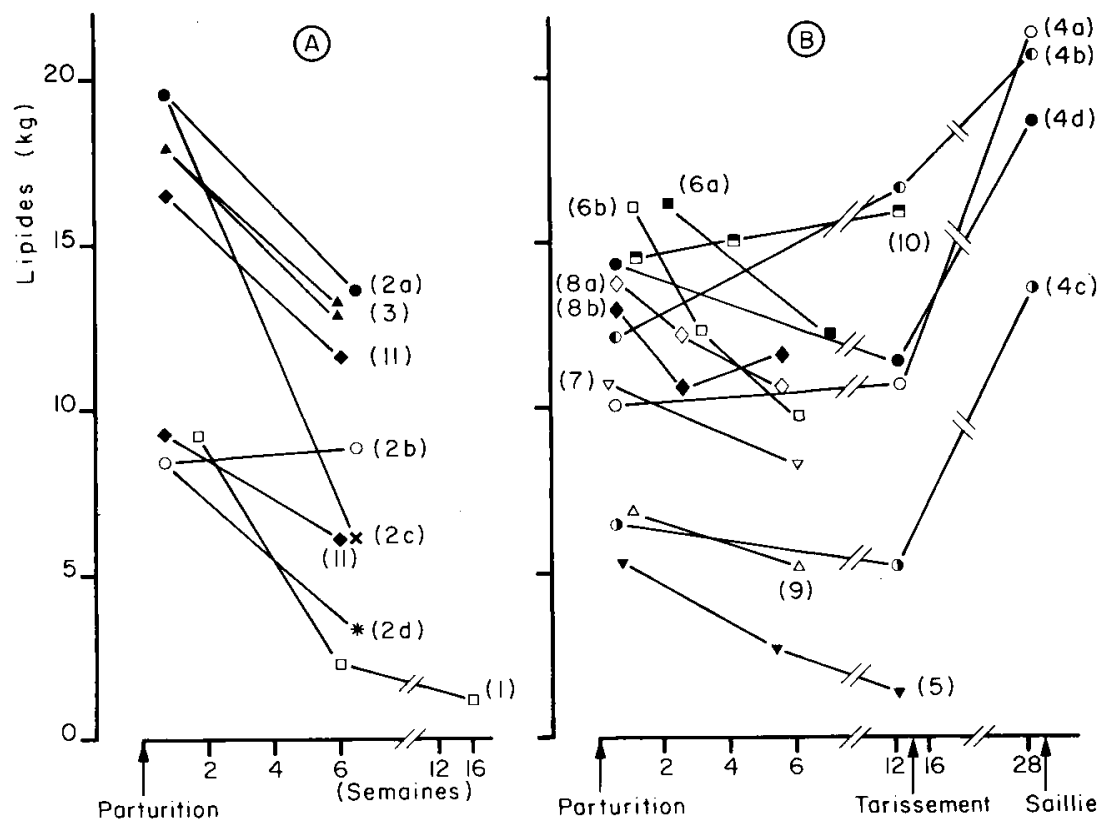

FIG. 1. 
à s'additionner, et l'effet de l'état d'engraissement est d'autant plus marqué que le niveau alimentaire ou l'ingestibilité de la ration sont faibles (fig. 2). Un effet saisonnier est aussi suggéré par Purroy Unanua et al. (1978) qui rapportent chez deux groupes de 24 brebis des mobilisations (mesurées à l'aide de l'eau lourde) de 3,4 et $6,5 \mathrm{~kg}$ de lipides (environ 20 et $40 \%$ des lipides corporels) après un agnelage de printemps et d'automne, respectivement. En automne, la fonte lipidique était en outre significativement liée à la race, au niveau alimentaire et au gain de poids des agneaux. Cet effet saisonnier n'a pas été confirmé dans une autre expérience (Tissier et al., 1980b). Un effet de la photopériode est cependant probable, car des brebis faibles productrices placées en photopériode longue produisent plus de lait et déposent moins de lipides corporels (Bocquier et al., 1986), probablement en raison d'une meilleure préparation de la lactation avant mise-bas. De

FIG. 1 A. - Lipides mesurés après abattage.

1. - Cowan et al., 1979 - () 3 à 4 brebis de race Leicester Blackface par stade, allaitant 2 agneaux et recevant 1,6 kg de MS/j (50\% concentré - $50 \%$ foin).

2. - Cowan et al., $1980-6$ brebis de race Finnish Landrace $\times$ Dorset Horn par point, allaitant 2 agneaux.

2a (•) et $2 \mathrm{~b}(\mathrm{o})-$ Ad libitum $(60 \%$ foin broyé $-40 \%$ de concentré $-2,2 \mathrm{Kcal}$ EM/g MS). Ingestion $=5,9$ et $6,9 \mathrm{Mcal} E M / \mathrm{j}-$ Production laitière $=3,2$ et $3,3 \mathrm{~kg} / \mathrm{j}$.

$2 \mathrm{c}(\times)$ et $2 \mathrm{~d}(*)=$ Ad libitum $(90 \%$ foin broyé $-10 \%$ concentré $-1,9 \mathrm{Kcal} \mathrm{EM} / \mathrm{g} \mathrm{MS})$. Ingestion $=4,4$ et $4,9 \mathrm{Mcal} \mathrm{EM} / \mathrm{j}-$ Production laitière $=2,5$ et $2,2 \mathrm{~kg} / \mathrm{j}$.

3. - Cowan et al., 1981 ( « ) 25 brebis de race Finnish Landrace $\times$ Dorset Horn (10 en $\mathrm{S}+1$ et 15 en $S+6$ ), allaitant 2 agneaux et recevant à volonté une ration contenant $60 \%$ de foin broyé et $40 \%$ de concentré $(2,2 \mathrm{Kcal} \mathrm{EM} / \mathrm{g} \mathrm{MS}$ et 11,6 ou $14,3 \%$ de protéines brutes $)$. Ingestion $=6,3$ ou $6,2 \mathrm{Mcal} \mathrm{EM} / \mathrm{j}-$ Production laitière $=3,3$ ou $3,5 \mathrm{~kg} / \mathrm{j}$.

11. - Geenty et Sykes, 1986 ( $\bullet 189$ brebis au pâturage de race Dorset $(40$ en $S+1$ et 149 en $S+$ 6 ), traites ou allaitant 2 agneaux, produisant de 1,5 à $3,0 \mathrm{~kg}$ de lait par jour et ingérant de 4,1 à 6,6 Mcal EM/j. Les lipides corporels des différents lots en $S+6$ variaient de 5,9 à 10,8 kg selon les traitements.

FIG. 1 B. - Lipides estimés d'après l'espace de diffusion de l'eau marquée.

4. - Foot et Russel, 1979 - 6 à 8 brebis de race Scottish Blackface par lot, recevant de l'herbe déshydratée à volonté et allaitant $1(4 \mathrm{a}, 0 ; 4 \mathrm{~b}, 0)$ ou $2(4 \mathrm{c}, 0 ; 4 \mathrm{~d}$, - ) agneaux.

5. - Foot et al., $1979-(-) 10$ brebis de race Border Leicester $\times$ Scottish Blackface, allaitant 2 agneaux (Alimentation non précisée).

6. - Purroy Unanua et al., 1978 - Deux lots de 24 brebis de race Limousine ou Romanov $\times$ Limousine allaitant environ 2 agneaux. $6 a(-)$, agnelage de printemps; apport énergétique couvrant l'entretien et $1,7 \mathrm{~kg}$ de lait $(5,2 \mathrm{Mcal} E M / j$ pour une brebis pesant $60 \mathrm{~kg}$ à $90 \mathrm{j}$ de gestation). $6 b(\square)$, agnelage d'automne; apport énergétique couvrant l'entretien et 1,7/1,2 ou $0,8 \mathrm{~kg}$ de lait $(5,2 / 4,2$ ou $3,5 \mathrm{Mcal} E M / j)$. (Le pic de production de ces brebis est d'environ $2,2 \mathrm{~kg}$ de lait).

7. - Tissier et al., 1980a $-(\nabla)$ Trois lots de 8 brebis de race Limousine ou Romanov $\times$ Limousine, allaitant environ 2 agneaux. Apport énergétique de 4,8/4,3 ou 3,8 Mcal EM/j.

8. - Tissier et al., 1980b - Brebis de race Limousine ou Romanov $\times$ Limousine, allaitant environ 2 agneaux. 8a ( $\diamond), 14$ brebis recevant environ 3,5 Mcal EM/j. 8b $(\bullet), 17$ brebis recevant environ 5,2 Mcal EM/j.

9. - Bocquier et al., $1984-(\Delta) 6$ brebis traites de race Frisonne $\times$ Sarde $\times$ Lacaune, produisant environ $0,6 \mathrm{~kg}$ de lait et recevant environ $2,4 \mathrm{Mcal} \mathrm{EM} / \mathrm{j}$ (couvrant l'entretien et $0,3 \mathrm{~kg}$ de lait).

10. - Bocquier, 1985 - (E) 48 brebis traites de race Préalpes du Sud produisant environ 1,2 kg de lait/j et recevant environ 5 Mcal EM/j (120\% de leurs besoins énergétiques). 
plus, la photopériode longue n'a une action favorable sur la production laitière que si les réserves lipidiques sont suffisantes à la mise-bas (Périer et al., 1986).

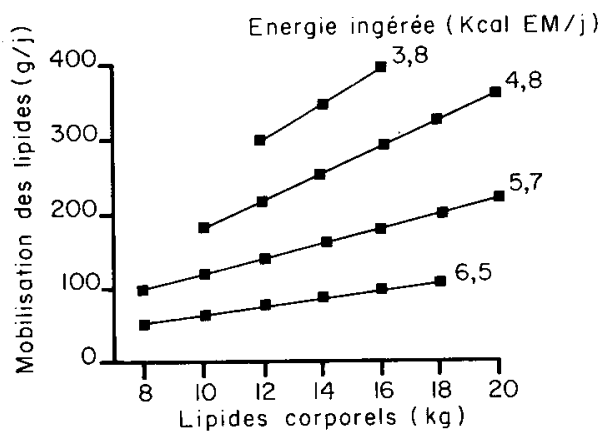

FIG. 2. - Relations entre l'état d'engraissement à l'agnelage, l'énergie ingérée et la mobilisation des lipides corporels chez la brebis pendant 6 semaines de lactation (adapté à partir des données de Cowan et al., 1982 et d'après Vernon et Flint, 1984).

Par ailleurs, des brebis alimentées de façon libérale et produisant peu de lait ont plus de lipides corporels après 1 ou 2 mois de lactation qu'à la parturition (Foot et Russel, 1979 ; Bocquier, 1985, fig. 1). Ces différentes observations confirment les tendances suggérées par les expériences zootechniques antérieures où la composition corporelle n'était pas mesurée (Peart, 1968a, b, 1970 ; Treacher, 1971).

Les quantités de lipides mobilisées par la brebis en début de lactation peuvent donc atteindre $400 \mathrm{~g} / \mathrm{j}$ et dépasser au total $13 \mathrm{~kg}$, ou $75 \%$ des lipides initiaux. Des brebis ayant subi de fortes sous-alimentations en conditions pratiques d'élevage, peuvent ne posséder que moins d'un $\mathrm{kg}$ de lipides corporels à l'issue d'un cycle gestation-lactation (Field et al., 1968 ; Sykes et al., 1974).

Les tissus adipeux périrénal, épiploïque et mésentérique contribuent à 20$30 \%$ de la mobilisation lipidique en début de lactation (tabl. 2). Ils sont en outre légèrement sollicités (- $420 \mathrm{~g}$ de lipides) chez des brebis dont le reste des lipides corporels augmente de $800 \mathrm{~g}$ environ pendant la même période. La lipomobilisation concerne aussi les lipides musculaires (Smith et al., 1981a). Le volume des adipocytes des tissus adipeux sous-cutané et omental diminue de moitié en deux mois de lactation chez des brebis allaitant 2 ou 3 agneaux, mais ne varie pas chez celles qui n'en allaitent qu'un seul (Vernon et al., 1981 ; Vernon et Flint, 1984 ; Smith et Walsh, 1984 ; Vernon et Finley, 1985 ; Vernon et Taylor, 1986), et il augmente après le sevrage.

Quelques études en chambres respiratoires ont été conduites. Des brebis produisant moins de $0,5 \mathrm{~kg}$ de lait déposent de 10 à $50 \mathrm{~g}$ d'équivalent lipides par jour au cours du premier mois de lactation (Graham, 1964). Toutefois, des brebis produisant en moyenne $1,2 \mathrm{~kg}$ ou $2 \mathrm{~kg}$ de lait en deuxième semaine de lactation mobilisent environ $60 \mathrm{~g}$ ou $170 \mathrm{~g}$ de lipides par jour (Cristian et al., 1980 ; Vermorel et al., 1984). Des mobilisations supérieures à $210 \mathrm{~g} / \mathrm{j}(80 \%$ de l'énergie du lait) sont observées pour une production de $3 \mathrm{~kg}$ de lait par jour. Au début du deuxième mois de lactation, des brebis produisant en moyenne de 0,7 à $1,5 \mathrm{~kg}$ de lait peuvent déposer de 25 à $30 \mathrm{~g}$ de lipides (Cristian et al., 1980 ; Corbett et al., 1982) ou en mobiliser jusqu'à $90 \mathrm{~g} / \mathrm{j}$ (Vermorel et al., 1984, 1985) selon la qualité de la ration distribuée et la quantité d'énergie volontairement ingérée. 
La lipomobilisation est assez bien liée à l'exportation d'énergie dans le lait chez les animaux alimentés en quantités limitées et elle contribue pour $80 \%$ à la couverture du déficit énergétique et pour 25 à $75 \%$ à l'énergie nécessaire à la production laitière (Vermorel et al., 1984, 1985).

La brebis gravide normalement alimentée ne mobilise ses lipides corpore/s que pendant le dernier tiers de la gestation et lorsqu'elle porte plusieurs fœtus. Lorsqu'elle est sous-alimentée, elle peut toutefois mobiliser plus de $50 \%$ de ses réserves lipidiques. En début de lactation, la lipomobilisation est fortement liée au nombre d'agneaux allaités ou au niveau de production laitière, au niveau alimentaire et à l'état d'engraissement initial des brebis, ainsi qu'à la saison. Elle peut atteindre et dépasser $300 \mathrm{~g} / \mathrm{j}$, et concerne l'ensemble des dépôts adipeux.

\section{Métabolisme du tissu adipeux.}

a) Synthèse et prélèvement d'acides gras.

La lipogenèse de novo des tissus adipeux sous-cutanés et épiplö̈que est élevée en début de gestation (0-70 j), diminue pendant la deuxième partie de la gestation, est très faible pendant la lactation et reste faible ou augmente après deux mois de lactation et après le sevrage (Vernon et al., 1981, 1985a, fig. 3 ; Christie

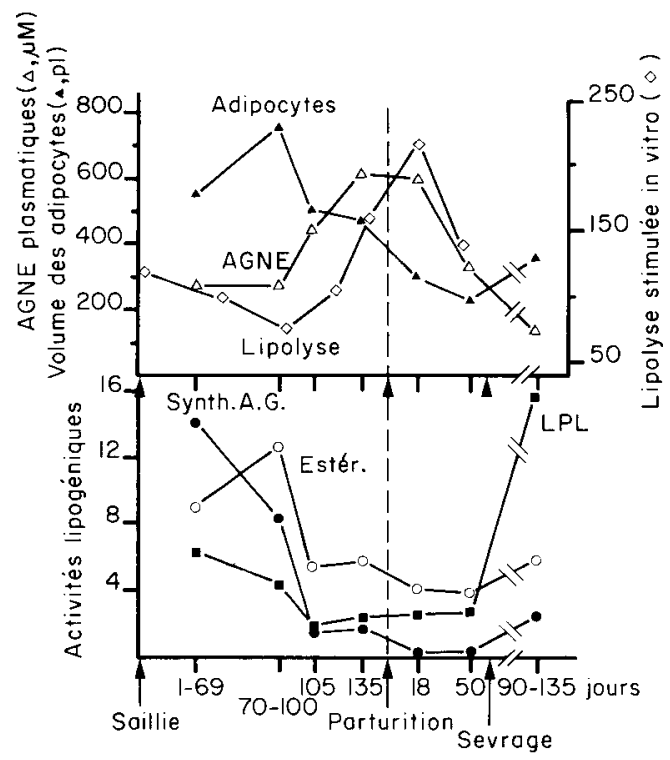

FIG. 3. - Activité métabolique du tissu adipeux chez la brebis au cours du cycle gestation-lactation. (Données de Vernon et al., 1981, sauf pour la lipolyse in vitro, Guesnet, 1984). $\bullet$, Synth. A.G. = synthèse d'acides gras ( $\mu$ moles d'acétate incorporé $/ \mathrm{h} / 10^{7}$ cellules). 0 , Estér. = synthèse du glycérol des glycérides ( $\mu$ moles de glucose incorporé $/ \mathrm{h} / 10^{\circ}$ cellules) (estérification)., $\mathrm{LPL}=$ lipoprotéine-lipase (nmoles $\mathrm{AG} / \mathrm{mn} / \mathrm{mg}$ protéines). $\diamond$, Lipolyse in vitro $=\mu \mathrm{g}$ de glycérol libéré/2 $h / 10^{6}$ cellules, en présence d'isoprénaline $\left(10^{-6} \mathrm{M}\right)$. 
et Noble, 1982 ; Smith et Walsh, 1984 ; Guesnet, 1984 ; Guesnet et al., 1986a). $L$ 'activité de la $L P L$ évolue en général parallèlement à la lipogenèse de novo (Vernon et al., 1981, 1985a, fig. 3 ; Smith et Walsh, 1984). Les quantités ingérées et produites par les animaux n'étaient toutefois pas précisées dans ces études. La lipogenèse et l'activité LPL en début de gestation ne semblent pas être supérieures à celles des témoins non gravides (Vernon et al., 1985a, 1986).

Glascock et al. (1983) ont mesuré la distribution de trioléine radioactive injectée à des brebis taries ou en lactation. Chez les brebis taries, de 65 à $80 \%$ des acides gras marqués sont oxydés, alors que 20 à $40 \%$ seulement le sont chez les brebis en lactation. Selon le stade de lactation, de 45 à $10 \%$ de la radioactivité est retrouvée dans les lipides du lait et, par différence, de 35 à $70 \%$ dans les lipides corporels (fig. 4). Selon ces auteurs, et Oldham et Lindsay (1983), ces données reflèteraient un fort ralentissement du dépôt corporel en début de lactation. Cette conclusion doit toutefois être nuancée puisque le flux total pourrait être approximativement doublé (si l'on se réfère aux quantités de lait produites) chez les brebis en début de lactation produisant de 1,2 à $2 \mathrm{~kg}$ de lait, par rapport à celles ne produisant que 0,5 à $1 \mathrm{~kg}$ par jour. Dans cette hypothèse, le dépôt corporel des acides gras circulants n'évoluerait que faiblement en cours de lactation chez les fortes productrices, et serait supérieur en début de lactation à celui observé chez les brebis produisant moins de lait ? Corrélativement, la mobilisation des acides gras endogènes était probablement accrue puisque ces brebis recevaient une ration constante (environ 1,5 UFL) couvrant les besoins d'entretien et de production correspondant seulement à $1,2 \mathrm{~kg}$ de lait à $6,4 \%$ de matières grasses (Tissier et Thériez, 1978).

La lipogenèse et l'activité LPL du tissu adipeux présentent des variations saisonnières considérables (Vernon, 1984 ; Vernon et Flint, 1984 ; Vernon et al.,

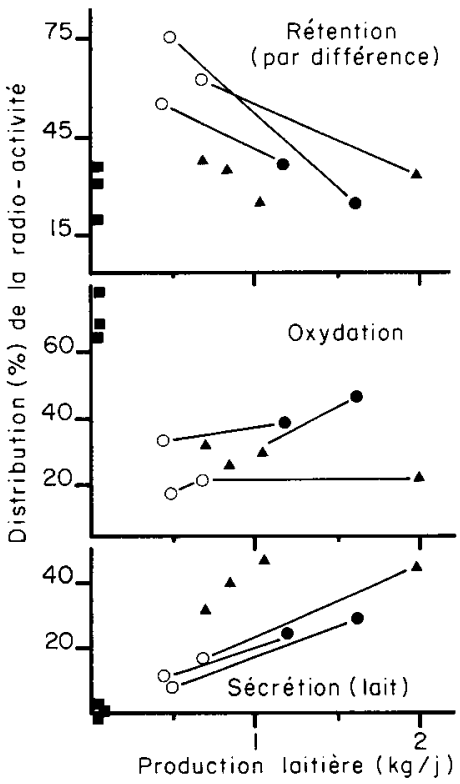

FIG. 4. - Partition des triglycérides circulants chez la brebis en lactation (adapté d'après Glascock et al. 1983). Stades de lactation: ^, $J_{12}$ à $J_{18} ; \bullet, J_{32}$ à $J_{34} ; 0, J_{58}$ à $J_{73} ; \bullet$, taries. Les traits indiquent un même animal 
1985a, 1986) qui peuvent interagir avec les variations liées au stade physiologique, et pourraient expliquer les observations de Purroy Unanua et al., 1978) (cf. cidessus). Les études effectuées au cours du cycle gestation-lactation sans témoins taris et non gravides doivent donc être interprétées avec précaution.

\section{b) Lipolyse et estérification des acides gras.}

Selon Vernon et al. (1981, 1985a) et Smith et Walsh (1984), I'incorporation du glucose dans le glycérol des trig/ycérides (l'estérification des acides gras) est élevée jusqu'au $70-100^{\circ}$ jour de gestation puis elle diminue et reste faible pendant les 6 dernières semaines de gestation, ainsi que pendant la lactation et après le sevrage (fig. 3).

A partir de mesures des entrées ou des pertes irréversibles de glycérol et d'AGNE chez 6 brebis, Wilson (1983) a estimé qu'à la fin du $4^{\mathrm{e}}$ mois de gestation une sous-alimentation modérée entraîne une augmentation de la lipolyse et une diminution de la réestérification. Au début du $5^{e}$ mois, la lipolyse et la réestérification augmenteraient simultanément, et la lipomobilisation ne serait que faiblement accrue chez des brebis en alimentation restreinte. Elle augmente par contre $(+65 \%)$ durant la dernière quinzaine en raison d'une diminution de la réestérification (Wilson, 1984). Le flux d'AGNE sortant du tissu omental in vivo augmente en fin de gestation (Sensenig et al., 1985). L'augmentation de la lipolyse durant le dernier mois est confirmée in vitro par Guesnet $(1984$, fig. 3) et par lliou et Demarne (1986), mais pas par Vernon et Finley (1985).

Par ailleurs, la lipolyse stimulée par l'isoprénaline (béta agoniste) mesurée sur adipocytes isolés de tissu omental est élevée en début de lactation (fig. 3) et se normalise en fin de lactation (Guesnet, 1984; lliou et Demarne, 1986). Ces auteurs n'observent pas de variations simultanées de la taille des adipocytes, malgré l'effondrement simultané de la lipogenèse, ce qui suggère l'existence d'autres facteurs in vivo. Par contre, Vernon et Finley (1985) rapportent une diminution de la lipolyse stimulée par la noradrénaline mesurée sur morceaux de tissu adipeux sous-cutané de brebis pendant la lactation, et l'expliquent par la diminution de la taille des adipocytes, qui conditionnerait l'intensité lipolytique. Pour une même taille des cellules, la lipolyse est en effet plus élevée pendant la lactation, surtout chez les brebis grasses.

En fin de gestation et durant la lactation la sensibilité du tissu adipeux de brebis à l'action antilipolytique de l'adénosine est accrue, comme chez la ratte (Vernon et Finley, 1985; lliou et Demarne, 1986). Toutefois, l'activité de la 5'nucléotidase (qui synthétise l'adénosine) serait simultanément inhibée (Vernon et Taylor, 1986).

L'essentiel des informations sur la lipomobilisation chez la brebis provient des mesures de concentrations des métabolites plasmatiques. Ainsi, les AGNE sanguins (et probablement la mobilisation des lipides corporels) (1) augmentent pen-

(1) Les teneurs en AGNE plasmatiques ne reflètent qu'en partie leur vitesse d'entrée dans l'organisme puisqu'elles résultent par ailleurs de leur vitesse de pénétration et d'utilisation dans les différents tissus (West et Annison, 1964) et des variations du volume plasmatique. Il existe toutefois généralement une bonne liaison entre leur teneur plasmatique et leur vitesse d'entrée ou leur turn-over (Armstrong et al., 1961 ; Leat et Ford, 1966 ; Annison et al., 1967b ; Jackson et al., 1968 ; Yamdagni et Schultz, 1969 ; Lindsay, 1978 ; Pethick et al., 1983 ; Emmanuel et Kennely, 1984b). 
dant le dernier tiers de la gestation. Cette augmentation est plus marquée lorsqu'on approche du terme, chez des brebis grasses, chez les brebis portant plusieurs fotus ou des fœetus plus lourds et chez les brebis sous-alimentées (Annison, 1960 ; Reid et Hinks, 1962a, b ; Graham, 1964 ; Patterson et al., 1964 ; Leat et Ford, 1966 ; Russel et al., 1967 ; Peart, 1968b ; Bowden, 1971 ; Davies et al., 1971 ; Robinson et al., 1971 ; Tissier et al., 1975, 1977 ; Blom et al., 1976 ; Demigné et al., 1976 ; Guada et al., 1976 ; Prior et Christenson, 1976 ; Rémésy et Demigné, 1976, 1979 ; Russel, 1978 ; Stern et al., 1979 ; Vernon et al., 1981, 1985a ; Magdus et al., 1985). La lipomobilisation se produit à une période (dernier mois) où le développement fœtal et mammaire s'accélère fortement (Rattray et al., 1974b ; Heaney et Lodge, 1975 ; Robinson et al., 1978b). Elle a été confirmée par des mesures de dilution isotopique (Pethick et al., 1983).

Les teneurs en AGNE plasmatiques augmentent fortement dans les jours qui précèdent et qui suivent la mise-bas, restent élevées jusqu'au pic de lactation, puis diminuent (Graham, 1964 ; Noble et al., 1971; Comline et Silver, 1972 ; Leat, 1974 ; Vernon et al., 1981 ; Smith et Walsh, 1984). L'augmentation des teneurs en AGNE en début de lactation tend à être d'autant plus forte que le niveau de production laitière est élevé, que le niveau d'ingestion des brebis est faible et qu'elles sont grasses à la mise-bas (Adler et Lotan, 1967 ; Reid et Hinks, 1962b ; Tissier et al., 1975, 1977 ; Cowan et al., 1980, 1981). Elle s'accompagne d'une augmentation du volume sanguin, et d'une vitesse accrue de renouvellement de l'albumine plasmatique (qui transporte les AGNE) (Mackie et Fell, 1971).

Le métabolisme du tissu adipeux de brebis se caractérise par une lipogenèse et une activité $L P L$ élevées, et une lipolyse faible en début de gestation et pendant la période sèche. La lipogenèse est toutefois sujette à d'importantes variations saisonnières. La fin de gestation (dernier tiers) et le début de lactation (4 à 6 semaines) s'accompagnent chez les brebis prolifiques ou fortes laitières, grasses ou sous-alimentées, d'une réduction marquée de la lipogenèse et d'une activation de la lipolyse, en particulier par une sensibilité accrue aux stimuli béta-adrénergiques. La sensibilité à l'action antilipolytique de l'adénosine s'accroît simultanément, reflétant peut-être un mécanisme protecteur destiné à limiter une lipomobilisation excessive.

\section{Métabolisme hépatique.}

La lipogenèse de novo est très faible dans le foie de ruminant (cf. Préambule) et elle est encore diminuée chez la brebis en période de lipomobilisation (Patterson, 1966). La néog/ucogenèse, qui lui est en partie antagonique et obligatoire chez le ruminant, augmente en effet en fin de gestation et surtout en début de lactation pour couvrir les besoins en glucose de l'utérus gravide et de la mamelle. Cette augmentation résulte à la fois d'accroissements de l'ingestion lapport des précurseurs, propionate notamment) et du potentiel enzymatique du foie (Charton et al., 1965 ; Bergman et Hogue, 1967 ; Katz et Bergman, 1969 ; Lindsay, 1971 ; Mackie et Campbell, 1972 ; Steel et Leng, 1973 ; Bergman et al., 1974 ; Herriman 
et al., 1976 ; Prior et Christenson, 1976 ; Smith et Walsh, 1982 ; Macrae et Egan, 1983 ; Wilson et al., 1983 ; Van der Walt, 1984).

Le foie de ruminant capte de 10 à $25 \%$ des AGNE qui lui arrivent par voie sanguine (revues de Schultz, 1974 et Bell, 1980). Les AGNE qui affluent en période de lipomobilisation peuvent être dirigés soit vers une oxydation mitochondriale totale ou partielle (cétogenèse et formation d'acétate endogène), soit vers une réestérification en triglycérides avec stockage in situ (stéatose) ou recyclage par sécrétion de VLDL (revues de Rémésy et al., 1984, 1986).

En fin de gestation les brebis sous-alimentées, qui mobilisent fortement leurs réserves et sont hypoglycémiques, présentent une cétogenèse intense, pouvant devenir pathologique (toxémie de gestation) (Leng, 1965 ; Patterson, 1966 ; Reid, 1963, 1968 ; Katz et Bergman, 1969 ; Kronfeld, 1972 ; Demigné et al., 1976 ; Rémésy et Démigné, 1976, 1979 ; Tissier et al., 1977 ; Stern et al., 1979). Le potentiel cétogénique du foie est élevé chez la brebis gravide bien alimentée (Varnam et al., 1978). L'augmentation de cette voie métabolique in vivo résulte à la fois de l'aflux des AGNE sangins (Sensenig et al., 1985) et d'une carence relative en composés glucoformateurs dans le foie (entrée de précurseurs inférieure aux besoins de la néoglucogenèse), entraînant à la fois des limitations de l'oxydation des acides gras et de l'acétyl-CoA, et de la réestérification des acides gras (Herriman et Heitzman, 1978 ; Lomax et al., 1983).

Une stéatose hépatique (accumulation de triglycérides, enrichis en acide oléique) d'ampleur variable s'installe simultanément à la cétogenèse en fin de gestation (Dryerre et Robertson, 1941 ; Wallace, 1948c ; Patterson et al., 1964 ; Patterson, 1966 . Luthman et Holtenius, 1972 ; Lodge et Heaney, 1973b ; Smith et Walsh, 1975 ; Wastney et al., 1983 ; Magdus et al., 1985), ce qui suggère une limitation de la synthèse des VLDL (voir aussi Bergman et al., 1971 ; Payne et Masters, 1971 ; Mamo et al., 1983 ; Mazur et al., 1987). Robinson et al. (1978) n'ont cependant pas observé de stéatose hépatique avant mise-bas chez des brebis qui avaient fortement maigri, et Leat et Ford (1966) ont rapporté une augmentation du recyclage des triglycérides chez des brebis gravides.

La cétogenèse est aussi accrue en début de lactation, surtout chez les brebis qui présentent une forte lipomobilisation et sont hypoglycémiques (Reid et Hinks, 1962b, c ; Charton et al., 1965 ; Emmanuel et Kennely, 1984a). La brebis est toutefois moins sensible à la cétose en lactation qu'en gestation (voir $\S$ III.4.c.).

La mobilisation des réserves corporelles et l'intensification de la néoglucogenèse hépatique en fin de gestation prédisposent les brebis à la cétogenèse et à l'infiltration lipidique du foie, surtout lorsque l'apport de précurseurs glucogéniques est insuffisant en présence de plusieurs fœtus.

\section{Régulations métaboliques et hormonales.}

a) Niveau d'ingestion et bilans nutritionne/s.

Durant le cycle gestation-lactation, les brebis peuvent être sous-alimentées pour des raisons économiques, ce qui entraîne une forte lipomobilisation durant 
les périodes de fin de gestation et début de lactation où les besoins sont très élevés, mais aussi une diminution des poids de la mamelle et des agneaux à la naissance, et de la production laitière (Wallace, 1948a ; Reid et Hinks, 1962b ; Peart, 1967, 1968a, b, 1970 ; Russel et al., 1967 ; Treacher, 1970, 1971 ; Rattray et al., 1974b ; Prior et Christenson, 1976 ; Stern et al., 1978b). Le niveau de production laitière n'est toutefois pas réduit lorsque des brebis maigres à la mise bas sont correctement alimentées pendant la lactation (Peart, 1967, 1970 ; Cowan et al., 1980 ; Geenty et Sykes, 1986).

Lorsque les brebis sont alimentées ad libitum, la qualité de la ration interagit très fortement avec l'état physiologique de l'animal, en raison de la limitation physique et digestive de l'ingestion propre aux ruminants (cf. Jarrige, 1978). Lorsque la ration est très ingestible, cette limitation est faible, et les brebis gravides ingèrent plus que les témoins non gravides (Reid et Hinks, 1962a ; Forbes, 1970 a, b, 1977 ; Arnold, 1975). L'augmentation du niveau d'ingestion reste toutefois plus faible que chez la ratte, peut-être en raison d'une moindre réponse à la progestérone chez les ruminants (Forbes, 1971).

Le niveau d'ingestion volontaire diminue pendant le dernier tiers et surtout les 3 dernières semaines de la gestation, en particulier chez les brebis portant plusieurs fœtus, chez les brebis grasses et lorsqu'elles reçoivent une ration de faible concentration énergétique (Reid et Hinks, 1962a, b ; Forbes et al., 1967 ; Forbes 1970a, b, 1977 ; Tissier et al., 1975, 1977 ; Tissier et Brelurut, 1979).

Les mécanismes de cette chute d'ingestion semblent être multiples. Une limitation physique du volume du rumen par l'expansion de l'unité fœeto-placentaire et des graisses abdominales pourrait jouer, avec les rations riches en fourrages grossiers (Forbes, 1970a, 1971). En outre, avec des rations riches en concentrés, un effet inhibiteur des œstrogènes ou du rapport œstrogènes/progestérone, qui augmentent en fin de gestation, a été suggéré (Forbes, 1971, 1974). Une régulation négative de l'ingestion, de type métabolique et liée à l'état d'engraissement est par ailleurs probable (Reid et Hinks, 1962a ; Reid, 1963). II est donc recommandé de ne pas laisser trop s'engraisser les brebis en début de gestation, afin de ne pas favoriser les toxémies de fin de gestation (Robinson, 1973). En effet, toute limitation supplémentaire de la capacité d'ingestion à ce stade accroît la lipomobilisation et réduit les apports de précurseurs du glucose.

Plusieurs auteurs ont toutefois rapporté des expériences où le niveau d'ingestion volontaire ne chute pas avant les derniers jours de la gestation (Treacher, 1970 ; Foot et Russel, 1979), notamment lorsque les besoins des animaux sont accrus par une chute brutale de température (Tissier et al., 1975).

L'ingestion volontaire en début de lactation est fortement liée au nombre d'agneaux allaités et/ou à la production laitière (Hadjipieris et Holmes, 1966 ; Peart, 1967, 1968a, 1970 ; Forbes, 1969 ; Peart et al., 1972 ; Tissier et al., 1975, 1977 ; Stern et al., 1978a ; Foot et Russel, 1979), mais aussi à la qualité de la ration distribuée. L'ingestion, qui a diminué juste avant la parturition, augmente à nouveau après celle-ci. Cette augmentation est plus rapide avec les rations fortement ingestibles. Le maximum n'est généralement observé que pendant le deuxième mois de lactation (lbid.) en raison de la lenteur de l'adaptation des processus digestifs (Jarrige, 1978). Mais des niveaux d'ingestion élevés et proches du 
maximum ont aussi été rapportés en première ou deuxième semaine de lactation par Cowan et al. $(1980,1981)$ et Geenty et Sykes (1986) avec des rations relativement peu concentrées $(1,9$ et $2,2 \mathrm{Kcal} \mathrm{EM} / \mathrm{g} \mathrm{MS})$ ou au pâturage. Toutefois, les brebis allaitant deux agneaux perdent systématiquement des lipides, même lorsqu'elles reçoivent une ration très ingestible, alors que les besoins sont rapidement couverts avec un seul agneau (fig. 1).

L'influence de l'état d'engraissement sur l'ingestion en début de lactation a généralement été étudiée en modifiant les apports alimentaires pendant la gestation. Ceci peut biaiser les résultats dans la mesure où les brebis sous-alimentées en fin de gestation produisent moins de lait et ingèrent moins (Wallace, 1948a ; Peart, 1967, 1968b ; Treacher, 1970) soit parce que les agneaux sont moins vigoureux à la naissance, soit en raison d'un plus faible développement de la mamelle, soit parce que les animaux (leur rumen) n'étaient pas préalablement habitués à ingérer (à digérer) autant. Lorsque cette interaction est évitée, en créant les différences d'état corporel en milieu de gestation, les brebis grasses présentent un plus faible niveau d'ingestion volontaire en début de lactation (Stern et al., 1978a ; Cowan et al., 1980), bien que ceci n'ait pas été observé par Peart (1970) et Geenty et Sykes (1986). Une inhibition de la prise alimentaire par infusion de faibles quantités d'acides gras libres a été observée (Vandermeerschen-Doizé et Paquay, 1984) ; elle pourrait intervenir lorsque la lipomobilisation est intense. Toutefois les teneurs en AGNE précédant un repas sont corrélées positivement avec la taille de celui-ci, chez la brebis en début de lactation (Thỳe et al., 1970).

Dans l'ensemble, les évolutions relatives du niveau d'ingestion et des besoins sont cohérentes avec les observations sur les activités métaboliques. II apparaît toutefois qu'à un stade donné de gestation ou de lactation, les variations de l'ingestion volontaire (liées aux besoins, à la qualité de la ration et à l'état d'engraissement de l'animal) et des besoins (liées au nombre de fotus portés ou d'agneaux allaités) peuvent être telles que les brebis soient en situation de déposer ou de mobiliser de l'énergie (tabl. 1 et fig. 1), si l'on excepte les quelques jours qui précèdent et suivent la mise-bas. Un effet du stade de gestation proprement dit n'est cependant pas à exclure car les teneurs en AGNE sanguins augmentent en fin de gestation, même chez des brebis ne portant qu'un seul fotus et recevant une ration très ingestible (Sykes et Field, 1972 ; Heaney et Lodge, 1975).

\section{b) Régulations hormonales.}

Les modifications métaboliques qui ont lieu chez la brebis durant la gestation et la lactation (fig. 3 ) accompagnent des modifications des teneurs en hormones circulantes (fig. 5, Vernon et al., 1981).

Bien que le profil hormonal de la figure 5 soit généralement rencontré, les taux d'hormones (les conditions de prélèvement et de dosage ?) et les stades où ils augmentent ou diminuent sont très variables d'une expérience ou d'un contexte zootechnique à l'autre. Par exemple, l'insulinémie peut diminuer dès le deuxième mois de gestation (Vernon et al., 1985a) ou être stable jusqu'au 50e jour de gestation, $\mathrm{n}^{\prime}$ augmenter que légèrement $(+0,2 \mathrm{ng} / \mathrm{ml})$ jusqu'au $100^{\mathrm{a}}$ jour (qui

Reproduction, Nutrition, Développement $n^{\circ}$ 2A.87. 2 
coïncidait avec la tonte des brebis), puis diminuer surtout chez les brebis portant 3 fœetus, qui sont simultanément en hypoglycémie (Blom et al., 1976). La diminution de l'insulinémie est en outre plus accentuée chez les brebis sous-alimentées en fin de gestation (Bassett et Madill, 1974 ; Prior et Christenson, 1976 ; Grizard et al., 1977, 1979b) ou en début de lactation (Gow et al., 1981).

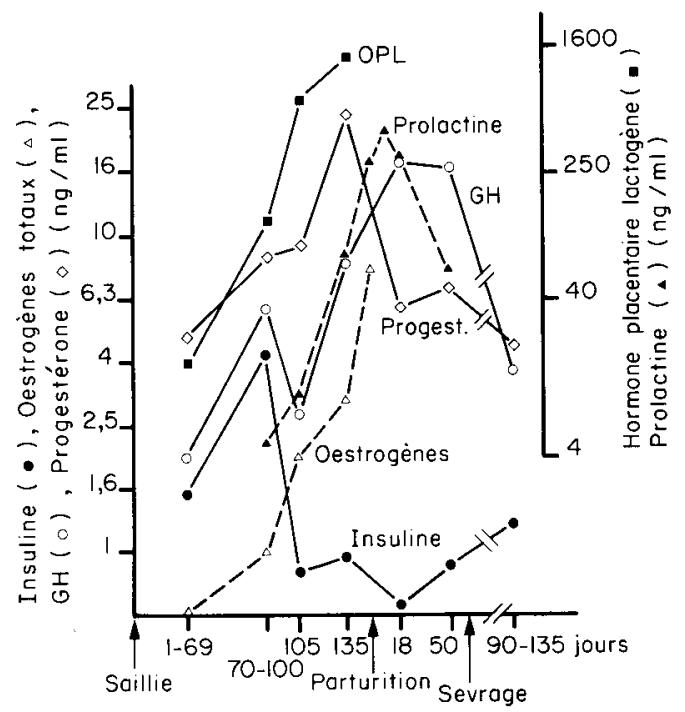

FIG. 5. - Teneurs en quelques hormones plasmatiques chez la brebis au cours du cycle gestationlactation. (données de Vernon et al., 1981, sauf pour la prolactine, Djiane et Kann, 1975 et Kann et al., 1977; et les oestrogènes, Terqui, 1978). (OPL = Ovine placental lactogen).

Par contre, des brebis amaigries en début de gestation, qui portent de plus petit fœtus, peuvent présenter une plus forte insulinémie un mois avant mise-bas, en raison d'une réduction du besoin en glucose et peut être d'une moindre inhibition des processus digestifs par le volume des graisses abdominales (Grizard et al., 1979a, b). Par ailleurs, une augmentation très marquée mais temporaire (une semaine environ) de l'insulinémie a été observée après le sevrage (Bassett, 1983a), mais probablement sans élévation simultanée de la lipogenèse (Vernon et al., 1981).

L'insuline, malgré de plus faibles réponses in vitro que chez les monogastriques (Broad et al., 1983), a un effet lipogénique et antilipolytique substantiel chez les ovins (Jarret et al., 1972 ; Bassett, 1975 ; Bauman, 1976 ; Vernon, 1980 ; Guesnet et al., 1986b). Elle agit notamment en stimulant le prélèvement du g/ucose in vivo (Khachadurian et al., 1966) et en diminuant la stimulation de la lipolyse par l'isoprénaline in vitro (Guesnet, 1984). Le nombre de récepteurs de l'insuline sur les adipocytes est élevé en milieu de gestation et diminue en fin de gestation et en début de lactation (Vernon et al., 1981, 1985a ; Guesnet et al., 1986b). Les variations simultanées de l'insulinémie et des récepteurs de cette hormone n'expliquent cependant qu'en partie les variations des différentes activités 
anaboliques du tissu adipeux ou de la lipomobilisation. L'insuline inhibe par ailleurs directement la cétogenèse et la néoglucogenèse hépatiques (Brockman et Laarveld, 1986).

Le glucagon n'a que peu ou pas d'effet lipolytique chez les ruminants in vivo (Radloff et Schultz, 1966 ; Bassett, 1971 ; Luthman et Jonson, 1972a ; Brockman, 1978 ; Vernon, 1980) ou in vitro (Etherton et al., 1977). Cette hormone intervient en premier lieu pour stimuler la néoglucogenèse hépatique, ce qui va de pair avec une faible action sur les tissus périphériques (Bassett, 1975). La signification des variations du nombre de récepteurs hépatiques de l'insuline et du glucagon pendant la lactation et la gestation (Gill et Hart, 1980, 1982) n'est pas entièrement élucidée.

La prolactinémie est élevée en fin de gestation et en début de lactation chez la brebis (Djiane et Kann, 1975 ; Kann et al., 1977 ; fig. 5). II n'existe toutefois pas de lien entre la prolactinémie et l'activité métabolique du tissu adipeux chez les ovins en croissance, et l'hormone accroît le poids des dépôts adipeux internes (Eisemann et al., 1984a) ; elle n'augmente pas non plus les teneurs en AGNE plasmatiques in vivo (Manns et Boda, 1965 ; Luthman et Jonson, 1972a), ne diminue pas la lipogenèse in vitro (Vernon et Finley, 1986) et n'aurait pas de récepteurs sur les adipocytes (Guesnet, 1984).

La sécrétion d'hormone placentaire lactogène augmente fortement à partir du 90 jour de lactation environ et elle est corrélée à la taille de la portée (Djiane et Kann, 1975 ; Martal et Djiane, 1977 ; Butler et al., 1981 ; Bosc et al., 1982, fig. 5) et serait accrue lors d'une sous-alimentation (McDowell, 1983). Cette hormone possède des récepteurs spécifiques dans le foie et le tissu adipeux (Chan et al., 1978 ; N'Guema Emane et al., 1986). Contrairement à Handwerger et al. (1976), Thordarson et al. (1984) observent un effet diabétogène et lipolytique de I'hormone in vivo. Elle aurait un effet lipolytique in vitro, mais seulement sous forme faiblement purifiée et lorsque le tissu adipeux est prélevé en dernière semaine de gestation (Guesnet, 1984 ; Iliou, 1985), ce qui suggère l'interaction d'autres facteurs.

La progestéronémie augmente en début de gestation et surtout pendant le $4^{\bullet}$ mois (fig. 5) ; elle est liée à la taille de la portée, et diminue durant les dernières semaines (Bassett et al., 1969 ; Heap et Jenkin, 1978 ; Butler et al., 1981). La progestérone stimule in vitro la lipogenèse de novo d'adipocytes prélevés sur brebis après ablation des ovaires, mais pas sur brebis entières (Guesnet, 1984).

Les teneurs en cestrogènes circulants augmentent aussi à partir du $90^{\circ}$ jour de gestation chez la brebis, et sont corrélées, ou non, avec la taille de la portée (Terqui et Delouis, 1975 ; Butler et al., 1981). L'effet lipolytique ou antilipogénique des œstrogènes in vivo pourrait être dû à une réduction du niveau d'ingestion ou à une stimulation de la sécrétion d'hormone de croissance (Trenkle, 1969 ; Luthman et al., 1972 ; Galbraith et Topps, 1981). L'œstradiol-17 $\beta$ n'augmente pas la lipolyse in vitro ou in vivo chez les ovins et les bovins (Etherton et al., 1977 ; Prior et al., 1983 ; Guesnet, 1984). Pendant la gestation, l'effet métabolique des œstrogènes pourrait être indirect, via l'augmentation du flux sanguin à travers l'utérus et la mamelle (Rosso, 1977 ; Bauman et Currie, 1980). 
Plusieurs auteurs pensent qu'il n'y a pas de phénomène de résistance à l'insuline chez les ovins en fin de gestation (Prior et Christenson, 1978 ; Van der Walt et al., 1980 ; Bassett, 1983b), contrairement aux espèces monogastriques. Ceci peut être à relier à une résistance générale des ruminants à l'action de l'insuline (Reid, 1951, 1952), permettant une épargne de glucose (Prior et Christenson, 1978). Les ovins obèses semblent cependant présenter une résistance à l'insuline (McNiven, 1984) qui pourrait expliquer certains résultats obtenus sur brebis grasses (cf. ci-dessus). Selon Guesnet (1984), la réponse à l'insuline de la lipogenèse de novo du tissu adipeux in vitro est supérieure chez des brebis en début de gestation (effet de la progestérone ?) à celle de brebis ovariectomisées, mais elle disparaîtrait en fin de gestation et pendant la lactation, où la réponse et la sensibilité à l'insuline du tissu adipeux et du muscle sont diminuées (Vernon, 1986), malgré un nombre de récepteurs de l'insuline sur les adipocytes supérieur ou égal à celui des animaux témoins (Vernon et al., 1981).

La teneur en hormone de croissance plasmatique augmente en fin de gestation et surtout en début de lactation (Blom et al., 1976; Hove et Blom, 1976 ; Vernon et al., 1981 ; fig. 5). Elle s'accroît fortement chez la brebis sous-alimentée ou hypoglycémique en début de lactation (Bassett et Madill, 1974 ; Gow et al., 1981 ; Bassett, 1983b) et diminue après le sevrage (Vernon et al., 1981 ; Bassett, 1983a). L'hormone de croissance ovine a un effet lipolytique in vivo à long terme, qui est généralement accompagné d'une hyperglycémie reflétant une inhibition de I'utilisation périphérique de glucose (Manns et Boda, 1965 ; Bassett et Wallace, 1966 ; Luthman et Jonson, 1972a ; Vézinhet, 1973 ; Vézinhet et al., 1974 ; Hart et al., 1985). Alors que cette hormone stimule la lipolyse des adipocytes de rat in vitro, cet effet n'a pas pu être montré sur adipocytes ovins (Vézinhet, 1976 ; Vernon, 1978, 1980 ; Duquette et al., 1984), qui ne répondent pas non plus aux autres hormones lipolytiques hypophysaires. Par contre, l'hormone de croissance ovine ou bovine inhibe l'action stimulatrice de l'insuline sur la lipogenèse du tissu adipeux ovin in vitro (Vernon, 1978, 1979, 1982 ; Vernon et Finley, 1986). De plus, des modifications des teneurs en AGNE entraînent des modifications en sens opposé de la sécrétion de l'hormone de croissance (Hertelendy et Kipnis, 1973).

La réponse lipolytique à la noradrénaline in vivo est accrue chez la brebis en fin de gestation, qui ne développe pas d'hyperglycémie durable pendant la perfusion de cette hormone, en raison d'un épuisement des réserves de glycogène hépatique (Luthman et Holtenius, 1972). Or, cette faible réponse de la glycémie est favorable à une lipomobilisation prolongée (Bost et al., 1967 ; Luthman et Holtenius, 1972). L'effet antilipolytique de l'hyperglycémie pourrait en outre être réduit chez la brebis en lactation (Bost et al., 1967). Les variations de la glycémie sont susceptibles de modifier la lipolyse du tissu adipeux et/ou la lipomobilisation, en absence de toute action hormonale (revue de Vernon, 1980 ; Brockman, 1984 ; Garwacki et al., 1984).

La sécrétion des catécholamines est mal connue, mais leur administration stimule la néoglucogénèse et la lipolyse, et inhibe l'utilisation périphérique du glucose chez la brebis en lactation, comme chez les autres espèces (McDowell, 1983). 
L'insuline est la principale hormone lipogénique et antilipolytique chez la brebis. En fin de gestation et en début de lactation la sensibilité à l'insuline diminue, probablement sous l'influence de l'hormone de croissance, et la réponse lipolytique bêta-adrénergique augmente, surtout lorsque la taille des adipocytes est élevée. L'hypoglycémie favorise aussi la lipomobilisation.

\section{c) Utilisation des substrats énergétiques.}

c.1. Fin de gestation. - L'utérus gravide consomme de grandes quantités de glucose, d'acétate et d'acides aminés en fin de gestation (Prior et Christenson, 1978 ; Battaglia et Meschia, 1978 ; Duée et Girard, 1983 ; Van der Walt, 1984), en raison du développement rapide des fœtus. Les diminutions de la glycémie, de I'insulinémie et de la lipogenèse de novo des tissu adipeux, et l'accroissement de la teneur en hormone de croissance, sont autant de facteurs qui tendent à réduire la consommation extra-utérine d'acétate et de glucose (Lindsay, 1971 ; Luthman et Jonson, 1972a ; Hove et Blom, 1976 ; Oddy et al., 1985). Le concept de la priorité métabolique des fœetus demande toutefois à être nuancé. Chez des brebis portant un seul fœetus, les tissus extra-utérins, l'ensemble utéro-placentaire et le foetus consomment respectivement 65,25 et $10 \%$ du glucose produit par la mère deux semaines avant mise-bas. Or, ces pourcentages ne varient pas lorsque la glycémie et la production de glucose sont réduites de moitié chez la brebis sousalimentée, ce qui signifie que le glucose n'est pas utilisé prioritairement par l'unité fœto-placentaire (Hay et al., 1983 ; Prior et Christenson, 1978 ; Hay et al., 1983).

Ceci est corroboré en partie par les données de Wilson $(1983,1984)$ qui observe que, pendant le dernier mois de gestation, la réestérification des acides gras liée au turn-over du tissu adipeux consommerait de 15 à $35 \%$ du glucose produit par des brebis portant un seul foetus, si le glycérol n'est pas réutilisé. Ces chiffres sont surprenants, puisque le tissu adipeux capte moins de $10 \%$ d'une surcharge en glucose chez le rat (Curtis-Prior et al., 1969) et moins de $3 \%$ de l'énergie métabolisable de la ration chez le ruminant en croissance ou à l'entretien (Lindsay, 1981), et que le métabolisme des ruminants est normalement orienté pour épargner ce métabolite. II faut toutefois souligner que le g/ycérol du tissu adipeux est recyclé et peut contribuer à 10-30\% de la production hépatique de glucose chez la brebis en fin de gestation (Bergman, 1973 ; Wilson et al., 1983).

Par ailleurs, pendant la sous-alimentation, le métabolisme fotal s'adapte en augmentant l'oxydation des acides aminés (Girard et al., 1979 ; Schreiner et al., 1981), probablement à la suite de la mobilisation des réserves protéiques maternelles (Sykes et Field, 1972 ; Guada et al., 1976 ; Robinson et al., 1978b ; Rémésy et Demigné, 1979 ; Vincent et Lindsay, 1985 ; Geenty et Sykes, 1986). Chez l'animal normalement alimenté, la néoglucogenèse fœtale augmenterait aussi en fin de gestation (Boyd et al., 1973; Girard et al., 1979).

Le placenta n'est que peu ou pas perméable aux AGNE, au glycérol et aux corps cétoniques chez les ovins, et ces substrats sont peu utilisés par le fœetus (revue de Battaglia et Meschia, 1978). Toutefois, ces produits de la lipomobilisation peuvent se substituer au glucose, et être oxydés par certains tissus maternels, y compris l'utérus ou le placenta. Ainsi, environ $10 \%$ ou $30 \%$ de la produc- 
tion totale de $\mathrm{CO}_{2}$ proviennent des corps cétoniques chez des brebis en fin de gestation alimentées ou à jeun, respectivement (Pethick et Lindsay, 1982a). Les corps cétoniques contribueraient en particulier à $15-45 \%$ de la production de $\mathrm{CO}_{2}$ par les muscles et à $10-20 \%$ de celle de l'utérus gravide, qui consommerait 20 $25 \%$ des corps cétoniques produits par la brebis à jeun (Pethick et Lindsay, 1982a ; Chandler et al., 1983, 1985). Les AGNE sont largement oxydés par les muscles squelettiques mais pas par l'utérus (Pethick et al., 1983).

La mobilisation des réserves et l'épargne de nutriments au niveau des tissus maternels, si elles permettent à l'organisme de s'adapter à l'accroissement des besoins relativement à l'ingestion volontaire, ne semblent pas suffire à éviter une diminution de poids des agneaux à la naissance lorsque la mère est sousalimentée en fin de gestation (cf. références § III.4.a). Par contre, la tonte favoriserait la croissance des fœtus et la mobilisation corporelle, pour une même ingestion d'énergie par la mère (Symonds et al., 1985).

c.2. Lactation. - Le besoin en glucose est très élevé en lactation, en raison de son utilisation pour les synthèses mammaires de lactose, d'acides gras (NADPH) et de triglycérides (3-glycérol-phosphate) (Annison, 1971 ; Davis et Bickerstaffe, 1978). Le renouvellement du glucose est deux fois plus élevé en pleine lactation que pendant le dernier mois de gestation, pour 2 agneaux portés ou allaités (Bergman et al., 1974). La brebis en début de lactation tend donc à être hypoglycémique, surtout lorsqu'elle produit beaucoup de lait et que l'ingestion est limitée. La brebis est cependant moins sensible à l'acétonémie en début de lactation qu'en fin de gestation (Baird et al., 1983) car son niveau d'ingestion est plus élevé, et parce qu'elle peut probablement réduire son niveau de production laitière plus facilement que la croissance fœtale. La production d'acétate endogène serait en outre considérablement accrue en début de lactation (Costa et al., 1976) et la mamelle peut « épurer » des quantités importantes d'acides gras longs.

La lipomobilisation entraîne en effet un enrichissement du lait en matières grasses, et de celles-ci en acides stéarique et oléique, ce qui limite la lipogenèse de novo mammaire et épargne du glucose et de l'acétate (Hadjipieris et al., 1966 ; Mayer, 1970 ; Noble et al., 1970 ; Treacher, 1971 ; Cowan et al., 1980 ; Payne et Rattray, 1980 ; Emmanuel et Kennelly, 1984a ; Geenty et Sykes, 1986), en raison d'un prélèvement direct des AGNE circulants par la mamelle. En outre, I'utilisation des AGNE et des corps cétoniques comme substrats énergétiques s'accompagne d'une diminution de celle de glucose et d'acétate par les muscles pendant la lactation, sauf lorsque la ration est de nature à augmenter la glycémie et l'insulinémie (Pethick et Lindsay, 1982b ; Vernon et al., 1984).

La contribution des protéines corporelles en début de lactation semble être quantitativement limitée, même en cas de sous-alimentation (Cowan et al., 1980, 1981). Bryant et Smith (1982) rapportent toutefois une accélération du catabolisme et un ralentissement de la protéosynthèse musculaire, et Geenty et Sykes (1986) observent chez des brebis allaitant deux agneaux et restreintes au pâturage des pertes de protéines de $30 \mathrm{~g} / \mathrm{j}$ qui pourraient jouer un rôle non négligeable dans la satisfaction des besoins du tissu mammaire et le rendement d'utilisation de l'énergie. Les interactions énergie-azote sont importantes puisque la quantité et la qualité des protéines alimentaires modifient la production laitière, la mobilisa- 
tion des lipides corporels et les rendements énergétiques (Robinson et al., 1974 ; Cowan et al., 1961 ; Benazzouz et Thériez, 1985).

\section{Conclusion.}

Le métabolisme lipidique de la brebis au cours du cycle gestation-lactation est dominé par les évolutions relatives des besoins (fœetus, mamelle) et du niveau d'ingestion. Les besoins sont essentiellement liés au nombre de fotus ou d'agneaux allaités, alors que l'ingestion volontaire est soumise à la fois à des régulations de type physique (encombrement du rumen et adaptations de sa flore) et métabolique (hypoglycémie, œstrogènes, état d'engraissement).

Les conclusions des études consacrées au métabolisme du tissu adipeux ne peuvent être généralisées qu'avec prudence dans la mesure où l'état nutritionnel des animaux et les effets saisonniers n'y sont généralement que peu évalués. En effet, les mesures de la composition corporelle et des bilans énergétiques ont bien montré la grande diversité des situations qui peuvent se rencontrer aussi bien en fin de gestation qu'en début de lactation. Chez des brebis portant et allaitant deux agneaux, la lipogenèse est réduite durant ces périodes, où la lipomobilisation et la cétogenèse hépatique deviennent intenses. Par contre, la réestérification des acides gras resterait assez forte fin de gestation.

Les médiateurs connus de ces adaptations téléophorétiques sont essentiellement le glucose, l'insuline, I'hormone de croissance. Les catécholamines et l'adénosine interviennent aussi dans la régulation de la lipolyse, directement ou par l'intermédiaire du flux sanguin dans les tissus adipeux. Les interactions métaboliques et hormonales in vivo (AGNE, taille des adipocytes, hormone placentaire lactogène, œstrogènes, progestérone...) sont probablement importantes, mais peu connues.

Plusieurs résultats montrent que les fournitures de nutriments pour le développement foetal et le métabolisme mammaire restent normalement soumises au maintien de l'homéostasie maternelle. Celui-ci est en particulier facilité en gestation par la lipomobilisation et la cétogenèse (épargne de glucose), alors que le besoin des fœtus en glucose pourrait être en partie satisfait par la mobilisation des protéines corporelles maternelles, couplée à la néoglucogenèse fœtale et maternelle. La lipomobilisation en début de lactation peut représenter de zéro à $75 \%$ des lipides corporels, et jusqu'à $75 \%$ de l'énergie sécrétée par la mamelle. Ces diverses adaptations sollicitent fortement le métabolisme hépatique et accroissent les risques pathologiques (rupture de l'homéostasie maternelle), surtout en fin de gestation.

\section{Métabolisme des lipides dans les tissus adipeux et le foie chez la vache.}

Bien que la lactation et la gestation soient confondues pendant 7 mois environ chez la vache laitière, les principaux problèmes zootechniques et métaboliques se posent en début de lactation. Cette femelle ne porte en effet dans la majorité des cas qu'un fœtus, alors que sa production de lait est très élevée dès la 
mise-bas. Ceci explique le faible nombre d'études consacrées à la gestation chez les bovins, en dehors du cas des vaches nourrices sous-alimentées en période hivernale pour des raisons économiques.

\section{Variations quantitatives des dépôts lipidiques et de l'énergie corporelle.}

\section{a) Gestation.}

Ferrel et al. (1976a, b) et Saul (1983) n'observent pas de différences de composition corporelle (hors utérus gravide) entre des génisses de race Hereford non gravides ou à différents stades de gestation, et recevant de 1,2 à 1,8 fois leurs besoins d'entretien. Le dépôt d'énergie dans la mamelle est très faible jusqu'en fin de gestation (Ferrell et al., 1976c). La première moitié de la gestation ne semble pas modifier (ou augmente légèrement) l'état d'engraissement de génisses de race Charolais $\times$ Salers ou Charolais $\times$ Aubrac (Malterre, 1986a). Des génisses de races à viande ou laitières taries dès la mise-bas ont une composition de carcasse très voisine de celle de génisses nullipares (Malterre, 1986a). Par contre, des génisses alimentées selon les normes américaines (NRC) perdraient environ $24 \mathrm{~kg}$ de lipides (estimés à l'aide de l'eau lourde) pendant la gestation, et près de $50 \mathrm{~kg}$ lorsqu'elles reçoivent une ration ne couvrant que les besoins d'entretien (Warrington et al., 1985).

L'analyse chimique de 3 vaches adultes de race Jersey par Moulton et al. (1923) ne permet pas de conclure à un dépôt supplémentaire de lipides corporels

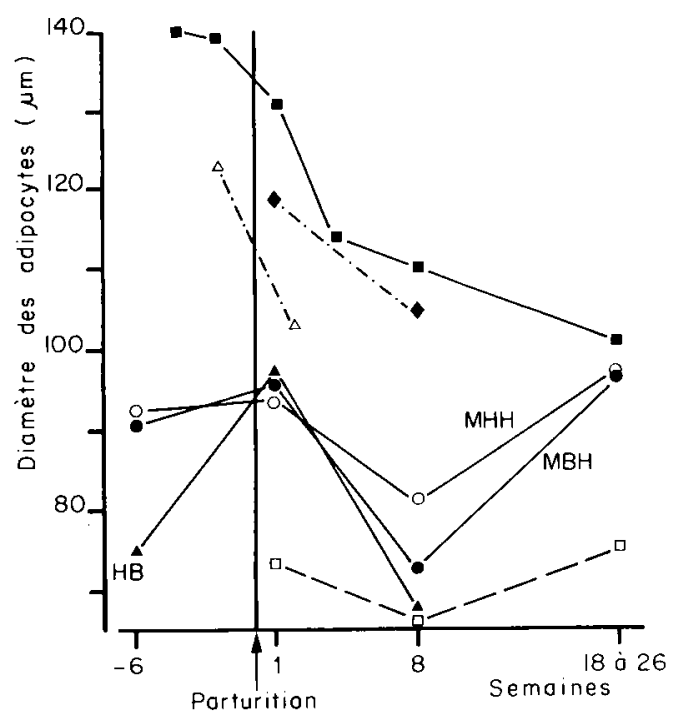

FIG. 6. - Evolution du diamètre des adipocytes du tissu adipeux sous-cutané chez la vache laitière en fin de gestation et en début de lactation. $\triangle$ Pike et Roberts, 1980 (4 vaches) ; * Roberts et al., 1981 (19 vaches) ; 口 Larnicol et al., 1984 (45 vaches) ; • , o . . Chilliard et al., 1984a 4 vaches par lot) : . lot HB - Vaches ayant un potentiel laitier de $33 \mathrm{~kg}$ de lait à $4 \%$, alimentées ad libitum avant mise-bas et restreintes de $\mathrm{S}+1$ à $\mathrm{S}+8$. 0 lot $\mathrm{MHH}-$ Vaches ayant un potentiel laitier de $29 \mathrm{~kg}$ de lait à $4 \%$, restreintes de S -6 à S -1 , et alimentées ad libitum pendant la lactation. - lot MBH - Vaches ayant un potentiel laitier de $28 \mathrm{~kg}$ de lait à $4 \%$, restreintes de S 6 à $S+8$ et alimentées ad libitum de $S+9$ à $S+18$. Reid et al., 1986 (18 vaches, alimentées ad libitum de $\mathrm{S}+1$ à $\mathrm{S}+10)$. 
après 6 mois de gestation. II en est de même des observations de terrain effectuées sur vaches de réforme, gravides ou non (Malterre, 1986b).

Pendant les 6 dernières semaines de gestation, 8 vaches multipares de race Charolaise $\times$ Angus recevant une ration proche du niveau d'entretien perdent environ $10 \mathrm{~kg}$ de matière sèche corporelle maternelle, d'après des estimations par mesure de l'espace de diffusion de l'eau marquée (Degen et Young, 1980). Par contre, 18 vaches de race Holstein recevant une ration très ingestible à volonté gagnent de 8 à $16 \mathrm{~kg}$ de lipides au cours des 6 dernières semaines de gestation (y compris les lipides fœtaux et mammaires), d'après des estimations par mesure de la radioactivité du potassium-40 (Belyea et al., 1978). De même, la taille des adipocytes du tissu adipeux sous-cutané augmente pendant les 6 dernières semaines de gestation chez 4 vaches de race Pie Noire recevant le même type de ration ad libitum, alors qu'elle est stable lorsque les apports couvrent seulement les besoins de gestation, chez 8 autres animaux (Chilliard et al., 1982 ; fig. 6).

Les autres données disponibles proviennent d'études en chambres respiratoires. L'ensemble mère-fœtus (race Holstein) est en bilan énergétique positif (faiblement ou fortement selon le niveau alimentaire) pendant les $3 / 4$ de la gestation (6 à 7 mois). Ce bilan diminue pendant les 2 derniers mois, ce qui suppose fréquemment une mobilisation des tissus materne/s, même lorsque les animaux sont alimentés à volonté (Hashizume et al., 1965 ; Flatt et al., 1969a ; Iwasaki et al., 1980). Durant le dernier mois de gestation, des vaches Holstein peuvent perdre jusqu'à $1 \mathrm{~kg}$ de lipides par jour, ou en gagner $1,5 \mathrm{~kg} / \mathrm{j}$, selon le niveau alimentaire (Flatt et al., 1969a ; Bullis et al., 1985).

Ces tendances ont été confirmées dans l'étude de Henseler et al. (1973) avec 10 vaches adultes Pie-Noires recevant 1,8 fois le niveau d'entretien (fig. 7). Avec ce niveau d'alimentation, le dépôt d'énergie dans l'organisme maternel décroît pendant le dernier mois, et concerne essentiellement le développement de la mamelle, si bien que les autres tissus maternels peuvent être mobilisés pendant les 2 dernières semaines de gestation (fig. 7). Ce n'est pas le cas chez 4 primipares dont le développement mammaire est plus faible (Henseler et al., 1973). Par contre, Burlacu et al. (1978) observent une perte de $16 \mathrm{~kg}$ de lipides materne/s

(c)

(b)

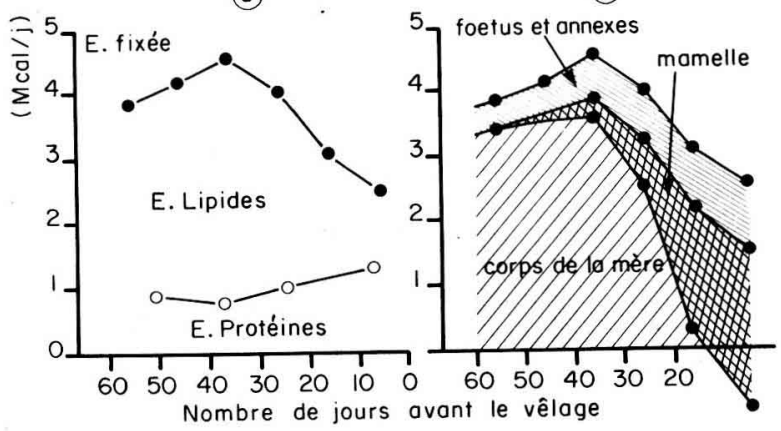

FIG. 7. - Variations des quantités d'énergie fixée (Mcal/j) par la vache au cours des 2 derniers mois de gestation (moyenne de 10 vaches). a : Répartition entre les protéines et les lipides (mère + fœetus et annexes). $b$ : Répartition entre le fotus et les annexes, la mamelle et l'organisme de la vache (Adapté par M. Vermorel, à partir des données de Henseler et al., 1973). 
durant les deux derniers mois de gestation chez 8 génisses de race Holstein, recevant à volonté une ration contenant $80 \%$ d'ensilage de maïs de qualité médiocre (25\% MS) et $20 \%$ de concentré.

La mobilisation des réserves maternelles en fin de gestation est par ailleurs plus importante chez les vaches ou les génisses qui portent des jumeaux (Koong et al., 1982), ou chez les vaches nourrices sous-alimentées qui peuvent perdre plus de $20 \%$ de leur masse corporelle (Petit, 1978).

b) Lactation.

b.1. Mesures sur vaches abattues. - Les mesures effectuées sur vaches abattues à différents stades de lactation sont relativement rares, et les chiffres

TABLEAU $3 a$

Poids des tissus adipeux viscéraux $(\mathrm{kg})$ chez la vache laitière au cours de la lactation

\begin{tabular}{|c|c|c|c|c|c|c|}
\hline \multirow{2}{*}{ Références } & \multirow{2}{*}{ Race } & \multirow{2}{*}{ Nombre } & \multicolumn{4}{|c|}{ Stade de lactation } \\
\hline & & & Peripartum & $1-2$ mois & $4-8$ mois & Taries (a) \\
\hline Homb et al., 1965 & Norvégienne & $(6 \times 4)$ & & & $\begin{array}{l}25-47 \text { (b) } \\
14-27 \text { (c) }\end{array}$ & \\
\hline Tulloh, 1966 & Jersey & $(3 \times 2)$ & & & 19 & $47(d)$ \\
\hline $\begin{array}{l}\text { Smith et Baldwin, } \\
1974\end{array}$ & $\begin{array}{l}\text { Jersey } \\
\text { Holstein }\end{array}$ & $\begin{aligned}(7) & +(9) \\
(10) & +(15)\end{aligned}$ & & & $\begin{array}{l}29(e) \\
42(e)\end{array}$ & $\begin{array}{l}42 \\
54\end{array}$ \\
\hline $\begin{array}{l}\text { Robelin et } \\
\text { Chilliard, 1983- } \\
1984 \text {. Chilliard et } \\
\text { Robelin, } 1985\end{array}$ & $\begin{array}{l}\text { Holstein } \\
\times \\
\text { Frisonne }\end{array}$ & $(4 \times 5)$ & 32 & 9 & & $\begin{array}{c}6-15-29 \\
(f)\end{array}$ \\
\hline $\begin{array}{l}\text { Butler-Hogg } \\
\text { et al., } 1985\end{array}$ & Frisonne & $(4 \times 5)$ & 22 & 12 & $9-21$ & 48 \\
\hline
\end{tabular}

(a) Les vaches taries sont pour la plupart non gravides; (b) 2 lots témoins ; (c) 2 lots ayant reçu une alimentation restreinte $(-2,5 \mathrm{UF}$ /jour, pendant 5 mois après le pic de lactation) ; (d) 3 à plus de 6 mois après le tarissement; (e) Stade de lactation non précisé ; (f) 3 lots de vaches taries, maigres ou après 50 et $150 \mathrm{j}$ d'engraissement.

TABLEAU 3b

Poids des tissus adipeux de la carcasse $(\mathrm{kg})$ chez la vache laitière au cours de la lactation.

\begin{tabular}{|c|c|c|c|c|c|c|}
\hline \multirow{2}{*}{ Références } & \multirow{2}{*}{ Race } & \multirow{2}{*}{ Nombre } & \multicolumn{4}{|c|}{ Stade de lactation (a) } \\
\hline & & & Peripartum & $1-2$ mois & $5-8$ mois & Taries \\
\hline $\begin{array}{c}\text { Tyrrell et } \\
\text { Haaland, } 1983 \\
\end{array}$ & Holstein & $(5+10+3)$ & 97 & - & 65 & $85(a)$ \\
\hline $\begin{array}{l}\text { Robelin et } \\
\text { Chilliard, 1983- } \\
\text { 1984. Chilliard et } \\
\text { Robelin, } 1985\end{array}$ & $\begin{array}{l}\text { Holstein } \times \\
\text { Frisonne }\end{array}$ & $(4 \times 5)$ & 90 & 32 & - & $\begin{array}{c}28-49-93 \\
\text { (b) }\end{array}$ \\
\hline $\begin{array}{l}\text { Butier-Hogg } \\
\text { et al., } 1985\end{array}$ & Frisonne & $(4 \times 5)$ & 50 & 28 & $25-51$ & 96 \\
\hline
\end{tabular}

(a) Chiffres approximatifs estimés à partir d'une note des auteurs ; (b) Voir tableau 3a, note (f). 
obtenus indiquent plutôt des plages possibles de variation, en raison des difficultés à réaliser des lots ayant des états d'engraissement initiaux homogènes. $L e$ poids des tissus adipeux tend à être plus faible après le pic de lactation que pendant la période sèche (tabl. 3a et b). Les pertes de lipides, estimées à partir de mesures de la densité des carcasses chez des primipares en pleine lactation, étaient de 16 et $30 \mathrm{~kg}$ pour des durées de sous-alimentation ( - $35 \%$ par rapport aux besoins) de 7 et 15 semaines, respectivement (Bath et al., 1965).

La dissection anatomique et l'analyse chimique du corps entier de 20 vaches taries ou en début de lactation (Robelin et Chilliard, 1983, 1984) montre que les lipides corpore/s totaux peuvent varier (en moyenne par lot) de 40 à $140 \mathrm{~kg}$, chez des vaches pesant de 520 à $660 \mathrm{~kg}$. Ces variations sont observées aussi bien pendant la période sèche (engraissement) qu'en début de lactation (amaigrissement). Les tissus adipeux sous-cutanés, internes et intermusculaires contribuent à environ 25,38 et $34 \%$ des différences de poids des tissus adipeux totaux ; parmi les tissus adipeux internes, les tissus épiploïque, mésentérique et périrénal représentent environ 14, 8 et $9 \%$ (respectivement) de ces différences de poids (Robelin et Chilliard, 1984 ; Butler-Hogg et al., 1985). Celles-ci résultent principalement de variations de la taille des adipocytes, dont le nombre total ne varie pas significativement (Robelin, 1982 ; Chilliard et Robelin, 1985).

b.2. Estimation de la composition corporelle in vivo. - L'évolution de la quantité de lipides corporels chez le même animal peut être estimée à partir de mesures de l'espace de diffusion de l'eau marquée, ou de la radioactivité du potassium 40 , lorsque ces méthodes ont été préalablement étalonnées sur animaux abattus.

Des vaches à viande de race Hereford $\times$ Frisonne, faibles productrices de lait $(7 \mathrm{~kg} / \mathrm{j})$ et alimentées selon leurs besoins, ne semblent pas mobiliser leurs réserves

\section{TABLEAU 4}

Effet de la sous-alimentation et de la réalimentation en pleine lactation sur les variations de lipides corporels de vaches de race Hereford $\times$ Frisonne (a).

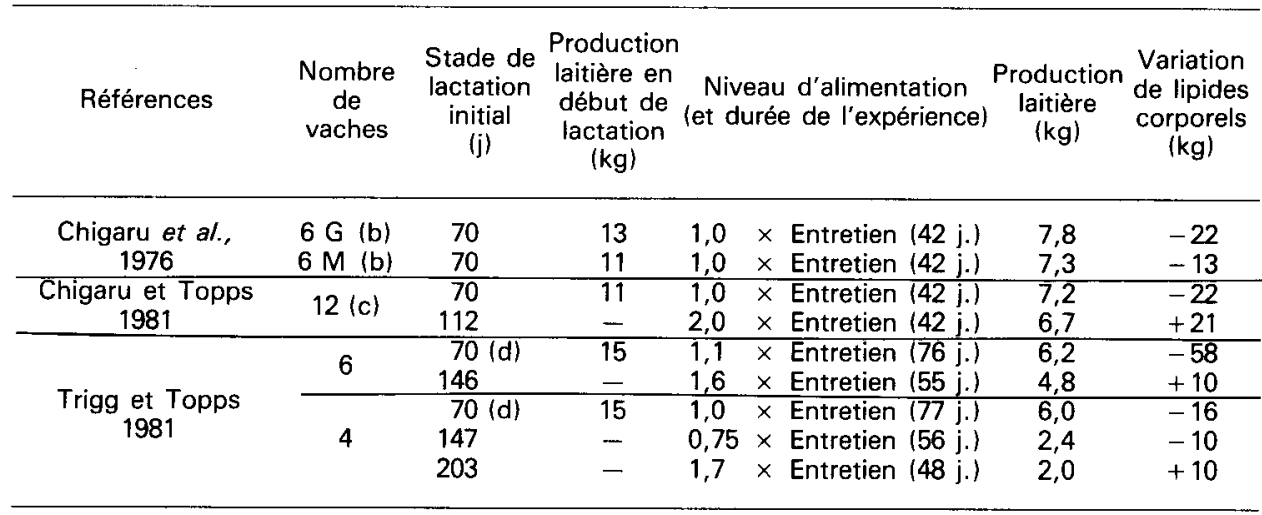

(a) Les quantités de lipides corporels ne sont pas précisées par les auteurs. Les variations de lipides sont estimées à partir de la mesure de l'espace de l'eau marquée, sans étalonnage de la méthode ; (b) 6 vaches " grasses" $(G)$ ou " maigres " $(M)$ d'après le niveau d'alimentation avant mise-bas ; (c) 12 vaches suivies deux années consécutives ; (d) 35 à 105 jours en réalité. 
corporelles en début de lactation (Degen et Young, 1980). Lorsqu'elles sont sousalimentées en pleine lactation, elles peuvent mobiliser de 15 à $25 \mathrm{~kg}$ de lipides en 6 semaines, et en redéposer de 10 à $20 \mathrm{~kg}$ pendant la réalimentation (tabl. 4). La lipomobilisation s'accompagne dans la plupart des cas d'une diminution de production laitière, et augmente avec celle-ci. Elle est probablement plus faible chez des vaches préalablement amaigries (Chigaru et al., 1976). De même, des vaches Charolaises qui sont naturellement peu grasses au vêlage (environ $40 \mathrm{~kg}$ de lipides estimés par l'eau lourde) ne perdraient qu'environ $10 \mathrm{~kg}$ de lipides en 14 semaines de sous-alimentation (- 2,6 Mcal/j par rapport aux besoins), mais pourraient aussi mobiliser la même quantité de protéines (Agabriel et al., 1985).

Les vaches laitières hautes productrices mobilisent de 20 à $60 \mathrm{~kg}$ de lipides pendant le premier ou les deux premiers mois de lactation, et ces quantités sont en particulier influencées par les niveaux de production et d'apport alimentaire (tabl. 5) et par le rapport fourrage/concentré de la ration (Martin et Ehle, 1986). La reconstitution des réserves peut s'effectuer presque entièrement pendant la lactation, puisque les animaux redéposent de 20 à $40 \mathrm{~kg}$ de lipides avant le $5^{\mathrm{e}}$ mois de lactation ou le tarissement.

\section{TABLEAU 5}

Evolution des lipides corporels $(\mathrm{kg})$ au cours de la lactation chez des vaches de type Holstein.

\begin{tabular}{|c|c|c|c|c|c|c|c|}
\hline Semaines de lactation & Note & $S_{-4}$ à $S_{-1}$ & $\mathrm{~S}_{1}$ & $S_{2}$ a 4 & $\mathrm{~S}_{6 \text { à } 10}$ & $\mathrm{~S}_{18}$ à 20 & $S_{32 \text { a } 40}$ \\
\hline Belyea et al., 1978 & (1) & 194 & - & 146 & 136 & 153 & 178 \\
\hline $\begin{array}{c}\text { Chilliard et al. } \\
1982,1984 a\end{array}$ & $\begin{array}{l}\text { (2) } \\
(3) \\
(4)\end{array}$ & - & $\begin{array}{l}90 \\
81 \\
86\end{array}$ & - & $\begin{array}{l}51 \\
52 \\
68\end{array}$ & $\begin{array}{l}- \\
90 \\
96\end{array}$ & - \\
\hline Martin et Ehle, 1986 & (5) & 123 & - & 89 & 73 & 95 & - \\
\hline $\begin{array}{l}\text { Vérité R. et } \\
\text { Chilliard Y. } \\
\text { (non publié) }\end{array}$ & $\begin{array}{l}\text { (6) } \\
\text { (7) }\end{array}$ & $\begin{array}{l}- \\
-\end{array}$ & $\begin{array}{l}104 \\
113\end{array}$ & - & $\begin{array}{l}72 \\
89\end{array}$ & - & $\begin{array}{r}104 \\
86\end{array}$ \\
\hline
\end{tabular}

(1) Lipides estimés à partir de la mesure de la radioactivité du potassium 40 . Ils sont probablement surestimés car les équations utilisées ne tenaient pas compte des contenus digestifs. Les vaches produisaient $32 \mathrm{~kg}$ de lait à $4 \%$ en $2^{\mathrm{e}}$ semaine de lactation et recevaient une ration très ingestible à volonté (12 à 18 vaches par stade). $(2,3,4,6,7)$ Lipides estimés à partir de la mesure de l'espace de diffusion de l'eau lourde et d'équations établies après analyse chimique de vingt vaches taries ou en début de lactation (Chilliard et Robelin, 1983). (2) 4 vaches hautes productrices (33 $\mathrm{kg}$ de lait à $4 \%$ ) sous alimentées $(0,75 \times$ niveau ad libitum). (3) 4 vaches moyennes productrices $(28 \mathrm{~kg})$ sousalimentées. (4) 4 vaches moyennes productrices $(29 \mathrm{~kg})$ recevant une ration très ingestible ad libitum. (5) Lipides estimés chez 36 vaches à partir de la mesure de l'espace de diffusion de l'eau lourde. Les valeurs obtenues avant mise-bas (19 vaches) ne sont pas corrigées pour tenir compte de l'eau foetale. (6) 9 multipares alimentées ad libitum. (7) 12 primipares alimentées ad libitum.

Différents auteurs (à l'exception de Jaster et Wegner, 1981) ont observé une diminution de la taille des adipocytes ou de l'épaisseur du tissu adipeux souscutané, peri-partum ou en début de lactation (Grichting et al., -1977a ; Roberts et al., 1979, 1981 ; Pike et Roberts, 1980, 1981 ; Roberts, 1982 ; Reid et al., 1986). Cette diminution est plus marquée chez les vaches sous-alimentées et la taille des adipocytes revient au niveau initial après 4-5 mois de lactation, parallèlement à la 
quantité de lipides corporels (fig. 6 et tabl. 5, Chilliard et al., 1984a ; Larnicol et al., 1984). La lipomobilisation s'accompagne par ailleurs d'une stéatose musculaire temporaire pendant les premières semaines de lactation (Roberts et al., 1981, 1983).

b.3. Mesures en chambres respiratoires. - Les données publiées à partir de mesures en chambres respiratoires (revue de Chilliard et al., 1983) confirment que la mobilisation de l'énergie corporelle (composée pour plus de $90 \%$ de lipides) en début de lactation varie sous les influences simultanées du stade de lactation, du niveau de production laitière, de la quantité et de la qualité de la ration distribuée. Ces facteurs (et d'autres) sont interdépendants et il est difficile de séparer expérimentalement leurs effets.

Des vaches fortes productrices ( $30 \mathrm{~kg}$ de lait et plus au pic de production) mobilisent l'équivalent énergétique de 30 à $60 \mathrm{~kg}$ de lipides, durant 7 à 14 semaines, selon les expériences (Flatt et al., 1969b ; Schiemann et al., 1974 ; Bauman et Currie, 1980 ; M. Vermorel et R. Vérité, communication personnelle). Une variation extrême de $120 \mathrm{~kg}$ de lipides a même été enregistrée chez une vache forte productrice sous-alimentée (Flatt et al., 1965a). Des mobilisations de $2 \mathrm{~kg}$ d'équivalent lipides par jour ne sont pas rares en début de lactation (Vermorel et al,, 1982). La perte d'énergie corporelle est liée au niveau de production laitière (Bauman et al., 1985). Toutefois, les corrélations sont plus fortes lorsque le niveau d'ingestion de l'animal est limité (début de lactation, ration peu ingestible ou apport limité) (revue de Chilliard et al., 1983). Des vaches fortes productrices ayant une capacité d'ingestion élevée peuvent même mobiliser moins de lipides que des productrices plus faibles (Trigg et Parr, 1981). Par ailleurs, une restriction alimentaire en début de lactation peut se traduire surtout par une réduction de la production de lait (Flatt et al., 1969b ; Trigg et al., 1980 ; Grainger et al., 1985) probablement par suite d'une carence en glucose et/ou en acides aminés (Vermorel et al., 1982).

Les réserves corporelles sont utilisées pour la production laitière avec un rendement d'environ $80 \%$, et fournissent 50 et $35 \%$ de l'énergie sécrétée par la mamelle, 15 et 30 jours après le vêlage (respectivement), chez des vaches produisant $40 \mathrm{~kg}$ de lait au pic de lactation (Flatt et al., 1969b ; Schiemann et al., 1974 ; Van Es, 1975 ; Moe, 1981 ; Vermorel et al., 1982).

Après le pic de lactation, l'énergie métabolisable ingérée (qui augmente puis diminue) se partage entre la production de lait qui diminue et le dépôt des réserves corporelles. Flatt et al. (1965b) ont montré que l'accroissement du dépôt énergétique est proportionnel à la réduction de la quantité de lait récolté, lors de traites volontairement incomplètes. Dans l'étude de Schiemann et al. (1974), le dépôt lipidique entre la $6^{e}$ et la $1^{\circ}$ semaine (environ $25 \mathrm{~kg}$ ) représente $60 \%$ des lipides qui avaient été mobilisés, en accord avec les données du tableau 5.

Par contre, lorsque des vaches sont alimentées en-dessous de leurs besoins en pleine lactation, elles réagissent à la fois en mobilisant de l'énergie (des lipides) corporelle et en réduisant leur production laitière (Kirchgessner et al., 1983), en accord avec les données du tableau 4. 
Le dépôt ou la mobilisation lipidique chez la vache au cours de la gestation dépend essentiellement du niveau des apports alimentaires et de la qualité de la ration. En début de lactation, la vache laitière forte productrice mobilise de 20 à $60 \mathrm{~kg}$ de lipides au cours des 6 à 8 premières semaines, selon la quantité et la qualité de la ration distribuée. Les tissus adipeux sous-cutanés, internes et intermusculaires contribuent à parts sensiblement égales à cette lipomobilisation, qui peut représenter plus de $50 \%$ de l'énergie sécrétée par la mamelle. La reconstitution des réserves lipidiques s'effectue généralement en majeure partie avant la fin de la lactation.

\section{Métabolisme du tissu adipeux.}

a) Synthèse et prélèvement d'acides gras.

Les activités d'enzymes lipogéniques (déshydrogénases) du tissu adipeux de génisses gravides (7-8 mois) sont inférieures ou égales à celles de vaches adultes non gravides (âge non précisé) et inférieures à celles de génisses âgées de 12 à 16 mois (Baldwin et al., 1973). Une note de Smith et al. (1981b) fait toutefois état de niveaux " élevés " de lipogenèse de novo en fin de gestation, en accord avec Hagemeister (1972a), Pike et Roberts (1981) et Reid et al. (1986). La lipogenèse serait plus faible, un mois avant la parturition, chez des génisses à plus fort potentiel laitier (Mc Namara et al., 1985).

L'apport alimentaire semble être déterminant en fin de gestation dans la mesure où les besoins sont relativement faibles (un seul fœtus). Ainsi, les activités de l'enzyme malique et de la LPL sont plus élevées 6 semaines avant mise-bas lorsque les vaches sont alimentẻes ad libitum (Chilliard et al., 1984b ; fig. 8). Shirley (1973) rapporte même une augmentation d'activité LPL let d'estérification des acides gras) pendant la dernière semaine de gestation chez des vaches recevant un supplément d'aliments concentrés (" préparation au vêlage "). Par contre, la lipogenèse de novo diminue durant le dernier mois chez des génisses qui ne reçoivent que du foin (Mc Namara et Hillers, 1986).
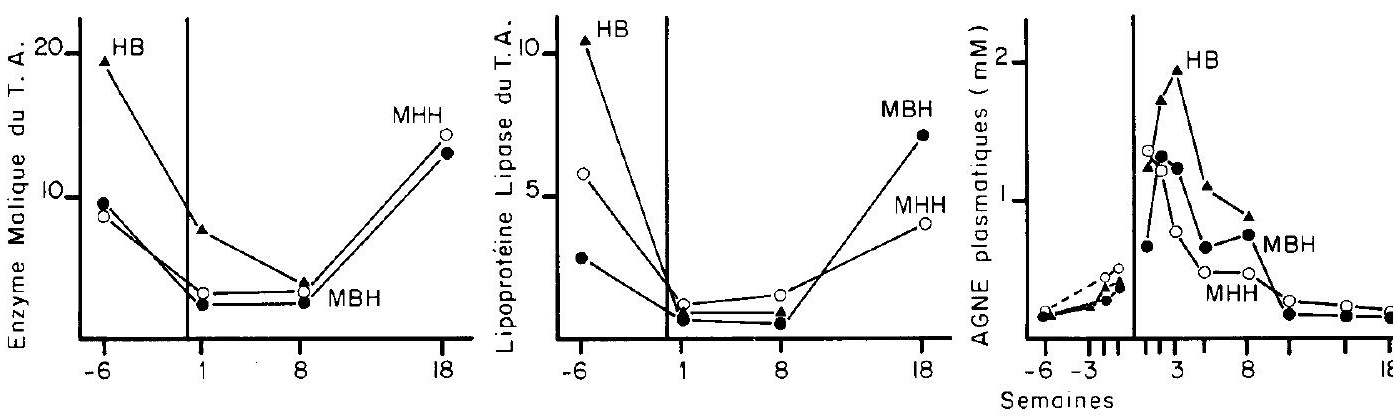

FIG. 8. - Influence du régime alimentaire avant et après mise-bas, et du niveau de production laitière, sur les AGNE plasmatiques, et les activités de la LPL et de l'enzyme malique du tissu adipeux sous-cutané caudal chez la vache laitière. (Chilliard et al, 1982, 1984a, b). (Voir la figure 6 pour les caractéristiques des lots) (Les activités enzymatiques sont exprimées en $\mu$ moles,de NADPH produit ou d'acides gras libérés par heure et par gramme de tissu). 
Les différentes activités enzymatiques ou métaboliques intervenant dans la synthèse ou le prélèvement des acides gras par le tissu adipeux (incorporation d'acétate dans les acides gras ; oxydation du glucose ; activité des déshydrogénases à NADP et de la LPL) sont très faibles chez la vache laitière pendant les deux premiers mois de lactation (Hagemeister, 1972a ; Shirley et al., 1973a, b ; Pike et Roberts, 1980, 1981 ; Chilliard et Robelin, 1985 ; Mills et al., 1986b). Ces activités augmentent à nouveau après le pic de lactation (Baldwin et al., 1973 ; Shirley, 1973 ; Grichting et al., 1977a, b ; Keys et Capuco, 1985 ; Mc Farland et Mc Namara, 1985 ; Mc Namara et Hillers, 1986 ; Reid et al., 1986), en particulier chez les animaux qui ont plus fortement mobilisé leurs lipides en début de lactation (fig. 6 et 8), ou chez les faibles productrices (Mc Namara et al., 1985).

\section{b) Lipolyse et estérification des acides gras.}

b.1. Fin de gestation. - La lipolyse basale du tissu adipeux in vitro varie peu en fin de gestation (3 dernières semaines). Par contre, la lipolyse stimulée par les catécholamines augmente, parallèlement aux teneurs en AGNE sanguins (Metz et Van den Bergh, 1977 ; fig. 9 ; Mc Namara et Hillers, 1986). Cette augmentation de lipolyse n'a toutefois pas été observée par Reid et al. (1986). L'ampleur de l'augmentation de teneur en AGNE plasmatiques est en outre faible par rapport aux brebis prolifiques, et variable selon les expériences ; lorsque le niveau d'ingestion reste élevé, elle peut ne concerner que les derniers jours de la gestation (Radloff et al., 1966 ; Decaen et Journet, 1967 ; Pehrson, 1971 ; Henseler et al., 1973 ; Metz et al., 1973 ; Rémond et al., 1973 ; Grigsby et al., 1974 ; Luthman et Persson, 1975 ; Schwalm et Schultz, 1976 ; Roberts, 1982 ; Blum et al., 1983 ; Pethes et al., 1985).

Les teneurs en AGNE sanguins sont en partie liées au poids des veaux, à la diminution du niveau d'ingestion volontaire et au bilan énergétique des mères (Petit et Rémond, 1977 ; Bernal-Santos, 1982 ; Chilliard et al., 1982, fig. 8 ; Doreau, 1983 ; Russel et Wright, 1983 ; Larnicol et al., 1984 ; Kunz et al., 1985).

Les faibles lipomobilisations observées en fin de gestation sont à relier au maintien d'une activité de (rélestérification des acides gras (Shirley, 1973; Mc Namara et Hillers, 1986) stimulable par le glucose et peu affectée par les catécholamines (Metz et Van den Bergh, 1977).

b.2. Début de lactation. - L'estérification des acides gras lou l'incorporation de glucose dans le glycérol des triglycérides) par le tissu adipeux diminue nettement en début de lactation chez la vache laitière (Shirley et al., 1973a, b ; Metz et Van den Bergh, 1977; Pike et Roberts, 1980, 1981) et elle devient alors insensible à la stimulation par le glucose (Metz et Van den Bergh, 1977). Cette voie métabolique est par contre active en pleine lactation (Baldwin et al., 1973 ; Shirley, 1973 ; Grichting et al., 1977b ; Mc Namara et Hillers, 1986).

La lipolyse basale ou stimulée par les catécholamines augmente fortement en début de lactation et reste assez élevée pendant toute la lactation (Metz et al., 1973 ; Yang et Baldwin, 1973a ; Grichting et al., 1977b ; Metz et Van den Bergh, 1977, fig. 9 ; Pike et Roberts, 1980, 1981 ; Mc Namara et Hillers, 1986 ; Mc Namara et al., 1986 ; Reid et al., 1986). La lipolyse stimulée in vitro par l'adrénaline est corrélée positivement avec le niveau de production laitière, après un mois 
de lactation (Jaster et Wegner, 1981). Mc Namara et Hillers (1986) rapportent une faible lipogenèse et une forte lipolyse en début de période sèche, mais ne précisent pas les conditions nutritionnelles des vaches.

Par ailleurs, Sidhu et Emery (1972) et Bai et al. (1986) rapportent que l'activité basale de la lipase hormono-sensible augmente en début de lactation, alors qu'il n'y a pas de différence entre les activités maximales obtenues après activation par I'AMP cyclique in vitro. Jaster et Wegner (1981) observent les mêmes teneurs en AMP cyclique dans des adipocytes de vaches avant ou après mise-bas, incubés in vitro en absence ou en présence d'adrénaline. Par contre, les vaches en début de lactation 11 mois) ont plus de récepteurs $\beta$-adrénergiques par adipocyte (+ $71 \%$ ) ou par unité de surface d'adipocyte (+ $81 \%$ ) que des vaches en fin de gestation (un mois avant terme) en accord avec les réponses très marquées aux catécholamines in vivo, jusqu'en $7^{\mathrm{e}}$ semaine de lactation au moins (Shidu et Emery, 1972 ; Sato, 1977 : Bernal-Santos, 1982, fig. 9).

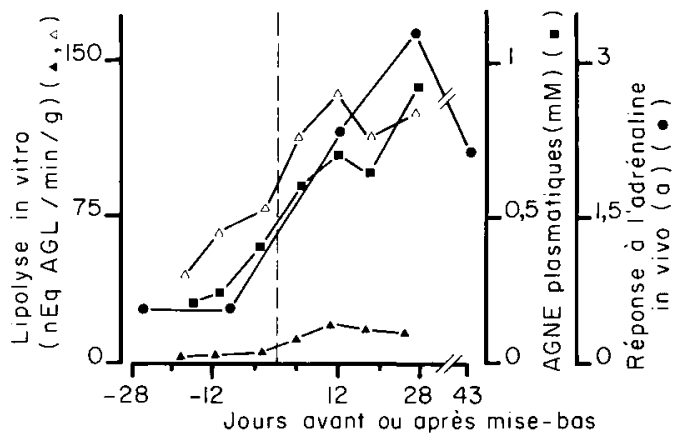

FIG. 9. - Lipomobilisation peri-partum chez la vache laitière (adapté d'après Metz et Van den Bergh, 1977) ( $\triangle, .$, , ) et Bernal-Santos, 1982 ( • ). . , lipolyse basale, in vitro ; $\Delta$, lipolyse en présence de noradrénaline $\left(2,5 \times 10^{-5} \mathrm{M}\right) ; \bullet$. AGNE plasmatiques ; $\bullet$, réponse des AGNE plasmatiques in vivo pendant l'heure qui suit une injection IV d'adrénaline $10,7 \mu \mathrm{g} / \mathrm{kg}$ ) (surface intégrée en $\mathrm{mM} \times \min$.) (Les différents échantillons sont prélevés 1 à $4 \mathrm{~h}$. après le repas du matin).

Les adipocytes des tissus adipeux périrénal et de la cavité pe/vienne présentent par ailleurs une plus faible activité lipolytique in vitro que ceux des tissus adipeux épip/ö̈que et sous-cutanés, chez la vache laitière sous-alimentée en début de lactation (Pike et Roberts, 1984).

Les variations simultanées de la lipolyse et de l'estérification des acides gras se traduisent par une lipomobilisation importante, confirmée par des mesures de flux de l'acide palmitique, qui est très élevé après le vêlage puis décroît progressivement (Konig et al., 1979). II en est de même des concentrations plasmatiques $d^{\prime} A G N E$, qui sont maximales en première ou deuxième semaine de lactation puis diminuent pour tendre vers leur valeur de base durant le $2^{e}$ à $4^{e}$ mois de lactation (voir par exemple Radloff et al., 1966 ; Rémond et Journet, 1970 ; Pehrson, 1971 ; Metz et al., 1973 ; Horst et al., 1976 ; Swan, 1976 ; Henricson et al., 1977 ; Roberts et al., 1979 ; Bernal-Santos, 1982 ; Garnsworthy et Topps, 1982a ; Roberts, 1982 ; Blum et al., 1983 ; Giesecke, 1984 ; Coulon et al., 1984, 
1985). Les valeurs absolues enregistrées varient en particulier avec la méthode de dosage, I'heure du prélèvement de sang par rapport aux repas, les niveaux de production laitière et d'alimentation des animaux,... Elles restent faibles, en particulier, chez la vache allaitante normalement alimentée (Agabriel et al., 1985 ; Easdon et al., 1985).

La signification des teneurs en acides gras libres plasmatiques est sujette à controverse (Roberts et al., 1978 ; Konig et al., 1979 ; Vermorel et al., 1982). Dans ces 3 expériences, il s'agissait soit de sous-alimentation à long terme, soit du seul acide palmitique chez des animaux recevant du concentré toutes les heures, soit d'animaux dont le sang était prélevé avant un séjour d'une semaine en chambres respiratoires. Cependant, il existe généralement des corrélations négatives étroites entre le bilan énergétique calculé des animaux et les teneurs préprandiales en AGNE plasmatiques au début de la lactation (Decaen et Journet, 1967 ; Rémond et al., 1973 ; Erfle et al., 1974 ; Parker et Lewis, 1978 ; Dale et al., 1979 ; Doreau, 1983 ; Chilliard et al., 1984a ; Larnicol et al., 1984 ; Kunz et al., 1985 ; Kunz et Blum, 1985). De plus, ces teneurs sont étroitement liées aux variations de lipides corporels estimées à partir de mesures de l'eau lourde, et dans une moindre mesure aux variations de taille des adipocytes du tissu sous-cutané (Roberts et al., 1981 ; Chilliard et al., 1984a ; tabl. 5 et fig. 6 et 8 ) ou aux variations d'apports alimentaires chez des animaux à faibles besoins (Holmes et Lambourne, 1970 ; Fisher et al., 1975). Des corrélations négatives significatives sont aussi observées avec les bilans énergétiques mesurés en chambres respiratoires (Vermorel et al., 1982), y compris dans le cas défavorable de teneurs post-prandiales (Schiemann et al., 1974).

Ces relations sont logiques si le prélèvement des AGNE par les différents tissus est supposé proportionnel à leur concentration sanguine (Fritz, 1961 ; Eisemann et al., 1984b) relativement à celle de l'albumine plasmatique (Metz et al., 1973 ; Soler-Argilaga et al., 1974). Il a été montré chez les ovins et les bovins que cette concentration est bien liée au taux d'entrée dans l'organisme (cf. § III 2b). Les teneurs en AGNE plasmatiques évoluent parallèlement à la lipolyse in vitro dans l'étude de Metz et Van den Bergh (1977, fig. 9). Il est toutefois possible que les variations de la vitesse d'utilisation des AGNE par les tissus non adipeux puissent modifier cette relation dans certaines situations nutritionnelles ou expérimentales (cf. Vernon, 1980).

La lipogenèse du tissu adipeux est active chez la vache en fin de gestation et le potentiel lipolytique augmente durant les dernières semaines, si bien que ce tissu peut alors déposer ou mobiliser rapidement des acides gras selon le niveau des apports alimentaires. La lipogenèse et l'estérification sont presque totalement supprimées en début de lactation, mais fortement réactivées à partir du troisième mois de lactation. Le potentiel lipolytique du tissu est par contre élevé durant toute la lactation, après une phase de lipomobilisation particulièrement active pendant les 4 à 8 premières semaines chez les vaches fortes productrices ou sous-alimentées. 


\section{Métabolisme hépatique.}

Alors que l'absorption intestinale de glucose est généralement comprise entre 0,3 et $1 \mathrm{~kg} / \mathrm{j}$, le besoin journalier de glucose, lié essentiellement au prélèvement mammaire, est de plus de $3 \mathrm{~kg} / \mathrm{j}$ chez des vaches hautes productrices $(35-40 \mathrm{~kg}$ de lait $/ \mathrm{j}$ ), et a atteint $7 \mathrm{~kg} / \mathrm{j}$ chez une championne produisant $89 \mathrm{~kg}$ de lait par jour (Kronfeld et al., 1968 ; Armstrong et Prescott, 1971 ; Patterson et Linzell, 1974 ; Young, 1977 ; Peeters et al., 1979 ; Thilsted, 1985a). La néoglucogenèse hépatique et le renouvellement du glucose augmentent donc très fortement en début de lactation (Lindsay, 1971, 1979 ; Baird et al., 1975, 1980, 1983; Lomax et al., 1979 ; Kenna et al., 1981 ; Aiello et al., 1984) et ils sont corrélés au niveau de production laitière (Lomax et Baird, 1983).

Chez les ruminants, la néoglucogenèse dépend en premier lieu des entrées de précurseurs exogènes, c'est-à-dire des quantités d'aliments ingérées (Elliot, 1980 ; Lomax et Baird, 1983). Toutefois, la vitesse d'entrée du glucose dans l'organisme est plus élevée après qu'avant mise-bas (Bennink et al., 1972), pour un même niveau d'ingestion. Baird et Heitzman (1970), Smith et al. (1982), Mesbah et Baldwin (1983), Mills et al. (1986b) et De Boer et al. (1986) n'observent pas de variations des activités potentielles des enzymes de la néoglucogenèse, in vitro, ou de la réponse au glucagon in vivo chez des vaches taries ou en lactation, et suggèrent que cette voie métabolique est surtout régulée par la disponibilité en substrats (propionate, glycérol, lactate, acides aminés,...) provenant du tube digestif ou de la mobilisation des réserves glucidiques et protéiques (Oldham et Lindsay, 1983 ; Journet et al., 1983 ; Rémésy et al., 1984, 1986).

Les AGNE circulants sont en partie captés par le foie (de 15 à $25 \%$, selon Schultz, 1974 et Reid et al., 1979) et leur estérification augmente pendant la lactation (Mesbah et Baldwin, 1983). II est possible qu'une fraction des triglycérides ainsi formés soit sécrétée (Reid et al., 1979) sous forme de VLDL hépatiques bien que la teneur sanguine de celles-ci diminue en début de lactation (Raphaël et al., 1973; Mazur et al., 1986a), du fait de leur hydrolyse par la LPL mammaire dont l'activité est très élevée à ce stade (Yousef et al., 1969 ; Shirley, 1973 ; Y. Chilliard, non publié).

Toutefois, la sécrétion des triglycérides par le foie est probablement inférieure à leur synthèse puisque les vaches développent, de façon variable, une stéatose hépatique en début de lactation (Ford, 1959; Reid, 1980 ; Mazur et al., 1986b) qui peut être fortement accentuée par le jeûne (Brumby et al., 1975 ; Reid et al., 1979). La capacité de sécrétion des lipoprotéines par le foie pourrait être diminuée en début de lactation (Reid et al., 1980), comme chez l'animal sous-alimenté, ce qui se traduirait par une baisse des teneurs en phospholipides et en cholestérol des LDL circulantes (Herdt et al., 1983; Gerloff et al., 1986 ; Mazur et al., 1986a, c ; Rayssiguier et al., 1986a). Les œstrogènes ont un effet lipotropique chez la vache sous-alimentée (Laarveld et al., 1982) mais leur rôle limitant éventuel pour le recyclage des acides gras en début de lactation n'a pas été étudié.

La stéatose hépatique est liée à l'intensité de lipomobilisation en début de lactation (Roberts et al., 1981 ; Reid et al., 1983 ; Gerloff et al., 1986a ; Rayssiguier et al., 1986b) mais pas systématiquement (Perkins et al., 1983 ; Reid et al., 1986). Lorsqu'elle est excessive, elle peut s'accompagner de troubles métaboli- 
ques, infectieux ou de la reproduction (Morrow, 1976 ; Reid et Roberts, 1982, 1983 ; Reid et al., 1983a, b, 1986 ; Smith et al., 1983a).

Les AGNE captés par le foie peuvent aussi être oxydés totalement $\left(\mathrm{CO}_{2}\right)$ ou partiellement (corps cétoniques) dans les mitochondries hépatiques. La cétogenèse hépatique permet un recyclage des AGNE, sous forme de 3-hydroxybutyrate notamment (Palmquist, 1972 ; Lomax et Baird, 1983), qui peut être réutilisé par les différents organes. Une cétogenèse excessive peut cependant conduire à des déviations pathologiques graves. Bien qu'une lipomobilisation importante soit nécessaire à l'intensification de la cetogenèse, il semble que celle-ci soit surtout exacerbée lorsque les entrées en substrats glucoformateurs sont faibles, relativement à l'intensité de la néoglucogenèse. En effet, ceci diminue la disponibilité en oxaloacétate mitochondrial nécessaire à l'oxydation totale de l'acétyl-CoA provenant de l'oxydation des acides gras (Krebs, 1966 ; Baird et al., 1968). En outre, cette situation nutritionnelle stimule l'entrée et l'oxydation des acides gras dans les mitochondries, et diminue les possibilités de réestérification des acides gras (Bergman, 1971 ; Schultz, 1974 ; Jesse et al., 1983 ; Aiello et al., 1984). La teneur en glycogène du foie diminue d'environ $75 \%$ peri-partum (Mills et al., 1986a).

Ceci peut expliquer que l'élévation des corps cétoniques et la fréquence des crises d'acétonémie des vaches hautes productrices soient maximales après la deuxième semaine de lactation, lorsque la synthèse du lactose par le tissu mammaire atteint son maximum et la glycémie ses plus faibles valeurs (Adler et al., 1963 ; Dale et al., 1979 ; Kauppinen, 1983a, b ; Coulon et al., 1984, 1985 ; Larnicol et al., 1984), alors que la stéatose hépatique se met en place immédiatement après la mise-bas et n'augmente que jusqu'en deuxième semaine de lactation. L'acétonémie est accompagnée dans la plupart des cas par une stéatose hépatique (Ford et Boyd, 1960 ; Groehn et al., 1983 ; Reid et al., 1983). Les causes primaires des cétoses spontanées à caractère pathologique sont toutefois controversées (Ballard et al., 1986; Kronfeld, 1971, 1982 ; Baird, 1977, 1982).

Le foie de vache contribue à la production d'acétate endogène, dont l'origine (oxydation des AGNE ?) est encore débattue (Williams et al., 1963 ; Palmquist, 1972 ; Baird et al., 1977 ; Snoswell et al., 1978 ; Bell, 1980 ; Lomax et Baird, 1983). On ignore presque tout de la synthèse et du métabolisme hépatique des lipoprotéines chez les bovins. La triglycéridémie augmente fortement chez la vache en fin de lactation lorsque le catabolisme extra-hépatique des VLDL est bloqué par administration de Triton (Wrenn et al., 1971). Pendant la phase descendante de la lactation, le prélèvement d'AGNE par le foie n'expliquerait que $50 \%$ de la sécrétion hépatique de triglycérides, d'après les calculs théoriques de Waghorn (1983), ce qui est difficile à concilier avec l'absence de lipogenèse de novo hépatique (Ballard et al., 1968, 1969).

Le besoin mammaire en glucose, la néoglucogenèse intense et l'éventuelle insuffisance d'absorption de précurseurs glucogéniques prédisposent la vache laitière à l'acétonémie en période de lipomobilisation. La capacité du foie à sécréter des lipoprotéines semble être limitée en début de lactation, ce qui favorise aussi la stéatose hépatique. 


\section{Régulations métaboliques et hormonales.}

a) Niveau d'ingestion et bilans nutritionnels.

L'évolution de la capacité d'ingestion des vaches au cours de la gestation a rarement été étudiée indépendamment de la lactation. Penzhorn et Meintjes (1972) rapportent un accroissement en milieu de gestation. Pendant les 6 dernières semaines de gestation, la plupart des auteurs observent une diminution d'ampleur variable de l'ingestion volontaire, surtout avec des rations à base de foin ou d'ensilage de qualité médiocre (Forbes, 1970a, 1971 ; Journet et Rémond, 1976 ; Burlacu et al., 1978 ; Iwasaki et al., 1980 ; Doreau et Rémond, 1982 ; Koong et al., 1982). Des chutes plus fortes sont fréquemment enregistrées pendant les jours qui précèdent la mise-bas, y compris avec des rations très ingestibles et riches en énergie.

La variabilité de ce phénomène explique probablement les contradictions apparentes entre les données de composition corporelle ou de teneurs en AGNE sanguins en fin de gestation, et certaines études en chambres respiratoires où la ration était de qualité médiocre ou distribuée en quantité limitée (cf. § IV. 1a et $2 b)$.

La régulation de l'ingestion, chez la vache comme chez la brebis, est à la fois de type physique et métabolique (cf. § III 4a). La capacité d'ingestion augmente avec le potentiel de production laitière, mais il existe un double décalage entre ces deux paramètres. En effet, la première augmente moins vite que la seconde jusqu'au pic de production, et cet écart s'accentue entre vaches de potentiels laitiers croissants (Bines, 1976 ; Journet et Rémond, 1976 ; Davey et al., 1983). II en résulte que les progrès de la sélection génétique tendent à accroître la perte de poids (Vérité et Journet, 1978) et la mobilisation des réserves corporelles en début de lactation (cf. Introduction et $\S$ IV 1b). La capacité d'ingestion élevée des vaches pendant la phase descendante de la lactation et la période sèche (Bines, 1976) favorise ensuite la reconstitution des réserves.

En cas de sous-alimentation, on observe généralement à la fois une augmentation de la lipomobilisation (ou une diminution du dépôt lipidique) et une réduction de la production laitière, et c'est l'inverse lorsque le niveau d'alimentation augmente. Cependant, la production laitière est mieux maintenue ou accrue chez les fortes productrices et en début de lactation (Flatt et al., 1969b ; Journet, 1978 ; Wiktorsson, 1979 ; Broster, 1980). Ceci reflète une priorité du métabolisme mammaire, peut être liée aux caractéristiques hormonales des animaux (cf. $\S$ IV 4b). La réponse est toutefois largement modulée par l'importance des réserves lipidiques (cf. § IV 4c) et la composition de la ration distribuée (cf. IV 4d).

L'ampleur du cycle lipomobilisation-reconstitution dépend donc essentiellement des interactions entre le potentiel laitier de l'animal, le stade de lactation, la quantité et la qualité de la ration et l'état d'engraissement de l'animal au vêlage.

b) Influence du stade physiologique et du niveau de production.

L'augmentation de la lipomobilisation en fin de gestation et surtout en début de lactation a été reliée au profil hormonal de l'animal à cette période, caractérisé 
par une faible insulinémie, une teneur élevée en hormone de croissance plasmatique, et une tendance à l'hypoglycémie (Adler et al., 1963 ; Kronfeld, 1965 ; Radloff et Schultz, 1966 ; Yang et Baldwin, 1973a, b ; Jenny et al., 1974 ; Swan, 1976 ; Beck et Tucker, 1978 ; Hart et al., 1978 ; Parker et Lewis, 1978 ; De Boer et al., 1985 ; Herbein et al., 1985 ; fig. 10). Ces taux hormonaux résultent de diminutions de la sécrétion d'insuline et de sa réponse au glucose ou au propionate, et d'une augmentation de la sécrétion d'hormone de croissance (Bourne et al., 1977 ; Vines et al., 1977 ; Lomax et al., 1979 ; Hart et al., 1980 ; Peters et al., 1981 ; Giesecke, 1984). L'avancement de la lactation s'accompagne d'une inversion de ces tendances.

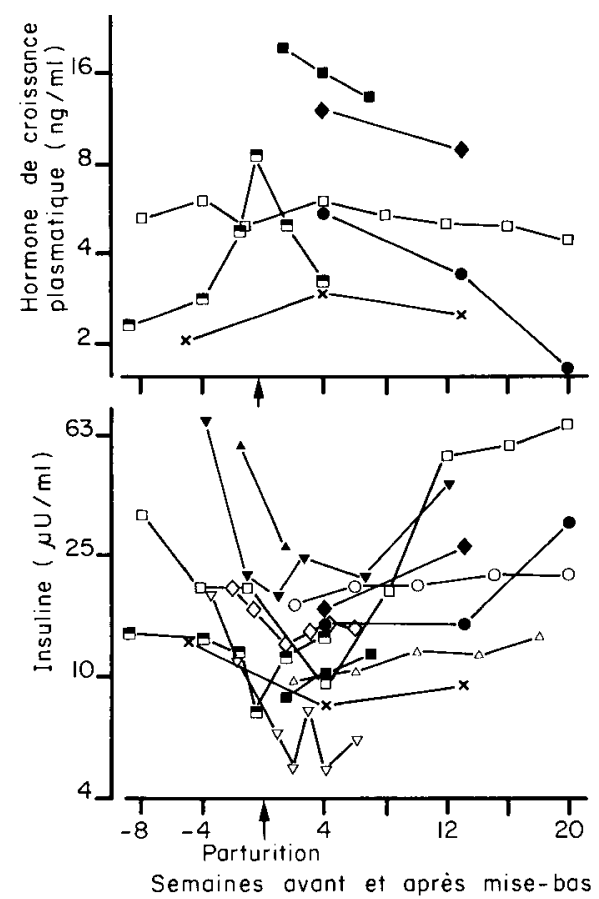

FIG. 10. - Teneurs en insuline et en hormone de croissance du plasma chez la vache laitière. A Blum et al., 1973. - 9 vaches ( $8 \mathrm{~h}$ et $16 \mathrm{~h}$ ) ; 口 Koprowski et Tucker, $1973-26$ vaches (après-midi) (ensilage de maï). o Hove, 1974 - 60 vaches (de nuit) (ensilage d'herbe) ; Smith et al., 1976. 24 vaches (après-midi) (ensilage de maïs); $\diamond$ Schwalm et Schultz, 1976 - 31 vaches ; - Hart et al., $1980-4$ vaches (post-prandial) $(9 \mathrm{~kg}$ concentré $+1 \mathrm{~kg}$ foin) (20 kg lait); $\triangle$ Walsh et al., 1980 - 86 vaches (post-prandial) (foin) (32 kg lait) ; $\checkmark$ Vasilatos et Wangsness, 1981 - 5 vaches (en continu) (60\% concentré) (35 kg lait) ; a Chew et al., $1984-30$ vaches (3 prélèvements $/ 24 \mathrm{~h}$.) (ration mixte) (30 kg lait); $\nabla$ Giesecke, 1984 - 12 vaches (30 kg lait). × Kunz et al., 1985 - 9 vaches (après-midi) (ration mixte) (22 kg lait) ; • Grizard J. et Rémond B. (non publié) -7 vaches (post-prandial) (ensilage de maïs $+40 \%$ concentré) (30 $\mathrm{kg}$ lait).

La comparaison à même stade de lactation de vaches de race laitière ou à viande, recevant la même quantité d'aliments mais produisant des quantités très différentes de lait, montre que les premières (fortes productrices) ont une insulinémie et une glycémie plus faible, et des teneurs plasmatiques en hormone de croissance, AGNE et corps cétoniques plus élevées (Hart et al., 1978, 1980). Cet effet 
du niveau de production a aussi été confirmé à l'intérieur d'une même race, chez des vaches de races laitière ou à viande (Flatlandsmo, 1971 ; Luthman et Jonson, 1972b ; Johnson et al., 1976 ; Miller et al., 1978 ; Thilsted, 1983), mais pas dans des expériences où l'alimentation était généralement plus libérale (Radloff et al., 1966 ; Koprowski et Tucker, 1973 ; Schwalm et Schultz, 1976 ; Walsh et al., 1980 ; Blum et al., 1983 ; Davey et al., 1983 ; Hart, 1983).

Bien qu'il soit difficile de séparer les différents effets, il est probable que le bilan nutritionnel (apports-besoins) des animaux explique en grande partie les effets du stade de lactation et du niveau de production et les contradictions apparentes entre différentes études. En effet, les concentrations sanguines et la sécrétion d'hormone de croissance augmentent chez la vache en lactation lorsque le bilan énergétique ou la glycémie diminuent (Hove et Blom, 1973; Athanasiou et Phillips, 1978 ; Miller et al., 1978 ; Bauman et al., 1979 ; Mc Dowell, 1983 ; Kunz et al., 1985 ; De Boer et al., 1985, 1986). Inversement, l'insulinémie diminue dans ces situations nutritionnelles, où la disponibilité en glucose est plus faible (/bid. ; Hove, 1974, 1978a ; Smith et al., 1976 ; Kunz et Blum, 1985 ; Gerloff et al., 1986b). Toutefois, des génisses sélectionnées sur le potentiel laitier montrent des teneurs en hormone de croissance et en AGNE plasmatiques plus élevées, indépendamment de leur niveau de production ou d'alimentation (Barnes et al., 1985).

b.1. Insuline. - L'adaptation de la néoglucogenèse hépatique au flux énorme de glucose vers la mamelle est probablement un déterminant majeur des adaptations métaboliques du début de lactation. Lomax et al. (1979) ont montré que des vaches en lactation répondent à une infusion de glucose par une réduction de la néoglucogenèse hépatique, alors que des vaches taries augmentent leur insulino-sécrétion. Cette réduction de l'insulino-sécrétion en lactation ne supprime pas la réponse post-prandiale de l'insulinémie (Hove et Blom, 1973 ; Vasilatos et Wangsness, 1980 ; Bines et al., 1983 ; Thilsted, 1985b), ni à la suite d'une injection de glucose (Bernal-Santos, 1982). Cette réponse est toutefois réduite en début de lactation, surtout chez les vaches hypoglycémiques et hypercétonémiques (Hove et Halse, 1978).

Les réductions de l'insulinémie et de la glycémie en début de lactation contribuent probablement à l'augmentation de la néog/ucogenèse hépatique (Bassett, 1978 ; Brockman, 1978 ; Baird, 1981) et à la diminution du prélèvement et de l'oxydation du glucose par les tissus extra-mammaires (Kronfeld et Raggi, 1964 ; Benninck et al., 1972 ; Bruckental et al., 1980 ; Thilsted, 1985a). Par contre, le prélèvement mammaire n'est pas affecté car il est moins dépendant de l'insuline (Hove, 1978b ; Bauman et al., 1973 ; Laarveld et al., 1981) et de la glycémie, lorsqu'elle reste supérieure à environ $0,4 \mathrm{~g} / \mathrm{l}$ (Kronfeld et al., 1963 ; Rook, 1979 ; Baldwin et al., 1980). Le flux sanguin à travers la mamelle augmente fortement pendant la lactation. II semble suivre, plutôt que précéder, l'accroissement de l'activité métabolique du tissu mammaire (revue de Collier et al., 1984).

Bien que les réponses du tissu adipeux bovin à l'insuline (in vitro ou in vivo) soient moins marquées que chez les monogastriques (Vernon, 1980 ; Vasilatos, 1982 ; Smith et al., 1983b), cette hormone stimule la lipoprotéine-lipase, la lipogenèse de novo et l'estérification des acides gras et diminue la réponse lipolytique aux catécholamines (Baldwin et al., 1973 ; Emery, 1973 ; Rao et al., 1973 ; Yang 
et Baldwin, 1973a, b ; Etherton et Evock, 1986), directement ou en augmentant I'utilisation du glucose (Prior et Smith, 1982 ; Vernon et al., 1985b). L'insuline et la disponibilité en glucose jouent donc probablement un rôle important dans les adaptations du métabolisme du tissu adipeux en début de lactation, comme le suggèrent les observations de Kronfeld (1965), Bernal-Santos (1982) et Faverdin (1986) sur les AGNE plasmatiques.

II faut cependant souligner que l'insuline et le glucose semblent perdre leurs effets lipogénique et antilipolytique sur le tissu adipeux in vitro en début de lactation (Metz et Van den Bergh, 1972, 1977), ce qui suggère que ces régulations homéostasiques sont modulées par d'autres régulations "téléophorétiques "qui permettraient d'assurer la priorité du métabolisme mammaire sur celui du tissu adipeux (Bauman et Currie, 1980). Ces régulations téléophorétiques conduiraient par exemple à la perte du potentiel enzymatique de réestérification, ou à l'augmentation du nombre de récepteurs $\beta$-adrénergiques et du potentiel lipolytique des adipocytes (Jaster et Wegner, 1981). Une résistance périphériques à l'insuline est aussi suggérée par les études in vivo de Bernal-Santos (1982) et Davey et al. (1983), dans lesquelles I'insulinémie et la glycémie varient peu avec le stade physiologique et le bilan énergétique. De plus, l'accroissement des réponses in vivo à l'adrénaline pendant la lactation ne semble pas lié au bilan énergétique (Bernal-Santos, 1982).

b.2. Hormone de croissance. - L'hormone de croissance pourrait jouer ce rôle téléophorétique au niveau du tissu adipeux, sur lequel elle a des effets variés à court et à long terme. La signification de ces effets est cependant controversée en raison de la difficulté à réaliser et à interpréter des études in vitro à long terme ; parce que les effets lipolytique et diabétogène de l'hormone de croissance bovine semblent dus soit à des contaminants d'origine hypophysaire, soit à des fragments de l'hormone, soit à des médiateurs induits par l'hormone in vivo (Salaman, 1972 ; Lee et al., 1974 ; Assa et Laron, 1977 ; Frigeri, 1980 ; Bauman et al., 1982 ; Hart, 1983 ; Hart et al., 1984a), et parce que ces effets ne sont pas retrouvés in vivo avec l'hormone produite par recombinaison génétique (Hart et al., 1984b).

Les effets de l'hormone de croissance humaine sur les adipocytes de rat sont multiples : inhibition de la pénétration du glucose in vivo, inhibition de l'acétylCoA-carboxylase et de la LPL in vitro, stimulation plus ou moins marquée de la lipolyse en présence de glucocorticoïdes in vitro (Murase et al., 1981 ; Schoenle et al., 1982 ; Bornstein et al., 1983 ; Frigeri et al., 1982 ; Goodman et Grichting, 1983). Selon Goodman et Schwartz (1974) I'hormone de croissance maintiendrait le potentiel lipolytique des adipocytes et amplifierait ainsi la réponse aux stimuli lipolytiques.

Ces résultats ne sont pas directement transposables aux ruminants, mais appuient certaines hypothèses. Ainsi, Bines et al. (1983) suggèrent que l'hormone de croissance maintiendrait un niveau élevé d'AGNE plasmatiques pendant la lactation, qui serait modulé par les variations post-prandiales de l'insuline, ou par d'autres facteurs. Par ailleurs, un ralentissement du prélèvement et de l'utilisation du glucose par les tissus périphériques serait cohérent avec le bloquage de la réestérification rapporté par Metz et Van den Bergh (1977) en début de lactation 
et avec l'augmentation de glycémie après injection d'hormone de croissance bovine (Brumby et Hancock, 1955 ; Bourne et al., 1977 ; Bines et al., 1980). Des résultats récents montrent que l'hormone de croissance diminue la réponse à l'insuline du tissu adipeux bovin in vitro, et accroît la réponse à l'adrénaline in vivo (Bauman et al., 1984 ; Bauman et Mc Cutcheon, 1986 ; Mc Cutcheon et Bauman, 1986). Les réponses in vitro peuvent de plus varier selon l'état nutritionnel de l'animal donneur de tissu (Keys et Capuco, 1985 ; Fekry et al., 1986).

L'administration d'hormone de croissance (somatotropine) bovine pendant 10 jours entraîne au bout de 4 à 6 jours une augmentation de production laitière chez la vache en pleine lactation (effet galactopoiétique), sans modification de l'ingestion volontaire. I/ en résulte soit une diminution du dépôt d'énergie corporelle lorsque les animaux sont en bilan positif, soit une perte d'énergie corporelle accompagnée des signes classiques de lipomobilisation (Bines et al., 1980 ; Peel et al., 1981, 1983 ; Tyrrell et al., 1982 ; Bitman et al., 1984a ; Eppard et al., 1985a, b ; Richard et al., 1985).

Cette redistribution des nutriments au profit de la mamelle ne semble pas avoir pour point de départ une moindre consommation de glucose et d'acides aminés par les tissus périphériques (Peel et al., 1982). L'hormone de croissance réduirait par contre le potentiel lipogénique du tissu adipeux (Bauman et Mc Cutcheon, 1986) et augmenterait la néoglucogenèse hépatique (Pocius et Herbein, 1986) lorsque le bilan nutritionnel de l'animal est positif. Lorsque celui-ci est négatif, elle accroitrait le potentiel lipolytique du tissu adipeux et augmenterait l'oxydation des acides gras libres par les tissus, épargnant ainsi du glucose au profit de la mamelle (revue de Bauman et Mc Cutcheon, 1986).

Un effet direct sur le tissu mammaire n'a pas pu être montré in vivo ou in vitro (Skarda et al., 1982 ; Gertler et al., 1983 ; Mc Dowell et Hart, 1984), mais on observe une augmentation du flux sanguin mammaire in vivo (Hart, 1983; Mc Namara et al., 1983 ; Mepham et al., 1984 ; Fleet et al., 1986). Une médiation de tel ou tel effet par les somatomédines est probable (Peel et al., 1985). Quoi qu'il en soit, le métabolisme du tissu adipeux semble s'adapter aux variations du métabolisme mammaire ou global de l'animal, plutôt que les précéder.

Des injections d'hormone de croissance pendant une longue durée entraînent par ailleurs une forte augmentation du niveau d'ingestion (Bauman et al., 1984, 1985 ; Peel et al., 1985), permettant à l'animal de ne pas épuiser ses réserves corporelles. Une tendance à la lipomobilisation a toutefois été observée dans certaines expériences de longue durée (Soderholm et al., 1986a, b).

b.3. Autres régulations. - Les connaissances sur les régulations hormonales du métabolisme du tissu adipeux et des flux de nutriments chez la vache en lactation sont encore embryonnaires. Outre l'insuline et l'hormone de croissance, d'autres hormones sont influencées par le stade de lactation, le niveau de production ou les bilans nutritionnels (glucose, acides aminés, énergie,...) : hormones thyroïdiennes (réduction probable de leur sécrétion en début de lactation permettant une réduction des métabolismes extra-mammaires), g/ucocorticoïdes, prolactine, catécholamines,... La régulation de leur sécrétion, leurs rôles métaboliques et leurs interactions ne sont pas toujours clairement établis (voir par exemple Emery, 1973 ; Convey, 1974 ; Patterson et Linzell, 1974 ; Bauman, 1976 ; Swan, 
1976 ; Coggins et Field, 1978 ; Hart et al., 1978, 1979 ; Miller et al., 1978 ; Cowie et al., 1980 ; Walsh et al., 1980 ; Trenkle, 1981 ; Blum et al., 1982, 1983 ; Blum, 1983, Mc Dowell, 1983 ; Bitman et al., 1984b ; Collier et al., 1984 ; Refsal et al., 1984 ; Aceves et al., 1985 ; Akasha et al., 1985 ; Frohli et Blum, 1985 ; Kunz et al., 1985 ; Kunz et Blum, 1985 ; Pethes et al., 1985 ; Plaut et al., 1985 ; Thilsted, 1985b ; Bauman et Mc Cutcheon, 1986 ; Gerloff et al., 1986b).

Les réponses de la sécrétion d'hormone de croissance à la sous-alimentation (revue de Vernon, 1980) ou à la gestation (Koprowski et Tucker, 1973) pourraient, par exemple, être amplifiées pendant la lactation. Les conséquences des modifications hormonales qui ont lieu pendant la lactogenèse, sur le potentiel métabolique ultérieur des tissus adipeux et hépatiques sont quasiment inconnues (Collier et al., 1984). La mobilisation des protéines corporelles (revue de Chilliard et al., 1983) peut par ailleurs être stimulée ou freinée (mécanismes d'épargne) par différentes voies encore mal connues.

Par ailleurs, la lipomobilisation est autolimitée par ses propres produits : elle est inhibée par un rapport "AGNE/albumine " élevé ou par la teneur en AGNE dans l'adipocyte (Metz et al., 1973), et par des teneurs élevées en corps cétoniques (Metz et Van den Bergh, 1972; Metz et al., 1974). Ces inhibitions ont lieu aux concentrations physiologiques d'AGNE et peuvent être renforcées par le bas niveau de l'albuminémie souvent observé en début de lactation (Little, 1974 ; Rowlands, 1978 ; Treacher, 1978 ; Larnicol et al., 1984). Le rapport " AGNE mobilisés/glycérol mobilisé " est supérieur à 3 (Yang et Baldwin, 1973a ; Etherton et al., 1977), probablement par suite d'une hydrolyse partielle des trig/ycérides (activité monoglycéride-lipasique limitante), qui pourrait représenter un mécanisme de sauvegarde des stocks lipidiques. De plus la sécrétion d'hormone de croissance pourrait être stimulée par une diminution, ou inhibée par une augmentation des AGNE circulants (Reynaert et al., 1975, 1977).

b.4. Conséquences sur la lipogenèse mammaire. - La lipomobilisation, en début de lactation ou lors d'une sous-alimentation de courte durée, se traduit par un enrichissement des AGNE circulants en acide oléique, du lait en matière grasse (taux butyreux) et de celle-ci en acides gras longs, stéarique et oléique essentiellement (Smith et Dastur, 1938 ; Luick et Smith, 1963 ; Decaen et Journet, 1967 ; Decaen et Adda, 1970 ; Rémond et Journet, 1970 ; Mulder, 1971 ; Rémond et al., 1973 ; Stobbs et Brett, 1974 ; Wittenburg et al., 1974 ; Brumby et al., 1975 ; Storry et al., 1980 ; Syrstad et al., 1982 ; Halse et al., 1983). Ces augmentations dans le lait sont la résultante de plusieurs phénomènes : limitation du volume de lait sécrété (qui est surtout lié à la synthèse du lactose donc à la disponibilité en glucose) ; augmentation du prélèvement d'AGNE par les cellules mammaires (Kronfeld, 1965 ; Varman et Schultz, 1968 ; Schwalm et al., 1972 ; Linzell, 1974) ; inhibition probable de la synthèse de novo d'acides gras (Moore et Christie, 1981). Ceci explique par ailleurs que l'énergie produite sous forme de lait soit maximale dès la deuxième semaine de lactation, et montre que la contribution des lipides corporels à cette sécrétion s'effectue en partie par un passage direct (ou après recyclage hépatique) des acides gras du tissu adipeux dans le lait.

La coexistence, en pleine lactation, d'une lipogenèse de novo et d'une lipolyse élevées dans le tissu adipeux suggère d'autre part que ce tissu contribue à 
ce stade également à la fourniture d'acides gras longs à la mamelle, qui n'en synthétise pas (revue de Moore et Christie, 1981) et alors que les quantités absorbées peuvent être inférieures aux quantités sécrétées (Storry et al., 1980). Le marquage des acides stéarique et oléique du lait lors d'administrations d'acétate radio-actif à des vaches en pleine lactation (Gerson et al., 1966 ; Baham, 1971 ; Rao et Hawkins, 1976) va aussi dans ce sens.

L'insuline joue un rôle clef dans la régulation à court terme, de nature homéostatique, de la lipogenèse du tissu adipeux et de l'utilisation extra-mammaire du glucose chez la vache en lactation. L'hormone de croissance interviendrait à plus long terme, en modifiant les potentiels de réponse lipogénique et lipolytique du tissu adipeux, et les métabolismes extra-mammaires, de façon à moduler les régulations homéostatiques dans un sens qui oriente le partage des nutriments au profit de la mamelle (téléophorèse). L'intervention des catécholamines et des hormones thyrö̈diennes dans ces régulations est probable mais encore mal connue.

c) Influence de l'état d'engraissement au vêlage.

Les vaches grasses tendent à ingérer moins, qu'elles soient taries (Bines et al., 1969 ; Bines et Morant, 1983) ou en début de lactation (Gardner, 1969 ; Lodge et al., 1975 ; Land et Leaver, 1981 ; Garnsworthy et Topps, 1982a, b), surtout lorsque la ration est riche en aliments concentrés (revue de Larnicol et al., 1984 ; Treacher et al., 1986) ce qui suggère une régulation de type métabolique. Cette diminution de l'ingestion entraîne (ou résulte $\mathrm{d}^{\prime}$ ) une plus forte perte de poids et de lipides corporels en début de lactation, et les teneurs en AGNE plasmatiques, la cétogénèse et la stéatose hépatiques, les teneurs en matière grasse et en acides gras longs du lait et les déficits énergétiques calculés s'accroissent (Ibid. ; Eckles, 1912 ; Foot et al., 1963 ; Davenport et Rakes, 1969 ; Lenkeit, 1972 ; Farries, 1975, 1982 ; Roberts et al., 1978 ; Fronk et al., 1980 ; Treacher et al., 1986). Naturellement, cette tendance est exacerbée chez les vaches grasses sous-alimentées après le vêlage (Larnicol et al., 1984 ; Kunz et al., 1985; Rayssiguier et al., 1986b) chez qui la très forte mobilisation corporelle limite la chute de production laitière et surtout de matière grasse, alors que les vaches maigres ne peuvent $y$ recourir.

Les mécanismes conduisant à une diminution de l'ingestion chez les vaches grasses n'ont pas été démontrés. L'augmentation de la lipomobilisation pourrait y contribuer (Journet et Rémond, 1976; Rémésy et al., 1984). Une résistance accrue des génisses grasses à l'insuline a été rapportée (Mc Cann et Reimers, 1985, 1986). Ce phénomène peut aussi être interprété comme un retour des animaux vers leur état d'équilibre, mais n'est pas observé dans toutes les expériences (revue de Larnicol et al., 1984 ; Reid et al., 1986).

d) Influence de la composition de la ration.

La composition de la ration peut modifier le métabolisme du tissu adipeux chez la vache en lactation, du seul fait des variations des niveaux respectifs d'ingestion et de production qu'elle peut entraîner (cf. ci-dessus). La nature du 
régime peut en outre modifier profondément le métabolisme lipidique de la vache laitière, lorsque l'apport ou le bilan énergétiques sont maintenus constants.

Ainsi, des chutes marquées du taux butyreux du lait et de la sécrétion de matières grasses sont observées chez des vaches qui reçoivent un régime trop riche en amidon et pauvre en fibres cellulosiques (Van Soest, 1963 ; Opstvedt et Ronning, 1967 ; Davis et Brown, 1970 ; Rémond et Journet, 1971 ; Jenny et al., 1974 ; Broster et al., 1979 1.

Les flux d'acétate et d'acides gras in vivo (Palmquist et Conrad, 1971 ; Jenny et al., 1972 ; Sidhu et Emery, 1973 ; Annison et al., 1974l, la lipolyse et l'oxydation du glucose in vitro, l'activité LPL et les activités d'enzymes intervenant dans la synthèse et l'estérification des acides gras par le tissu adipeux (Opstvedt et al., 1967 ; Baldwin et al., 1969, 1973 ; Baldwin et Smith, 1971 ; Benson et al., 1972 ; Hagemeister, 1972a, b ; Yang et Baldwin, 1973a ; Jenny, 1974) sont tous modifiés par ce type de régime dans un sens qui accroît le dépôt lipidique ou réduit la lipomobilisation, ce qui est cohérent avec la réduction de la synthèse des triglycérides observée parallèlement dans le foie (Benson et al., 1972).

Les études en chambres respiratoires montrent aussi que l'énergie ingérée par l'animal est alors orientée préférentiellement vers les réserves corporelles, au détriment de l'énergie sécrétée dans le lait (Flatt et al., 1969b), en accord avec des études plus globales (cf. Journet et al., 1976).

Alors que les sécrétions de lactose et de protéines ne sont que peu affectées (sauf dans certains cas extrêmes) (Sutton, 1981), le prélèvement par le tissu mammaire des précurseurs de la lipogenèse (acétate, 3-hydroxybutyrate et triglycérides) diminue (Bringe et Schultz, 1969 ; Benson et al., 1972 ; Annison et al., 1974 ; Bell, 1980 ; Rulquin, 1983), ainsi que l'oxydation du glucose et la lipogenèse de novo (Palmquist et al., 1969 ; Baldwin et al., 1972). Cette dernière modification suit probablement la disponibilité en précurseurs plus qu'elle ne la précède. En effet, le potentiel enzymatique de la lipogenèse mammaire n'est que peu affecté (Opstvedt et al., 1967 ; Baldwin et al., 1969, 1972 ; Askew et al., 1971 ; Emery, 1973 ; Zanartu et al., 1983), et un apport d'acides gras exogènes (suif protégé) permet de rétablir le taux butyreux en quelques jours (Storry et al., 1974), ce qui suggère que la fourniture en acides gras longs à la mamelle est un facteur important de cette déviation métabolique.

Plusieurs théories explicatives en ont été proposées (McClymont et Vallance, 1962 ; Davies et Brown, 1970 ; Emery, 1973 ; Elliot et al., 1979 ; Grummer et Davis, 1984). L'une d'entre elles, se fondant sur la liaison positive qui existe entre la production ruminale de propionate et la chute du taux buryreux, admet que cet acide gras volatil augmente la néoglucogenèse hépatique et stimule la production d'insuline qui, associée à la forte disponibilité en glucose, induirait une augmentation de l'anabolisme et une diminution de la lipolyse dans le tissu adipeux. Celui-ci concurrencerait ainsi la mamelle pour les précurseurs lipogéniques tout en réduisant sa fourniture d'AGNE. L'insulinémie post-prandiale est effectivement accrue chez les vaches qui ingèrent un régime riche en amidon (Walker et Elliot, 1973 ; Jenny et al., 1974 ; Jenny et Polan, 1975) et la teneur en hormone de croissance diminue (Sutton et al., 1980).

Bien que probablement simplificatrice, cette hypothèse permet d'expliquer la 
majeure partie des observations expérimentales et fournit un modèle intéressant (et important en pratique) où l'exacerbation des régulations homéostatiques prend le pas sur les régulations téléophorétiques. Les muscles, dont la consommation d'acétate est stimulée, sont vraisemblablement impliqués eux aussi dans cette déviation métabolique (Pethick et Lindsay, 1982b).

La composition de la ration peut aussi être manipulée dans un sens qui accroît la sécrétion mammaire. Par exemple, l'amélioration de l'équilibre des acides aminés arrivant dans l'intestin chez des vaches recevant une quantité fixe d'énergie se traduit par une stimulation de la sécrétion mammaire (lactose, protéines et lipides) et de la lipomobilisation (Ørskov et al., 1977 ; Vérité et Journet, 1977 ; Journet et Rémond, 1981 ; Oldham, 1984). Tout se passe alors comme si la levée d'un facteur limitant de la sécrétion mammaire accroissait le besoin en acides gras longs ou en substrats oxydables, besoin pouvant être couvert dans ce contexte nutritionnel par la mobilisation du tissu adipeux.

Une partie des cas cliniques ou sub-cliniques d'acétonémie des vaches hautes productrices en début de lactation peuvent par ailleurs être considérés comme le résultat d'un débordement des régulations homéostasiques par les régulations téléophorétiques. Certaines vaches (prédisposées ?) maintiennent en effet leur production laitière lorsqu'elles sont sous-alimentées, ou l'accroissent lorsqu'elles reçoivent suffisamment de précurseurs glucogéniques, en stimulant à la fois la néoglucogénèse hépatique et la lipomobilisation, ce qui débouche sur une cétogenèse hépatique excessive (cf. § IV.3. ; Kronfeld, 1976, 1982 ; Baird, 1982 ; Sauvant et al., 1983).

\section{Conclusion.}

Le métabolisme lipidique de la vache en fin de gestation semble dépendre essentiellement de l'apport alimentaire. L'élévation probable du potentiel lipolytique pendant le dernier mois ne s'exprime que très modérément in vivo, en liaison avec le maintien de la réestérification des acides gras.

La lipomobilisation est très importante en début de lactation chez la vache laitière, qui peut perdre de 30 à $60 \%$ de ses lipides corporels, en raison de l'augmentation relativement lente de sa capacité d'ingestion. Elle représente de $25 \%$ à $45 \%$ de l'énergie sécrétée pendant le premier mois de lactation. Outre l'élévation de son potentiel lipolytique, le tissu adipeux semble perdre simultanément l'essentiel de sa capacité anabolique (prélèvement, synthèse et estérification des acides gras). Les réserves mobilisées peuvent être entièrement reconstituées avant la fin de la lactation.

L'ampleur de ce cycle de mobilisation et de reconstitution des réserves lipidiques dépend des interactions entre le génotype (potentiel mammaire...) des animaux, leur état d'engraissement à la mise-bas, et la quantité et la nature des nutriments ingérés et absorbés lacides aminés, précurseurs du glucose et acides gras longs). Ces différents facteurs conditionnent à la fois les régulations homéostatiques et téléophorétiques, en particulier par l'intermédiaire de la disponibilité en glucose, des sécrétions d'insuline et d'hormone de croissance, et de la réponse du tissu adipeux aux catécholamines. 
Les relations de cause à effet entre ces différentes modifications sont encore mal connues. II en est de même du mode d'action là court et surtout à long terme) de la plupart des hormones, sur le métabolisme et le flux sanguin dans les tissus adipeux, hépatique, musculaire et mammaire. Par ailleurs, une partie importante des investigations sur le métabolisme et ses régulations a été effectuée sans contrôle précis des conditions nutritionnelles des animaux.

Dans la plupart des situations le métabolisme du tissu adipeux semble s'adapter au décalage existant entre le flux de nutriments allant vers la mamelle, et celui provenant du tube digestif et du foie. Ceci reflète la haute priorité métabolique de la sécrétion lactée chez la vache forte productrice. Ces adaptations téléophorétiques peuvent déboucher sur une rupture de l'homéostasie lorsque le drainage mammaire de glucose dépasse les autres régulations (acétonémie) ou lorsque la lipomobilisation est excessive (stéatose), en particulier chez les vaches grasses. On ignore presque tout du métabolisme non oxydatif des acides gras dans le foie (synthèse et sécrétion des VLDL notamment).

La sensibilité du tissu adipeux au glucose et à l'insuline chez la vache en pleine lactation est probablement à l'origine des chutes de taux butyreux observées lorsque les animaux ingèrent des rations favorisant trop la production d'acide propionique dans le rumen. Le flux des précurseurs lipogéniques et des acides gras longs est alors orienté vers le tissu adipeux, au détriment du tissu mammaire.

\section{Conclusion.}

Les connaissances sur le métabolisme lipidique au cours du cycle gestationlactation se sont considérablement accrues au cours des dix dernières années, en particulier dans des domaines où elles étaient insuffisantes : composition corporelle des femelles en lactation $\left(^{2}\right)$, métabolisme $d u$ tissu adipeux et sa régulation chez la ratte en lactation et chez la vache et la brebis au cours du cycle gestationlactation. Le domaine du métabolisme hépatique des lipoprotéines demeure peu connu.

L'accumulation préalable de réserves lipidiques et leur mobilisation en fin de gestation et/ou en début de lactation se retrouvent chez les trois espèces étudiées et, plus généralement, chez tous les mammifères $\left({ }^{3}\right)$. L'ampleur de ce phénomène (tabl. 6) est accrue chez les ruminants sélectionnés sur leur prolificité et surtout sur leur niveau de production laitière, et éventuellement sous-alimentés pour des raisons économiques. Or, ces espèces présentent des particularités digestives et métaboliques (néoglucogenèse,...) qui rendent plus délicate l'utilisation métabolique des grandes quantités d'acides gras mobilisés. Ceux-ci peuvent en effet être utilisés que comme source d'énergie ou sécrétés en lipides du lait, et le foie de ruminant ne semble pas pouvoir les recycler massivement en VLDL. Ceci explique

(2) Dont la connaissance revêt un intérêt pratique crucial en élevage pour estimer la valeur nutritionnelle des variations de poids des animaux.

(3) Des cycles saisonniers s'y surimposent, particulièrement spectaculaires chez les animaux hibernants ou dans les régions arctiques. 
la fréquence des observations de stéatose hépatique et d'acétonémie pendant ces périodes.

TABLEAU 6

Mobilisation des lipides corpore/s chez la ratte, la brebis et la vache en lactation.

\begin{tabular}{|c|c|c|}
\hline & $\begin{array}{l}\text { Quantités mobilisées } \\
\text { (durée de la période) }\end{array}$ & $\begin{array}{c}\text { Mobilisation journalière } \\
\left(\mathrm{g} / \mathrm{kg} \mathrm{P}^{0.75} / \mathrm{j}\right)\end{array}$ \\
\hline Ratte (a) & $0-43 \mathrm{~g} \quad$ (3 semaines) & $0-5$ \\
\hline Brebis allaitante (b) & $0-13 \mathrm{~kg}$ (6 semaines) & $0-15$ \\
\hline Vache laitière (b) & $15-70 \mathrm{~kg}$ ( 6 semaines) & $3-15$ \\
\hline Vache allaitante $(b, c)$ & $5-20 \mathrm{~kg}$ (6 semaines) & $1-4$ \\
\hline Chèvre laitière (d) & $4-8 \mathrm{~kg}$ (6 semaines) & $4-9$ \\
\hline
\end{tabular}

(a) Voir Chilliard (1986) pour les références; (b) Références citées dans cette revue ; (c) Vaches sous-alimentées au niveau de l'entretien ; (d) Chilliard, 1985.

Cette revue a particulièrement souligné l'importance de la prise en compte du contexte nutritionnel des animaux, tant pour l'interprétation des études sur le métabolisme et ses régulations, que pour en tirer des conséquences pratiques. II faut donc essayer de résister à la tendance consistant à séparer les études analytiques des études globales, qui résulte à la fois de la nécessaire spécialisation des recherches, et des difficultés financières et expérimentales rencontrées chez les espèces de grande taille, bovins en particulier.

Chez toutes les espèces, des mécanismes téléophorétiques permettent d'accroître et d'orienter les flux de nutriments vers les organes prioritaires, "productifs \%. Ces mécanismes apparaissent en tant que régulations à long terme, et consistent en premier lieu en une modulation des régulations homéostatiques dues au glucose et à l'insuline (résistance des tissus périphériques, diminution des effets lipogéniques sur le tissu adipeux) et aux catécholamines (accroissement des récepteurs béta adrénergiques et du potentiel lipolytique du tissu adipeux). Les " premiers messagers " téléophorétiques sont probablement la prolactine chez la ratte et l'hormone de croissance chez les ruminants en lactation, mais leurs médiateurs sont encore très mal connus. Les interactions hormonales sont encore plus complexes pendant la gestation. Les productions industrielles d'hormones dépourvues d'impuretés (recombinaisons bactériennes notamment), et de diverses substances permettant de moduler spécifiquement le métabolisme de tissus ou organes particuliers, stimulent fortement les recherches fondamentales et appliquées dans ce domaine depuis quelques années.

Les mécanismes de type homéostatique restent cependant fondamentaux pour la régulation du métabolisme du tissu adipeux pendant le cycle gestationlactation, et nous l'avons confirmé chez la chèvre laitière (Chilliard et al., 1977). L'insuline joue un rôle central du fait qu'elle régule l'utilisation des substrats par les tissus périphériques, alors que les tissus productifs en sont relativement indépendants (Brockman et Laarveld, 1986). Hypoinsulinémie et diminution des réponses à l'insuline permettent donc de limiter la compétition des tissus périphériques pour l'utilisation des nutriments. Ces adaptations sont en partie une conséquence du drainage de ceux-ci par les tissus productifs, mais probablement aussi de la production de messages de nature hormonale par ces tissus. 
Toutes les espèces étudiées (rat, homme, lapin, brebis, vache, chèvre, renne) semblent disposer d'un ou de plusieurs mécanismes permettant de limiter la lipomobilisation lacides gras libres, corps cétoniques, taille des adipocytes, rapport des récepteurs alpha et béta adrénergiques, sensibilité à l'adénosine, monoglycéride-lipase, hypothyroïdie,...) (cf. Larsen, 1985 et Lafontan, 1986). Ceci permet probablement de contre-balancer les effets de la cascade lipolytique, dont le rôle est d'assurer la mobilisation rapide et massive des triglycéride de réserve lorsque le besoin s'en fait sentir, et peut être considéré comme un " garde-fou homéostatique » des adaptations téléophorétiques.

La sauvegarde de la mère (qui permet de sauvegarder au mieux la portée et l'espèce) semble être la règle chez les espèces sauvages (cf. Léon et Woodside, 1983). La sélection et la conduite intensives des vaches laitières ou des brebis semble déboucher parfois sur une inversion de ces priorités, bien que la souplesse métabolique de ces animaux ne permette pas encore d'entrevoir les limites de leur productivité (Moe, 1981). Ceci accroît l'ampleur du cycle lipomobilisationlipogenèse, dont les mécanismes téléophorétiques (Bauman et Elliot, 1983) peuvent être considérés comme faisant globalement partie de l'homéostasie génétique telle que I'a définie Lerner (1954, cité par Blake et Custodio, 1984).

Reçu en novembre 1986.

Accepté en décembre 1986.

Remerciements. - Je tiens à remercier ici R. Jarrige, D. Sauvant et Marcelle Lavau, pour leurs conseils et encouragements au cours de la rédaction de cette revue, ainsi que Yvette Fournier, Jeanne Fléchet et $\mathrm{C}$. Chabrillat pour leur aide dans la préparation du manuscrit.

\section{Références}

ACEVES C., RUIZ J. A., ROMERo C., VALVERDE R. C., 1985. Homeorhesis during early lactation. Euthyroid sick-like syndrome in lactating cows. Acta endocr., 110, 505-509.

ADLER J. H., LOTAN E., 1967. The relationship of circulating glucose, ketones, and F.F.A. to milk production in Awassi ewes. J. agric. Sci. Camb., 69, 349-354.

ADLER J. H., WERTHEIMER E., BARTANA U., FLESH J., 1963. Free fatty acids (FFA) and the origin of ketone bodies in cows. Vet. Rec., 75, 304-307.

AGABRIEL J., BRUNEAU S., CHILLIARD Y., PETIT M., 1985. Variations de la composition corporelle de la vache allaitante au début de la lactation (Résultats préliminaires). In BRUNEAU S., Mémoire de D.E.A. Univ. Montpellier. Station des Productions Bovines et Chevalines. I.N.R.A. Theix, 63122 Ceyrat.

AIELLO R. J., KENNA T. M., HERBEIN J. H., 1984. Hepatic gluconeogenic and ketogenic interrelationships in the lactating cow. J. Dairy Sci., 67, 1707-1715.

AKASHA M. A., ANDERSON R. R., NIXON D. A., ELLERSIECK M., 1985. Concentrations of thyroid hormones (T4, T3 and $r$ T3) and prolactin in dairy cattle serum at three stages of lactation. J. Dairy. Sci, 68, supplt 1, 170 (Abstr.).

ANNISON E. Fi, 1960. Plasma non-esterified fatty acids in sheep. Aust. J. agric. Res., 11, 58-64.

ANNISON E. F., 1971. The mammary metabolism of glucose, acetate and ketone bodies, 281 . 295. In I. R. FALCONER, Lactation, Butterworths, London.

ANNISON E. F., BICKERSTAFFE R., LINZELL J. L., 1974. Glucose and fatty acid metabolism in cows producing milk of low fat content. J. agric. Sci, Camb., 82, 87-95. 
ANNISON E. F., BROWN R. E., LENG R. A., LINDSAY D. B., WEST C. E., 1967. Rates of entry and oxidation of acetate, glucose, $\mathrm{Dl}-\mathrm{B}$-hydroxybutyrate, palmitate, oleate and stearate, and rates of production and oxidation of propionate and butyrate in fed and starved sheep. Biochem. J., 104. 135-147.

ARMSTRONG D. G., PRESCOTT J. H. D., 1971. Amount, physical form and composition of feed and milk secretion in the dairy cow, 349-377. In I. R. FALCONER, "Lactation ", Butterworth, London.

ARMSTRONG D. T., STEELE R., ALTSZULER N., DUNN A., BISHOP J. S., de BODO R. C., 1961. Regulation of plasma free fatty acid turnover. Am. J. Physiol, 201, 9-15.

ARNOLD G. W., 1975. Herbage intake and grazing behaviour in ewes of four breeds at different physiological states. Aust. J. agric. Res., 26, 1017-1024.

ASKEW E. W., BENSON J. D., THOMAS J. W., EMERY R. S., 1971. Metabolism of fatty acids by mammary glands of cows fed normal, restricted roughage, or magnesium oxide supplemented rations. J. Dairy Sci., 54, 854-862.

ASSA S., LARON Z., 1977. The purification and characterization of a lipolytic factor from bovine pituitaries. Horm. Metab. Res., 9, 294-299.

ATHANASIOU V. N., PHILLIPS R. W., 1978. Effect of fasting on plasma metabolites and hormones in lactating dairy cows. Am. J. Vet. Res., 39, 957-960.

BAHAM A., 1971. Relationship between the diet of ruminants and lipid metabolism. Ph. D. thesis, Auburn University, U.S.A.

BAI S. C., McNAMARA J. P., HILLERS J. K., 1986. Hormone sensitive lipase activity of bovine adipose tissue during lactation. J. Dairy Sci, 69, supplt 1, 154. (Abstr.).

BAIRD G. D., 1977. Aspects of ruminant intermediary metabolism in relation to ketosis. Biochem. Rev., 5, 819-827.

BAIRD G. D., 1981. Lactation, pregnancy and metabolic disorder in the ruminant. Proc. Nutr. Soc., 40, 115-120.

BAIRD G. D., 1982. Primary ketosis in the high-producing dairy cow : clinical and subclinical disorders, treatment, prevention, and outlook. J. Dairy Sci, 65, 1-10.

BAIRD G. D., HEITZMAN R. J., 1970. Gluconeogenesis in the cow. The effects of a glucocorticoid on hepatic intermediary metabolism. Biochem. J., 116, 865-874.

BAIRD G. D., HIBBitT K. G., HUNTER G. D., LUND P., STUBBS M., KREBS H. A., 1968. Biochemical aspects of bovine ketosis. Biochem. J., 107, 683-689.

BAIRD G. D., LOMAX M. A., SYMONDS H. W., SHAW S. R., 1980. Net hepatic and splanchnic metabolism of lactate, pyruvate and propionate in dairy cows " in vivo" in relation to lactation and nutrient supply. Biochem. J., 186, 45-47.

BAIRD G. D., REID I. M., LOMAX M. A., SYMONDS H. W., ROBERTS C. J., MATHER D., 1977. Hepatic gluconeogenesis and fat metabolism in fed and fasted lactating dairy cows in vivo. Proc. Nutr. Soc., 36, 40A.

BAIRD G. D., SYMONDS H. W., ASH R. J., 1975. Some observations on metabolite production and utilization in vivo by the gut and liver of adult dairy cows. J. agric. Sci., Camb., 85, 281296.

BAIRD G. D., VAN DER WALT J. G., BERGMAN E. N., 1983. Whole-body metabolism of glucose, lactate and alanine in productive sheep and cows. Br. J. Nutr., 50, 249-265.

BALOWIN R. L., LIN H. J., CHENG W., CABRERA R., RONNING M., 1969. Enzyme and metabolite levels in mammary and abdominal adipose tissue of lactating dairy cows. J. Dairy Sci., 52, 183-187.

BALDWIN R. L., OSBOURNE E., REICHL J., SMITH N. E., YANG Y. T., 1972. Effect of chronic insulin administration and a high concentrate diet on cow mammary glucose oxidation and lipogenesis. Fed. Proc., 31, 675 (Abstr.).

BALDWIN R. L., REICHL J. R., LOUIS S., SMITH N. E., YANG Y. T., OSBORNE E., 1973. Effects of age, pregnancy, and lactation on rat, guinea pig, and cow adipose enzyme activities and cow adipose metabolism. J. Dairy Sci, 56, 340-349.

BALDWIN R. L., SMITH N. E., 1971. Intermediary aspects and tissue interactions of ruminant fat metabolism. J. Dairy Sci., 54, 583-595.

BALDWIN R. L., SMITH N. E., TAYLOR J., SHARP M., 1980. Manipulating metabolic parameters to improve growth rate and milk secretion. J. anim. Sci., 51, 1416-1428. 
BALLARD F. J., FILSELL O. H., JARRETT I. G., 1972. Effects of carbohydrate availability on lipogenesis in sheep. Biochem. J., 126, 193-200.

BALLARD F. J., HANSON R. W., KRONFELD D. S., RAGGI F., 1968. Metabolic changes in liver associated with spontaneous ketosis and starvation in cows. J. Nutr., 95, 160-172.

BALLARD F. J., HANSON R. W., KRONFELD D. S., 1969. Gluconeogenesis and lipogenesis in tissue from ruminant and non-ruminant animals. Fed. Proc., 28, 218-231.

BARNES M. A., KAZMER G. W., AKERS R. M., PEARSON R. E., 1985. Influence of selection for milk vield on endogenous hormones and metabolites in Holstein heifers and cows. J. anim. Sci., 60, 271-284.

BASSETT J. M., 1971. The effects of glucagon on plasma concentrations of insulin, growth hormone, glucose, and free fatty acids in sheep : comparison with the effects of catecholamines. Aust. J. biol. Sci., 24, 311-320.

BASSETT J. M., 1975. Dietary and gastro-intestinal control of hormones regulating carbohydrate metabolism in ruminants, 383-398. In I. W. McDONALD, A.C.I. WARNER, Digestion and metabolism in the ruminant. The Univ. New England Publ. Unit, Australia.

BASSETT J. M., 1978. Endocrine factors in the control of nutrient utilization : ruminants. Proc. Nutr. Soc., 37, 273-280.

BASSETT J. M., 1983a. Endocrine responses to cessation of lactation in sheep. Proc. Nutr. Soc., 42, 34A.

BASSETT J. M., 1983b. Endocrine and metabolic responses to intravenous glucose or insulin injection in sheep during pregnancy and lactation. Proc. Nutr. Soc., 42, 35A.

BASSETT J. M., MADILL D., 1974. The influence of maternal nutrition on plasma hormone and metabolite concentrations of foetal lambs. J. Endocr., 61, 465-477.

BASSETT J. M., OXBORROW T. J., SMITH I. D., THORBURN G. D., 1969. The concentration of progesterone in the peripheral plasma of the pregnant ewe. J. Endocr., 45, 449-457.

BASSETT J. M., WALLACE A. L. C., 1966. Short-term effects of ovine growth hormone on plasma glucose, free fatty acids and ketones in sheep. Metabolism, 15, 933-944.

BATH D. L., RONNING M., MEYER J. H., LOFGREEN G. P., 1965. Caloric equivalent of liveweight loss of dairy cattle. J. Dairy Sci, 48, 374-380.

BATTAGLIA F. C., MESCHIA G., 1978. Principal substrates of fetal metabolism. Physiol. Rev., 58, 499-527.

BAUMAN D. E., 1976. Intermediary metabolism of adipose tissue. Fed. Proc., 35, 2308-2313.

BAUMAN D. E., AKERS R. M., CHAPIN L. T., TUCKER H. A., CONVEY E. M., 1979. Effect of level of intake on serum concentrations of prolactin and growth hormone in lactating cows. J. Dairy Sci., 62, suppl. 1, 114 (Abstr.).

BAUMAN D. E., CURRIE W. B., 1980. Partitioning of nutrients during pregnancy and lactation : a review of mechanisms involving homeostatis and homeorhesis. J. Dairy Sci., 63, 1514-1529.

BAUMAN D. E., EISEMANN J. H., CURRIE W. B., 1982. Hormonal effects on partitioning of nutrients for tissue growth: role of growth hormone and prolactin. Fed. Proc., 41. 2538-2544.

BAUMAN D. E., ELLIOT J. M., 1983. Control of nutrient partitioning in lactating ruminants, 437-468. In MEPHAM T. B., Biochemistry of lactation, Elsevier Sci. Publ. B. V., Amsterdam.

BAUMAN D. E., EPPARD P. J., DeGEETER M. J., LANZA G. M., 1985. Responses of highproducing dairy cows to long-term treatment with pituitary somatotropin and recombinant somatotropin. J. Dairy. Sci., 68, 1352-1362.

BAUMAN D. E., EPPARD P. J., McCUTCHEON S. N., 1984. Effects of exogenous somatotropin in lactating dairy cows, 58-72. In New trends in animal nutrition and physiology, Laboratoire de Biochimie de la Nutrition, Université Catholique, Louvain-la-Neuve, Belgique.

BAUMAN D. E., INGLE D. L., MELLENBERGER R. W., DAVIS C. L., 1973. Factors affecting in vitro lipogenesis by bovine mammary tissue slices. J. Dairy Sci., 56, 1520-1525.

BAUMAN D. E., McCUTCHEON S. N., 1986. The effects of growth hormone and prolactin on metabolism. Ch. 23, 436-455. In Proc. VI int. Symp. ruminant Physiol. : Control of digestion and metabolism in ruminants. L. P. MILLIGAN, W. L. GROVUM, and A. DOBSON, ed. Reston Publ. Co., Inc., Reston, VA. (1984).

BAUMAN D. E., McCUTCHEON S. N., STEINHOUR W. D., EPPARD P. J., SECHEN S. J., 1985. Sources of variation and prospects for improvement of productive efficiency in the dairy cow: a review. J. anim. Sci., 60, 583-592.

Reproduction, Nutrition, Développement $n^{\circ} 2 \mathrm{~A}-87.4$ 
BECK N. F. G., TUCKER H. A., 1978. Mammary arterial and venous concentrations of serum insulin in lactating dairy cows. Proc. Soc. exp. Biol. Med., 159, 394-396.

BELL A. W., 1980. Lipid metabolism in liver and selected tissues and in the whole body of ruminant animals. Prog. Lipid Res., 18, 117-164.

BELYEA R. L., FROST G. R., MARTZ F. A., CLARK J. L., FORKNER L. G., 1978. Body composition of dairy cattle by potassium-40 liquid scintillation detection. J. Dairy Sci., 61, 206-211.

BENAZZOUZ H., THÉRIEZ M., 1985. Résultats préliminaires, In BENAZZOUZ H. Effets de la quantité et de la qualité des matières azotées du régime sur la production laitière et la mobilisation des réserves corporelles par la brebis allaitante en déficit énergétique. Thèse $3^{\mathbf{e}} \mathrm{cycle}$, Univ. Clermont-Fd, Labo. Prod. Ovine, I.N.R.A., Theix.

BENNINK M. R., MELLENBERGER R. W., FROBISH R. A., BAUMAN D. E., 1972. Glucose oxidation and entry rate as affected by the initiation of lactation. J. Dairy Sci. 55, 712-713 (Abstr.).

BENSON J. D., ASKEW E. W., EMERY R. S., THOMAS J. W., 1972. Metabolism of fatty acids by adipose tissue and liver of cows fed normal, restricted roughage or $\mathrm{MgO}$ supplemented rations. J. Dairy Sci, 55, 83-92.

BERGMAN E. N., 1971. Hyperketonemia-Ketogenesis and ketone body metabolism. J. Dairy Sci., 54, 936-948.

BERGMAN E. N., 1973. Glucose metabolism in ruminants as related to hypoglycemia and ketosis. Corne// Vet., 63, 341-382.

BERGMAN E. N., BROCKMAN R. P., KAUFMAN C. F., 1974. Glucose metabolism in ruminants : comparison of whole-body turnover with production by gut, liver and kidneys. Fed. Proc., 33. 1849-1854.

BERGMAN E. N., HAVEL R. J., WOLFE B. M., BOHMER T., 1971. Quantitative studies of the metabolism of chylomicron triglycerides and cholesterol by liver and extrahepatic tissues of sheep and dogs. J. clin. Invest., 50, 1831-1839.

BERGMAN E. N., HOGUE D. E., 1967. Glucose turnover and oxidation rates in lactating sheep. Am. J. Physiol., 213, 1378-1384.

BERNAL-SANTOS G., 1982. Changes in glucose and energy homeostasis with onset of lactation. M.S. Thesis, Cornell University, Ithaca, NY, USA

BICKERSTAFFE R., ANNISON E. F., LINZELL J. L., 1974. The metabolism of glucose, acetate, lipids and amino acids in lactating dairy cows. J. agric. Sci, 82, 71-85.

BINES J. A., 1976. Regulation of food intake in dairy cows in relation to milk production. Livest. Prod. Sci, 3, 115-128.

BINES J. A., HART I. C., MORANT S. V., 1980. Endocrine control of energy metabolism in the cow : the effect on milk yield and levels of some blood constituents of injecting growth hormone and growth hormone fragments. Brit. J. Nutr., 43, 179-188.

BINES J. A., HART I. C., MORANT S. V., 1983. Endocrine control of energy metabolism in the cow: diurnal variations in the concentrations of hormones and metabolites in the blood plasma of beef and dairy cows. Horm. metab. Res., 15, 330-334.

BINES J. A., MORANT S. V., 1983. The effect of body condition on metabolic changes associated with intake of food by the cow. Brit. J. Nutr., 50, 81-89.

BINES J. A., SUZUKI S., BALCH C. C., 1969. The quantitative significance of long term regulation of food intake in the cow. Br. J. Nutr., 23, 695-704.

BITMAN J., TAO H., AKERS R. M., 1984b. Triiodothyronine and thyroxine during gestation in dairy cattle selected for high and low milk production. J. Dairy Sci, 67, 2614-2619.

BITMAN J., WOOD D. L., TYRRELl H. F., BAUMAN D. E., PEEL C. J., BROWN A. C. G., REYNOLDS P. J., 1984a. Blood and milk lipid responses induced by growth hormone administration in lactating cows. J. Dairy Sci., 67, 2873-2880.

BLACKE W., CUSTODIO A. A., 1984. Feed efficiency: a composite trait of dairy cattle. J. Dairy Sci., 67, 2075-2083.

BLOM A. K., HOVE K., NEDKVITNE J. J., 1976. Plasma insulin and growth hormone concentrations in pregnant sheep. 11 : post-absorptive levels in mid- and late pregnancy. Acta endocr., 82, 553-560.

BLUM J. W., 1983. Endokrinologie und Tierproduktion. Schweiz. Arch. Tierheilk., 125, 827-850. 
BLUM J. W., FROEHLI D., KUNZ P., 1982. Effects of catecholamines on plasma free fatty acids in fed and fasted cattle. Endocrinologv, 110, 452-456.

BLUM J. W., KUNZ P., LEUENBERGER H., GAUTSCHI K., KELLER M., 1983. Thyroid hormones, blood plasma metabolites and haematological parameters in relationship to milk yield in dairy cows. Anim. Prod., 36, 93-104.

BLUM J. W., WILSON R., KRONFELD D. S., 1973. Plasma insulin concentrations in parturient cows. J. Dairy. Sci., 56, 459-461.

BOCQUIER F., 1985. Influencé de la photopériode et de la température sur les performances de la brebis en gestation et en lactation. Thèse Doct. Ing., INA Paris-Grignon, Lab. Prod. Ovine (I.N.R.A., Theix).

BOCQUIER F., THÉRIEZ M., BRELURUT A., 1984. Utilisation des réserves corporelles chez la brebis. C.R.ATP-I.N.R.A. (non publié).

BOCQUIER F., THÉRIEZ M., KANN G., DELOUIS C., 1986. Influence de la photopériode sur la partition de l'énergie nette entre la production laitière et les réserves corporelles chez la brebis traite. Reprod. Nutr. Dévelop., 26, 389-390.

BORNSTEIN J., NG F. M., HENG D., WONG K. P., 1983. Metabolic actions of pituitary growth hormone. I. Inhibition of acetyl-CoA carboxylase by human growth hormone and a carboxyl terminal part sequence acting through a second messenger. Acta endocr., 103, 479-486.

BOSC M. J., DJIANE J., DURAND P., PELLETIER J., RAVAULT J. P., 1982. Influence of season on mean plasma levels of prolactin, placental lactogen hormone and luteinizing hormone during the second half of gestation in the ewe. Reprod. Nutr. Develop., 22, 485-493.

BOST J., GUEHENNEUX A., DORLEAC E., NATARAJAN R., 1967. Variations du taux plasmatique des acides gras non estérifiés (FFA), de la glycémie et des lipides hépatiques totaux au cours de perfusions d'adrénaline et de noradrénaline chez le mouton. C. R. Soc. Biol., 161, 1588-1592.

BOURNE R. A., TUCKER H. A., CONVEY E. M., 1977. Serum growth hormone concentrations after growth hormone or thyrotropin-releasing hormone in cows. J. Dairy Sci., 60, 1629-1635.

BOWDEN D. M., 1971. Non-esterified fatty acids and ketone bodies in blood as indicators of nutritional status in ruminants (review). Can. J. anim. Sci., 51, 1-13.

BOYD R. D. H., MORRIS F. H., MESCHIA G., MAKOWSKI E. L., BATTAGLIA F. C., 1973. Growth of glucose and oxygen uptakes by fetuses of fed and starved ewes. Am. J. Physiol., 225, 897-902.

BRINGE A. N., SCHULTZ L. H., 1969. Effects of roughage type or added bentonite in maintaining fat test. J. Dairy Sci., 52, 465-471.

BROAD T. E., SEDCOLE J. R., NGAN A. S., 1983. Incorporation of giucose into lipid of perirenal and subcutaneous adipocytes of rats and sheep : influence of insulin. Aust. J. biol. Sci., 36, 147-156.

BROCKMAN R. P., 1978. Roles of glucagon and insulin in the regulation of metabolism in ruminants. A review. Can. Vet. J., 19, 55-62.

BROCKMAN R. P., 1984. Effect of glycemic changes on lipolysis in sheep in vivo. Metab. clin. Exp., 33, 329-331.

BROCKMAN R. P., LAARVELD B., 1986. Hormonal regulation of metabolism in ruminants, a review. Livest. Prod. Sci., 14, 313-334.

BROSTER W. H., 1980. Developments in feeding dairy cows. A.D.A.S. Q. Rev., 39, 234-255.

BROSTER W. H., SUTTON J. D., BINES J. A., 1979. Concentrate: forage ratios for highvielding dairy cows, 99-126. In W. HARESIGN, D. LEWIS, Recent Adv. anim. Nutr. (1978), Butterworths, London.

BRUCKENTAL I., OLDHAM J. D., SUTTON J. D., 1980. Glucose and urea kinetics in cows in early lactation. Br. J. Nutr., 44, 33-45.

BRUMBY P. E., ANDERSON M., TUCKLEY B., STORRY J. E., HIBBITT K. G., 1975. Lipid metabolism in the cow during starvation-induced ketosis. Biochem. J., 146, 609-615.

BRUMBY P. J., HANCOCK J., 1955. The galactopoietic role of growth hormone in dairy cattle. N. Z. J. Sci. Technol., A36, 417-436.

BRYANT D. T. W., SMITH R. W., 1982. The effect of lactation on protein synthesis in ovine skeletal muscle. J. agric. Sci., Camb., 99, 319-323.

BULLIS J. A., HOLTER J. B., HAYES H. H., 1985. Maternal tissue changes during first and subsequent dry periods of Holstein cows. J. Dairy. Sci., 68, supplt 1, 276. (Abstr.). 
BURLACU G., BAIA G., CHRISTIAN A., RUS V., STAVRI J., 1978. Die Verwertung des Futters und der Energiebedarf traechtiger Faersen. Arch. Tierernaehr., 28, 235-244.

BUTLER W. R., FULLENKAMP S. M., CAPPIELLO L. A., HANDWERGER S., 1981. The relationship between breed and litter size in sheep and maternal serum concentrations of placental lactogen, estradiol and progesterone. J. anim. Sci, 53, 1077-1081.

BUTLER-HOGG B. W., WOOD J. D., BINES J. A., 1985. Fat partitioning in British Friesian cows : the influence of physiological state on dissected body composition. J. agric. Sci., Camb., 104, 519-528.

CHAN J. S. D., ROBERTSON H. A., FRIESEN H. G., 1978. Distribution of binding sites for ovine placental lactogen in the sheep. Endocrinology, 102, 632-640.

CHANDLER K. D., LEURY B. J., BIRD A. R., BELL A. W., 1985. Effects of undernutrition and exercise during late pregnancy on uterine, fetal and uteroplacental metabolism in the ewe. $\mathrm{Br} . \mathrm{J}$. Nutr., 53, 625-635.

CHANDLER K. D., McHEMPHILL P. N., BIRD A. R., BELL A. W., 1983. Effects of undernutrition and exercise on uterine uptake of $\mathrm{D}(-)$ 3-hydroxybutyrate in the late-pregnant ewe. Proc. Nutr. Soc., 42, 41A.

CHARTON A., FAYE P., HERVY A., BERNARD C., GUESLIN M., 1965. Etude comparative des glycémies du plasma veineux jugulaire et du plasma veineux post-mammaire chez la brebis en lactation. Rec. Med. vét., CXLI, 1065-1077.

CHEW B. P., MURDOCK F. R., RILEY R. E., HILLERS J. K., 1984 . Influence of prepartum dietary crude protein on growth hormone, insulin, reproduction, and lactation of dairy cows. J. Dairy Sci., 67, 270-275.

CHIGARU P. N., MILLER T. B., TOPPS J. H., 1976. Mobilization of tissue reserves and milk production. Anim. Prod., 22, 158 (Abstr.).

CHIGARU P. R. N., TOPPS J. H., 1981. The composition of body-weight changes in underfed lactating beef cows. Anim. Prod., 32, 95-103.

CHILLIARD Y., 1985. Métabolisme du tissu adipeux, lipogenèse mammaire et activités lipoprotéinelipasiques chez la chèvre au cours du cycle gestation-lactation (134 pp., 1323 réf.). Th. Doct. Etat ès-Sci., Univ. Paris $6^{e}$.

CHILLIARD Y., 1986. Revue bibliographique : Variations quantitatives et métabolisme des lipides dans les tissus adipeux et le foie au cours du cycle gestation-lactation. $1^{\text {re }}$ partie : chez la ratte. Reprod. Nutr. Dévelop., 26, 1057-1103.

CHILLIARD Y., GASPERIN M., ROBELIN J., RÉMOND B., 1982. Méthodes d'estimation et variations quantitatives des réserves corporelles chez la vache au cours du cycle gestationlactation. Résultats préliminaires. In GASPERIN M., 1982, Mémoire de DEA, Université de Clermont-Fd II (Laboratoire de la lactation, I.N.R.A., Theix).

CHILLIARD Y., RÉMOND B., ROBELIN J., 1984b. Variations des réserves lipidiques chez la vache en lactation, estimées par différentes méthodes. 10 Réunion du Groupe Développement I.N.R.A., Productions Animales, Rennes, 9-10 mai 1984.

CHILLIARD Y., RÉMOND B., SAUVANT D., VERMOREL M., 1983. Particularités du métabolisme énergétique des hautes productrices de lait. Bull. tech. CRZV Theix, I.N.R.A., 53, 37-64.

CHILLIARD Y., ROBELIN J., 1983. Protein mobilization in early lactating cows measured by slaughter and D20 dilution techniques. Int. Symp. Protein metabuïsm and nutrition. ClermontFerrand. France. EAAP-Publ. $n^{\circ} 31$, vol. II, 195-198.

CHILLIARD Y., ROBELIN J., 1985. Activité lipoprotéine-lipasique de différents dépôts adipeux et ses relations avec la taille des adipocytes chez la vache tarie en cours d'engraissement, ou en début de lactation. Reprod. Nutr. Dévelop., 25, 287-294.

CHILLIARD Y., ROBELIN J., REMOND B., 1984a. In vivo estimation of body lipid mobilization and reconstitution in dairy cattle. Can. J. anim. Sci., 64 (suppl.), 236-237.

CHILLIARD Y., SAUVANT D., MORAND-FEHR P., DELOUIS C., 1987. Relations entre le bilan énergétique et l'activité métabolique du tissu adipeux de la chèvre au cours de la première moitié de la lactation. Reprod. Nutr. Dévelop., 27, 307-308.

CHRISTIE W. W., NOBLE R. C., 1982. Fatty acid biosynthesis in sheep placenta and maternal and fetal adipose tissue. Biol. Neonate, 42, 79-86.

COGGINS C. R. E., FIELD A. C., 1978. Changes in plasma concentrations of glucose, free fatty acids, ketone bodies, thyroxine and insulin of lactating beef cows in relation to time of fee- 
ding and energy status, 41-48. In The use of blood metabolites in animal production, Br. Soc. anim. Prod., Occasional Publ. no 1.

COLLIER R. J., McNAMARA J. P., WALLACE C. R., DEHOFF M. H., 1984. A review of endocrine regulation of metabolism during lactation. J. anim. Sci., 59, 498-510.

COMLINE R. S., SILVER M., 1972. The composition of foetal and maternal blood during parturition in the ewe. J. Physiol., 222, 233-256.

CONVEY E.M., 1974. Serum hormone concentrations in ruminants during mammary growth, lactogenesis, and lactation. J. Dairy Sci., 57, 905-917.

CORBETT J. L., FURNIVAL E. P., PICKERING F. S., 1982. Energy expenditure at pasture of shorn and unshorn Border Leicester ewes during late pregnancy and lactation, 34-37. In A. EKERN, F. SUNDSTOL, Energy metabolism of farm animals, EAAP. Publ. $\mathrm{n}^{\circ} 29$.

COSTA N. D., McINTOSH G. H., SNOSWELL A. M., 1976. Production of endogenous acetate by the liver in lactating ewes. Aust. J. biol. Sci., 29, 33-42.

COULON J. B., DOREAU M., RÉMOND B., JOURNET M., 1984. Capacité d'ingestion des vaches laitières en début de lactation. I. Evolution, liaison avec certains paramètres zootechniques et conséquences sur la production laitière. 2. Les anomalies de l'ingestion : liaisons avec l'état sanitaire et quelques paramètres du métabolisme énergétique et de la digestion. Bull. tech. C.R.Z.V. Theix, I.N.R.A., 55, 33-51.

COULON J. B., RÉMOND B., DOREAU M., JOURNET M., 1985 . Evolution de différents paramètres sanguins du métabolisme énergétique chez la vache laitière au début de la lactation. Ann. Rech. vét., 16, 185-193.

COWAN R. T., ROBINSON J. J., GREENHALGH J. F. D., Mc HATTIE I., 1979. Body composition changes in lactating ewes estimated by serial slaughter and deuterium dilution. Anim. Prod., 29, 81-90.

COWAN R. T., ROBINSON J. J., MCDONALD I., 1982. A note on the effects of body fatness and level of food intake on the rate of fat loss in lactating ewes. Anim. Prod., 34, 355-357.

COWAN R. T., ROBINSON J. J., MCDONALD I., SMART R., 1980. Effects of body fatness at lambing and diet in lactation on body tissue loss, feed intake and milk yield of ewes in early lactation. J. agric. Sci., Camb., 95, 497-514.

COWAN R. T., ROBINSON J. J., McHATTIE I., PENNIE K., 1981. Effects of protein concentration in the diet on milk yield, change in body composition and the efficiency of utilization of body tissue for milk production in ewes. Anim. Prod., 33, 111-120.

COWIE A. T., FORSYTH I. A., HART I. C., 1980. Hormonal control of lactation. SpringerVerlag, Berlin, Heidelberg, New York.

CRISTIAN A., MENESES E. E., BURLACU G., STAVRI J., 1980. Efficiency of utilization of corn-silage diets by pregnant and lactating sheep, 363-365. In L. E. MOUNT, Energy metabolism, EAAP Publ. $\mathrm{n}^{\circ} 26$.

CURTIS-PRIOR P. B., TRETHEWEY J., STEWART G. W., HANLEY T., 1969. The contribution of different organs and tissues of the rat to assimilation of glucose. Diabetologia, 5, 384-391.

DALE H., VIK-MO L., FJELLHEIM P., 1979. A field survey of fat mobilization and liver function of dairy cow during early lactation. Relationship to energy-balance, appetite and ketosis. Nord. Vet. Med., 31, 95-107.

DAVENPORT D. G., RAKES A. H., 1969. Effects of prepartum feeding level and body condition on the post-partum performance of dairy cows. J. Dairy Sci., 52, 1037-1043.

DAVEY A. W., GRAINGER C., MCKENZIE D. D., FLUX D. S., WILSON G. F., BROOKES I. M., HOLMES C. W., 1983. Nutritional and physiological studies of differences between Friesian cows of high and low genetic merit. Proc. N. Z. Soc. anim. Prod., 43, 67-70.

DAVIS C. L., BROWN R. E., 1970. Low-fat milk syndrome, 545-565. In A. T. PHILLIPSON. Physiology of digestion and metabolism in the ruminant, Oriel Press Ltd.

DAVIS P. J., JOHNSTON R. G., ROSS D. B., 1971. The influence of energy intake on plasma levels of glucose, non-esterified fatty acids and acetone in the pregnant ewe. J. agric. Sci. Camb., 77, 261-265.

DAVIS S. R., BICKERSTAFFE R., 1978. Mammary glucose uptake in the lactating ewe and the use of methionine arteriovenous difference for the calculation of mammary blood flow. Aust. J. biol. Sci., 31, 133-139. 
DE BOER G., TRENKLE A., YOUNG J. W., 1985. Glucagon, insulin, growth hormone and some blood metabolites during energy restriction ketonemia of lactating cows. J. Dairy Sci,, 68 , 326-337.

DE BOER G., TRENKLE A., YOUNG J. W., 1986. Secretion and clearance rates of glucagon in dairy cows. J. Dairy Sci., 69, 721-733.

DECAEN C., ADDA J., 1970. Evolution de la sécrétion des acides gras des matières grasses du lait au cours de la lactation de la vache. Ann. Biol. anim. Bioch. Biophys., 10, 659-677.

DECAEN C., JOURNET M., 1967. Evolution, au début de la lactation, de la sécrétion des principaux acides gras du lait et de la concentration en acides gras libres du sang chez la vache. Ann. Biol. anim. Biochim. Biophys., 7, 131-143.

DEGEN A. A., YOUNG B. A., 1980. Liveweight, total body-water and maternal body-solid changes in pregnant and lactating beef cows. J. agric. Sci, Camb., 95. 1-5.

DEMIGNÉ C., RÉMÉSY C., TISSIER M., 1976. La fin de gestation de la brebis. Problèmes nutritionnels, métaboliques et pathologiques. Bull. Techn. C.R.Z.V. Theix, I.N.R.A., 24, 47 53.

DJIANE J., KANN G., 1975. Mise en évidence de l'activité lactogène et mesure dans le sérum de l'activité prolactinique du placenta chez la brebis au cours de la gestation. C. R. Acad. Sci., Paris, sér. D, 280, 2785-2788.

DOREAU M., 1983. Influence de la prise alimentaire sur les variations de différents constituants plasmatiques chez la vache en fin de gestation et en début de lactation. Ann. Rech. vét., 14, 39-48.

DOREAU M., REMOND B., 1982. Comportement alimentaire et utilisation digestive d'une ration de composition constante chez la vache laitière en fin de gestation et début de lactation. Reprod. Nutr. Dévelop., 22, 307-324.

DRYERRE H., ROBERTSON A., 1941. The effect of pregnancy on tissue lipids in the ewe. $J$. Physiol., 99, 443-453.

DUEEE P. H., GIRARD J., 1983. Le métabolisme protéique pendant la gestation et la lactation. Ne Symp. int. Métabolisme et nutrition azotés, Clermont-Ferrand (France), Ed. I.N.R.A. Publ., Vol. 1, 137-158 (EAAP Publ. $n^{\circ} 31$ ).

DUQUETTE P. F., SCANES C. G., MUIR L. A., 1984. Effects of ovine growth hormone and other anterior pituitary hormones on lipolysis of rat and ovine adipose tissue in vitro. J. anim. Sci., 58, 1191-1197.

EASDON M. P., CHESWORTH J. M., ABOUL-ELA M. B. E., HENDERSON G. D., 1985. The effect of undernutrition of beef cows on blood hormone and metabolite concentrations post partum. Reprod. Nutr. Dévelop., 25, 113-126.

EAYRES S. M., LOMAX M. A., BRYANT M. J., 1985. Body tissue mobilization in the underfed pregnant ewe. Proc. Nutr. Soc., 44, 62A.

ECKLES C. H., 1912. Cité par LENKEIT, 1972.

EISEMANN J. H., BAUMAN D. E., HAMMOND A. C., REYNOLDS P. J., TYRRELL H. F., HAALAND G. L., 1984b. The influence of growth hormone administration on the kinetics of plasma nonesterified fatty acids in growing hereford heifers. Can. J. anim. Sci., 64 (suppl.), 308-309.

EISEMANN J. H., BAUMAN D. E., HOGUE D. E., TRAVIS H. F., 1984a. Influence of photoperiod and prolactin on body composition and in vitro lipid metabolism in wether lambs. J. anim. Sci., 59, 95-104.

ELLIOT J. M., 1980. Propionate metabolism and vitamin B12, 485-503. In Y. RUCKEBUSCH, P. THIVEND, Digestive physiology and metabolism in ruminants, MTP Press Ltd.

ELLIOT J. M., BARTON E. P., WILLIAMS J. A., 1979. Milk fat as related to vitamin B12 status. J. Dairy Sci., 62, 642-645.

EMERY R. S., 1973. Biosynthesis of milk fat. J. Dairy Sci., 56, 1187-1195.

EMMANUEL B., KENNELLY J. J., 1984a. Effect of propionic acid on ketogenesis in lactating sheep fed restricted rations or deprived of food. J. Dairy Sci. 67, 344-350.

EMMANUEL B., KENNELLY J. J., 1984b. Effect of propionic acid on kinetics of acetate and oleate and on plasma and milk fatty acid composition of goats. J. Dairy Sci, 67, 1199-1208.

EPPARD P. J., BAUMAN D. E., BITMAN J., WOOD D. L., AKERS R. M., HOUSE W. A., $1985 b$. Effect of dose of bovine growth hormone on milk composition : alpha-lactalbumin, fatty acids, and mineral elements. J. Dairy Sci., 68, 3047-3054. 
EPPARD P. J., BAUMAN D. E., McCUTCHEON S. N., 1985a. Effect of dose of bovine growth hormone on lactation of dairy cows. J. Dairy Sci., 68, 1109-1115.

ERFLE J. D., SAUER F. D., FISHER L. J., 1974. Interrelationships between milk carnitine and blood and milk components and tissue carnitine in normal and ketotic cows. J. Dairy Sci, 57, 671-676.

ETHERTON T. D., BAUMAN D. E., ROMAN J. R., 1977. Lipolysis in subcutaneous and perirenal adipose tissue from sheep and dairy steers. I. anim. Sci., 44, 1100-1106.

ETHERTON T. D., EVOVK C. M., 1986. Stimulation of lipogenesis in bovine adipose tissue by insulin and insulin-like growth factor. J. anim. Sci, 62, 357-362.

FARRIES E., 1975. Untersuchungen zum Fuetterungsniveau fuer trockentehende Kuehe. Der Tierzuechter, 27, 476-480.

FARRIES E., 1982. Milchfettgehalt und Fettsaurenmuster bei Kuhen in Abhangigkeit von der Gewichtsentwicklung post partum. Zuchtungskunde, 54, 25-33.

FAVERDIN P., 1986. Injections de doses physiologiques d'insuline chez la vache en lactation: effets sur les quantités ingérées et les métabolites sanguins. Reprod. Nutr. Dévelop., 26, 383384.

FEKRY A. E., KEYS J. E., CAPUCO A. V., BITMAN J., WOOD D. L., MILLER R. H., 1986. Influence of bovine growth hormone on secretion of triglycerides and free fatty acids by mammary, liver and/or adipose tissues explants. J. Dairy Sci., 69, supplt 1, 165 (Abstr.).

FERRELL C. L., GARRETT W. N., HINMAN N., 1976a. Estimation of body composition in pregnant and non-pregnant heifers. J. anim. Sci, 42, 1158-1166.

FERRELL C. L., GARRETT W. N., HINMAN N., 1976c. Growth, development and composition of the udder and gravid uterus of beef heifers during pregnancy. J. anim. Sci, 42, 1477-1489.

FERRELL C. L., GARRETT W. N., HINMAN N., GRICHTING G., 1976b. Energy utilization by pregnant and non-pregnant heifers. J. anim. Sci., 42, 937-950.

FERRERI L. F., ELBEIN R. C., 1982. Fractionation of plasma triglyceride-rich lipoproteins of the dairy cow : evidence of chylomicron-size particles. J. Dairy Sci., 65, 1912-1920.

FIELD A. C., SUTTLE N. F., GUNN R. G., 1968. Seasonal changes in the composition and mineral content of the body of hill ewes. J. agric. Sci., Camb., 71, 303-310.

FISHER L. J., DONNELLY P. E., HUTTON J. B., DUGANZICH D. M., 1975 . Relationships between levels of feeding and certain blood metabolites in dairy cows in mid lactation. $J$. agric. Sci., Camb., 84, 29-37.

FLATLANDSMO K., 1971. Free glycerol in the plasma of cows. Acta vet. scand., 12, 489-495.

FLATT W. P., COPPOCK C. E., MOORE L. A., 1965b. Energy balance studies with lactating, non-pregnant dairy cows consuming rations with varying hay to grain ratios, 121-130. In K. L. BLAXTER, Energy metabolism, EAAP. Publ. $n^{\circ} 11$, Acad. Press, London.

FLATT W. P., MOE P. W., MOORE L. A., 1969a. Influence of pregnancy and ration composition on energy utilization by dairy cows, 123-136. In BLAXTER K. L., KIELANOWSKI J., THORBEK G., Energy metabolism of farm animals, Oriel Press, Newcastle.

FLATT W. P., MOE P. W., MOORE L. A., HOOVEN N. W., LEHMANN R. P., ORSKOV E. R., HEMKEN R. W., 1969b. Energy utilization by high producing dairy cows, 221-251. In BLAXTER K. L., KIELANOWSKI J., THORBEK G., Energy metabolism of farm animals, Oriel Press, Newcastle.

FLATT W. P., MOORE L. A., HOOVEN N. W., PLOWMAN R. D., 1965a. Energy metabolism studies with a high producing lactating dairy cow. J. Dairy Sci., 48, 797-798.

FLEET 1. R., FULLERTON F. M., MEPHAM T. B., 1986. Effects of exogenous growth hormone on mammary function in lactating Jersey cows. J. Physiol., 376, 19 p. (Abstr.).

FOOT A. S., LINE C., ROWLAND J., 1963. The effect of prepartum feeding of heifers on milk composition. J. Dairy Res., 30, 403-409.

FOOT J. Z., 1969. Body water in ovine pregnancy. J. Reprod. Fert., Suppl. 9, 9-16.

FOOT J. Z., RUSSEL A. J. F., 1979. The relationship in ewes between voluntary food intake during pregnancy and forage intake during lactation and after weaning. Anim. Prod.,28, 2539.

FOOT J. Z., SKEDD E., MCFARLANE D. N., 1979. Body composition in lactating sheep and its indirect measurement in the live animal using tritiated water. J. agric. Sci., Camb., 92, 69-81.

FORBES J. M., 1969. A note on the voluntary feed intake of lactating ewes, their milk yield and the growth rate of their lambs. Anim. Prod., 11, 263-266. 
FORBES J. M., 1970a. The voluntary food intake of pregnant and lactating ruminants : a review. Brit. Vet. J., 126, 1-11.

FORBES J. M., 1970b. Voluntary food intake of pregnant ewes. J. anim. Sci., 31, 1222-1227.

FORBES J. M., 1971. Physiological changes affecting voluntary food intake in ruminants. Proc. Nutr. Soc., 30, 135-142.

FORBES J. M., 1974. Feeding in sheep modified by intraventricular estradiol and progesterone. Physiol. Behav., 12, 741-747

FORBES J. M., 1977. Interrelationships between physical and metabolic control of voluntary food intake in fattening, pregnant and lactating mature sheep : a model. Anim. Prod., 24, 91-101.

FORBES J. M., REES J. K. S., BOAZ T. G., 1967. Silage as a feed for pregnant ewes. Anim. Prod., 9. 399-408

FORD E. J. H., 1959. Metabolic changes in cattle near the time of parturition. I. hepatic fat and alkaline phosphatase activity of liver homogenates. J. comp. Path., 69, 20-28.

FORD E. J. H., BOYD J. W., 1960. Some observations on bovine acetonemia. Res. vet. Sci., 1, 232-239.

FRIGERI L. G., 1980. Absence of in vitro dexamethasone-dependent lipolytic activity from highly purified growth hormone. Endocrinology, 107, 738-743.

FRIGERI L. G., ROBEL G., STEBBING N., 1982. Bacteria-derived human growth hormone lacks lipolytic activity in rat adipose tissue. Biochem. biophys. Res. Commun., 104, 1041-1046.

FRITZ I. B., 1961. Factors influencing the rates of long-chain fatty acid oxidation and synthesis in mammalian systems. Physiol. Rev., 41, 52-129.

FROHLI D., BLUM J. W., 1985. Fat mobilisation and catecholamines in lactating dairy cows : effects of energy intake and insulin status. 13th int. Congr. Nutrition (Brighton, UK), Abstr., p. 23.

FRONK T. J., SCHULTZ L. H., HARDIE A. R., 1980. Effect of dry period overconditionning on subsequent metabolic disorders and performance of dairy cows. J. Dairy Sci., 63, 1080-1090.

GALBRAITH H., TOPPS J. H., 1981. Effect of hormones on the growth and body composition of animals. Nutr. Abstr. Rev. Ser. B., 51, 521-540.

GARDNER R. W., 1969. Interactions of energy levels offered to Holstein cows prepartum and postpartum. 1. Production responses and blood composition changes. J. Dairy Sci., 52 , 1973-1984.

GARNSWORTHY P. C., TOPPS J. H., 1982a. The effect of body composition of dairy cows at calving on their food intake and performance when given complete diets. Anim. Prod., 35 , 113-119.

GARNSWORTHY P. C., TOPPS J. H., 1982b. The effect of body condition at calving, food intake and performance on blood composition of dairy cows given complete diets. Anim. Prod. 35 , 121-125.

GARWACKI S., WIECHETEK M., BAREJ W., 1984. The influence of insulin on the appetite and metabolism of energy compounds in sheep fed ad libitum and fasted. Pr. Mater. Zootech., 30. 89-97.

GEENTY K. G., SYKES A. R., 1986. Effect of herbage allowance during pregnancy and lactation on feed intake, milk production, body composition and energy utilization of ewes at pasture. J. agric. Sci, Camb., 106, 351-367.

GERLOFF B. J., HERDT T. H., WELLS W. W., LIESMAN J. S., EMERY R. S., 1986a. Inositol and hepatic lipidosis. I. Effect of inositol supplementation and time from parturition on liver and serum lipids in dairy cattle. J. anim. Sci., 62, 1682-1692.

GERLOFF B. J., HERDT T. H., WELLS W. W., NACHREINER R. F., EMERY R. S., 1986b. Inositol and hepatic lipidosis. II. Effect of inositol supplementation and time from parturition on serum insulin, thyroxine and triiodothyronine and their relationship to serum and liver lipids in dairy cows. J. anim. Sci., 62, 1693-1702.

GERSON T., WILSON G. F., SINGH H., SHORLAND F. B., 1966. Origin of the glyceride fatty acids of milk fat. J. Dairy Sci., 49, 680-681.

GERTLER A., COHEN N., MAOZ A., 1983. Human growth hormone but not ovine or bovine growth hormones exhibits galactopoietic prolactin-like activity in organ culture from bovine lactating mammary gland. Mol. cell. Endocrinol., 33, 169-182

GIESECKE D., 1984. Stoffwechselstoerungen nach dem Kalben. Tierzuechter, 36, 300-301.

GILL R. D., HART I. C., 1980. Properties of insulin and glucagon receptors on sheep hepatocytes : 
a comparison of hormone binding and plasma hormones and metabolites in lactating and non-lactating ewes. J. Endocr., 84, 237-247.

GILL R. D., HART I. C., 1982. Hepatic receptors for insulin and glucagon in relation to plasma hormones and metabolites in pregnant unmated ewes. J. Endocr., 93, 221-238.

GIRARD J., PINTADO E., FERRE P., 1979. Fuel metabolism in the mammalian fetus. Ann. Biol. anim. Bioch. Biophys., 19, 181-197.

GLASCOCK R. F., SMITH R. W., WALSH A., 1983. Partition of circulating triglycerides between formation of milk fat and other metabolic pathways in sheep. J. agric. Sci. Camb., 101, 33 . 38.

GOODMAN H. M., GRICHTING G., 1983. Growth hormone and lipolysis : a reevaluation. Endocrino$\log y, 113,1697-1702$.

GOODMAN H. M., SCHWARTZ J., 1974. Growth hormone and lipid metabolism. Handbook of Physiology, Endocrinologv, vol. IV (2), p. 211-231. Am. Physiol. Soc. (Washington, DC).

GOW C. B., McDOWELL G. H., ANNISON E. F., 1981. Control of gluconeogenesis in the lactating sheep. Aust. J. biol. Sci., 34, 469-478.

GRAHAM N. McC., 1964. Energy exchanges of pregnant and lactating ewes. Aust. J. agric. Res., 15, 127-141.

GRAINGER C., HOLMES C. W., MOORE Y. F., 1985. Performance of Friesian cows with high and low breeding indexes. 2. Energy and nitrogen balance experiments with lactating and pregnant, non-lactating cows. Anim. Prod., 40, 389-400.

GRICHTING G., BALDWIN R. L., SMITH N. E., 1977a. Effect of stage of lactation and fasting on cellularity and lipogenesis in cow adipose tissue. J. Dairy Sci, 60 (Suppl. 1), 120 (Abstract).

GRICHTING G., SMITH N. E., BALDWIN R. L., 1977b. Effect of nutritional and physiological state on ruminant adipose tissue metabolism. Fed. Proc., 36, 1141 (Abstract).

GRIGSBY J. S., OXENDER W. D., HAFS H. D., BRITT D. G., MERKEL R. A., 1974. Serum insulin, glucose, and free fatty acids in the cow and fetus during gestation. Proc. Soc. exp. Biol. Med., 147, 830-834.

GRIZARD J., TISSIER M., CHAMPREDON C., PRUGNAUD J., PION R., 1979a. Variations des teneurs sanguines en acides aminés libres, urée et glucose chez la brebis en fin de gestation et début de lactation. Influence de l'état nutritionnel en fin de gestation. Ann. Biol. anim. Bioch. Biophys., 19, 55-71.

GRIZARD J., TISSIER M., PRUGNAUD J., PION R., 1977. Influence d'une restriction énergétique pendant la fin de la gestation sur l'insulinémie, la glycémie, l'urémie et l'aminoacidémie des brebis gestantes et allaitantes. C. R. Soc. Biol., 171, 1245-1253.

GRIZARD J., TISSIER M., THERIEZ M., PION R., 1979b. Variations de l'insulinémie chez la brebis en fin de gestation et début de lactation. Influence de l'état nutritionnel en fin de gestation. Ann. Biol. anim. Bioch. Biophys., 19, 73-78.

GROEHN Y., LINDBERG L. A., BRUSS M. L., FARVER T. B., 1983. Fatty infiltration of liver in spontaneously ketotic dairy cows. J. Dairy Sci., 66, 2320-2328.

GRUMMER R. R., DAVIS C. L., 1984. Plasma concentration and lipid composition of lipoproteins in lactating dairy cows fed control and high grain diets. J. Dairy Sci., 67, 2894-2901.

GUADA J. A., ROBINSON J. J., FRASER C., 1976. The effect of a reduction in food intake during late pregnancy on nitrogen metabolism in ewes. J. agric. Sci. Camb., 86, 111-116.

GUESNET P., 1984. Contribution à l'étude de la régulation du métabolisme lipidique au niveau du tissu adipeux de brebis au cours de la gestation et de la lactation. Thèse Doc. 3e Cycle Université Paris $X$.

GUESNET P.. MASSOUD M., DEMARNE Y., 1986a. Evolution des activités lipogénique et lipolytique du tissu adipeux épiploïque de Brebis pendant la gestation et la lactation. Cah. Nutr. Diét., 21, 52 (Abstr.).

GUESNET P., MASSOUD M., DEMARNE Y., 1986b. Contrôle hormonal du métabolisme lipidique du tissu adipeux de Brebis. Rôle joué par l'insuline pendant la gestation et la lactation. Cah. Nutr. Diét., 21, 52 (Abstr.).

HADJIPIERIS G., HOLMES W., 1966. Studies on feed intake and feed utilization by sheep. 1. The voluntary feed intake of dry, pregnant, and lactating ewes. J. agric. Sci., 66, 217-223.

HADJIPIERIS G., JONES J. G. W., WIMBLE R. H., HOLMES W., 1966. Studies on feed intake and feed utilization by sheep. II. The utilization of feed by ewes. J. agric. Sci., 66, 341-349.

HAGEMEISTER H., 1972a, Untersuchungen ueber den Einfluss der Energieversorgung der Milchkuehe 
auf die Enzymaktivitaet von Glucose-6-Phosphat-Dehydrogenase (G6PD) und Iso-CitratDehydrogenase (ICD) im Unterhautfettgewebe. Z. Tierphysiol. Tierernaehrg. Futtermittelkde, 30, 158-164.

HAGEMEISTER H., 1972b. Untersuchungen ueber den EinfluB der Rationsgestaltung und der Energieversorgung auf die Aktivitaet der Enzyme G-6-PD und ICD im Unterhautfettgewebe von Milchkuehen. Z. Tierphysiol. Tierernaehrg. Futtermittelkde, 30, 129-130.

HALSE K., STANDAL N., SYRSTAD O., 1983. Fatty acid composition of milk fat related to the concentrations of acetoacetate and glucose in blood plasma of cows. Acta agric. scand., 33. 361-368.

HANDWERGER S., FELLOWS R. E., CRENSHAW M. C., HURLEY T., BARRETT J., MAURER W. F., 1976. Ovine placental lactogen : acute effects on intermediary metabolism in pregnant and non-pregnant sheep. J. Endocr., 69, 133-137.

HANSON R. W., BALLARD F. J., 1967. The relative significance of acetate and glucose as precursors for lipid syntesis in liver and adipose tissue from ruminants. Biochem. J., 105, 529536.

HANSON R. W., BALLARD F. J., 1968. The metabolic fate of the products of citrate cleavage. ATP citrate lyase and NADP malate dehydrogenase in foetal and adult liver from ruminants and non-ruminants. Biochem. J., 108, 705-713.

HARRISON F. A., LEAT W. M. F., FORSTER A., 1974. Absorption of maize oil infused into the duodenum of the sheep. Proc. Nutr. Soc., 33, $101 \mathrm{~A}$.

HART I. C., 1983. Endocrine control of nutrient partition in lactating ruminants. Proc. Nutr. Soc., 42, 181-194

HART I. C., BINES J. A., MORANT S. V., 1979. Endocrine control of energy metabolism in the cow : correlations of hormones and metabolites in high and low yielding cows for stages of lactation. J. Dairy Sci., 62, 270-277.

HART I. C., BINES J. A., MORANT S. V., 1980. The secretion and metabolic clearance rates of growth hormone, insulin and prolactin in high- and low-yielding cattle at four stages of lactation. Life Sci., 27, 1839-1848.

HART I. C., BINES J. A., MORANT S. V., RIDLEY J. L., 1978. Endocrine control of energy metabolism in the cow : comparison of levels of hormones (prolactin, growth hormone, insulin and thyroxine) and metabolites in the plasma of high-and low-yielding cattle at various stages of lactation. J. Endocr., 77, 333-345.

HART I. C., CHADWICK M. E., SIMMONDS A. D., PAYNE G. A., CLEVELAND A., $1984 a$. Heterogeneity of bovine growth hormone. Nat. Inst. Res. Dairying, Rep. 1983, 99-100 (Abstr.).

HART I. C., CHADWICK M. E., SIMMONDS A. D., PAYNE G. A., CLEVELAND M. A., 1984b. Recombinant bovine growth hormone. Nat. Inst. Res. Dairying, Rep. 1983, 100-101 (Abstr.).

HART I. C., CHADWICK P. M. E., JAMES S., SIMMONDS A. D., 1985. Effect of intravenous bovine growth hormone or human pancreatic growth hormone-releasing factor on milk production and plasma hormones and metabolites in sheep. J. Endocr., 105, 189-196.

HASHIZUME T., MORIMOTO H., MASUBUCHI T., ABE M., HAMADA T., 1965. Some aspects of energy utilisation by cows during gestation and lactation. In K. L. BLAXTER Energy metabolism, 111-120, EAAP Publ. $\mathrm{n}^{\circ} 11$.

HAY W. W. Jr., SPARKS J. W., WILKENING R. B., BATTAGLIA F. C., MESCHIA G., 1983. Partition of maternal glucose production between conceptus and maternal tissues in sheep. Am. J. Physiol., 245, E347-E350.

HEANEY D. P., LODGE G. A., 1975. Body composition and energy metabolism during late pregnancy in the ad libitum fed ewe. Can. J. anim. Sci., 55, 545-555.

HEAP R. B., JENKIN G., 1978. Hormones of reproduction in farm animals, 13-30. In The use of blood metabolites in animal production, Br. Soc. Anim. Prod., occasional Publ. $\mathrm{n}^{\circ} 1$.

HENRICSON B., JONSSON G., PEHRSON B., 1977. "Lipid pattern », glucose concentration, and ketone body level in the blood of cattle. Zbl. Vet. Med. A, 24, 89-102.

HENSELER G., JENTSCH W., SCHIEMANN R., WITTENBURG H., 1973. Die Verwertung der Futterenergie fuer die Milchproduktion. 6. Mitteilung. Der Energieumsatz von Hochleistungsknehen in der Endphase der Traechtigkeit. Arch. Tierernaehr., 23, 353-384.

HERBEIN J. H., AIELLO R. J., ECKLER L. I., PEARSON R. E., AKERS R. M., 1985. Glucagon, insulin, growth hormone, and glucose concentrations in blood plasma of lactating dairy cows. J. Dairy Sci, 68, 320-325. 
HERDT T. H., LIESMAN J. S., GERLOFF B. J., EMERY R. S., 1983. Reduction of serum triacylglycerol-rich lipoprotein concentrations in cows with hepatic lipidosis. Am. J. vet. Res., 44, 293296.

HERRIMAN I. D., HEITZMAN R. J., 1978. The effects of fasting on the concentrations of intermediate metabolites in the blood and hepatic tissues of pregnant and non-pregnant ewes. $J$. agric. Sci., Camb., 90, 579-585.

HERRIMAN I. D., HEITZMAN R. J., PRIESTLEY I., SANDHU G. S., 1976. Concentrations of intermediate metabolites in the blood and hepatic tissues of pregnant and non-pregnant ewes. J. agric. Sci., Cámb., 87, 407-411.

HERTELENDY F., KIPNIS D. M., 1973. Studies on growth hormone secretion. Influence of plasma FFA levels. Endocrinology, 92, 402-406.

HOLMES J. H. G., LAMBOURNE L. J., 1970. The relation between plasma free fatty acid concentration and the digestible energy intake of cattle. Res. vet. Sci., 11, 27-36.

HOMB T., MATRE T., OPSTVEDT J., LYSO A., BREIREM K., 1965. Underforing av feite kyr de siste maneder for slakting (Underfeeding of fat dairy cows the last months before slaughtering). Tech. Bull., 127, Inst. Anim. Nutr., Agric. College of Norway, 44 pp.

HOOD R. L., THOMPSON E. H., ALLEN C. E., 1972. The role of acetate, propionate and glucose as substrates for lipogenesis in bovine tissues. Int. J. Biochem., 3, 598-606.

HORST R. L., THORNTON J. H., JORGENSEN N. A., SCHULTZ L. H., 1976. Calcium redistribution into subcutaneous fat at parturition in the dairy cow. J. Dairy Sci., 59, 88-90.

HOVE K., 1974. Nocturnal plasma insulin levels in cows with varying levels of plasma ketone bodiesrelations to plasma sugar and acetoacetate. Acta endocr., 76, 513-524.

HOVE K., 1978a. Insulin secretion in lactating cows : response to glucose infused intravenously in normal, ketonemic, and starved animals. J. Dairy Sci., 61, 1407-1413.

HOVE K., 1978b. Maintenance of lactose secretion during acute insulin deficiency in lactating goats. Acta physiol. scand. 103, 173-179.

HOVE K., BLOM A. K., 1973. Plasma insulin and growth hormone in dairy cows : diurnal variations and relation to food intake and plasma sugar and acetoacetate levels. Acta endocrinol., 73. 289-303.

HOVE K., BLOM A. K., 1976. Plasma insulin and growth hormone concentrations in pregnant sheep. 1 : Diurnal variations in mid- and late pregnancy. Acta endocrinol., 82, 544-552.

HOVE K., HALSE K., 1978. Absence of feeding-induced variations in plasma insulin in hypoglycaemic-ketonaemic cows. Acta vet. scand., 19, 215-228.

I.N.R.A., 1978. Alimentation des ruminants (R. JARRIGE et al.). INRA Publ., Route de Saint-Cyr, 78000 Versailles, France.

ILIOU J. P., 1985. Contribution à l'étude des mécanismes de régulation de la lipolyse du tissu adipeux au cours de la gestation et de la lactation. Thèse Doct. $3^{e}$ cycle, Univ. Paris VII-ENSIA.

ILIOU J. P., DEMARNE Y., 1986. Sensibilité de l'adipocyte de Brebis gestante et lactante à l'action de quelques effecteurs lipolytiques. Cah. Nutr. Diet., 21, 53 (Abstr.).

INGLE D. L., BAUMAN D. E., GARRIGUS U. S., 1972a. Lipogenesis in the ruminant : in vitro study of tissue sites, carbon source and reducing equivalent generation for fatty acid synthesis. J. Nutr., 102, 609-616.

INGLE D. L., BAUMAN D. E., GARRIGUS U. S., 1972b. Lipogenesis in the ruminant: in vivo site of fatty acid synthesis in sheep. J. Nutr., 102, 617-624.

IWASAKI K., HARYU T., KAMEOKA K., 1980. Energy utilization by japanese black cattle in late pregnancy. In L. E. MOUNT, Energy metabolism, Butterworths, London. EAAP Publ. $n^{\circ} 26$, 307-309.

JACKSON H. D., BLACK A. L., MOLLER F., 1968. Turnover of plasma palmitate in fed and fasted lactating cows. J. Dairy Sci, 51, 1625-1632.

JARRETT I. G., FILSELL O. H., BALLARD F. J., 1972. Metabolic and endocrine interrelationship in normal and diabetic sheep. Horm. Metab. Res., Suppl. Ser. 4, 111-116.

JARRIGE R., 1978. Consommation d'aliments et d'eau. In Alimentation des Ruminants, p. 177-206, (INRA Publ., 78000 Versailles).

JASTER E. H., WEGNER R. N., 1981. Beta-adrenergic receptor involvement in lipolysis of dairy cattle subcutaneous adipose tissue during dry and lactating states. J. Dairy Sci., 64, 16551663. 
JENNY B. F., 1974. Interrelationship of milk fat secretion with ruminal volatile fatty acids and serum insulin and glucose. Ph. D. Thesis, Virginia Univ., USA.

JENNY B. F., POLAN C. E., 1975. Postprandial blood glucose and insulin in cows fed high grain. J. Dairy Sci, 58, 512-514.

JENNY B. F., POLAN C. E., CHANDLER P. T., 1972. Acetate and stearate utilization by lactating cows fed high grain-restricted roughage rations. J. Dairy Sci, 55, 1481-1486.

JENNY B. F., POLAN C. E., THYE F. W., 1974. Effects of high grain feeding and stage of lactation on serum insulin, glucose, and milk fat percentage in lactating cows. J. Nutr., 104, 379-385.

JESSE B. W., EMERY R. S., THOMAS J. W., 1983. Control of fatty acid oxidation in bovine liver. J. Dairy Sci., 66, suppl. 1, 140 (Abstract.).

JOHNSON M. D., DE DIOS O., LIPPINCOTT A. C., 1976. Environmental stress, TRH and lactation effects on plasma growth hormone in cattle. (cités par HART et al., 1978).

JOURNET M., 1978. Rationnement énergétique et azoté des vaches laitières au cours de la lactation et en fonction du niveau de production. Publication $n^{\circ} 24$. 1978. Fac. Sci. agron. Gembloux (Belgique).

JOURNET M., CHAMPREDON C., PION R., VÉRITÉ R., 1983. Bases physiologiques de la nutrition azotée des vaches fortes productrices. Analyse critique des recommandations. Wth int. Symp. Protein metabolism and nutrition. Clermont-Ferrand (France), EAAP Publ. $n^{\circ} 31,433$. 437.

JOURNET M., RÉMOND B., 1976. Physiological factors affecting the voluntary intake of feed by cows : a review. Livest. Prod. Sci, 3, 129-146.

JOURNET M., RÉMOND B., 1981. Response of dairy cows to protein level in early lactation. Livest. Prod. Sci., 8, 21-35.

JOURNET M., VÉRITÉ R., RÉMOND B., 1976. Partition of energy intake between milk and body gain in dairy cows, 323-326. In M. VERMOREL, Energy metabolism of farm animals (EAAP Publ. $\left.n^{\circ} 19\right)$.

KANN G., HABERT R., MEUSNIER C., RYNIEWICZ H. S., 1977. Prolactin release in response to nursing or milking stimulus in the ewe. Is it mediated by thyrotrophin releasing hormone ? Ann. Biol. anim. Bioch. Biophys., 17, 441-452.

KATZ M. L., BERGMAN E. N., 1969. Hepatic and portal metabolism of glucose, tree tatty acıds, and ketone bodies in the sheep. Am. J. Physiol., 216, 953-960.

KAUPPINEN K., 1983a. Correlation of whole blood concentrations of acetoacetate, beta-hydraxybutyrate, glucose and milk yield in dairy cows as studied under field conditions. Acta vet. scand., 24, 337-348.

KAUPPINEN K., 1983b. Prevalence of bovine ketosis in relation to number and stage of lactation. Acta vet. scand., 24, 349-361.

KENNA T. M., AIELLO R. J., HERBEIN J. H., 1981. Influences of stage of lactation and ration on in vitro gluconeogenesis from propionate in ruminant liver (Abstr.). J. Dairy Sci., 64 (suppl. 1), 160 .

KEYS J. E., CAPUCO A. V., 1985. Effect of bovine growth hormone (bGH) on acetate incorporation by mammary and adipose tissue from Holsteins at different stages of first term gestation and lactation. J. Dairy Sci., 68, supplt 1, 106 (Abstr.).

KHACHADURIAN A. K., ADROUNI B., YACOUBIAN H., 1966. Metabolism of adipose tissue in the fat tail of the sheep in vivo. J. Lipid Res., 7, 427-436.

KIRCHGESSNER M., ROEHRMOSER G., MUELLER H. L., 1983. Energiebilanz und Energieverwertung laktierender Kuehe bei energetischer Unterversorgung und anschliessender Realimentation. Z. Tierphysiol. Tierernaehr. Futtermittelk., 49, 228-238.

KONIG B. A., PARKER D. S., OLDHAM J. D., 1979. Acetate and palmitate kinetics in lactating dairy cows. Ann. Rech. vét., 10, 368-370.

KOONG L. J., ANDERSON G. B., GARRETT W. N., 1982. Maternal energy status of beef cattle during single and twin pregnancy. J. anim. Sci, 54, 480-484.

KOPROWSKI J. A., TUCKER H. A., 1973. Bovine serum growth hormone, corticoids and insulin during lactation. Endocrinology, 93, 645-651.

KREBS H. A., 1966. Bovine ketosis. Vet. Rec., 78, 187-192.

KRONFELD D. S., 1965. Plasma non-esterified fatty acid concentrations in the dairy cow: Responses to nutritional and hormonal stimuli and significance in Ketosis. Vet. Rec., 77, 30-34. 
KRONFELD D. S., 1971. Hypoglycemia in ketotic cows. J. Dairy Sci., 54, 949-961.

KRONFELD D. S., 1972. Ketosis in pregnant sheep and lactating cows. A rewiew. Aust. Vet. J., 48 680-687.

KRONFELD D. S., 1976. The potential importance of the proportions of glucogenic, lipogenic and aminogenic nutrients in regard to the health and productivity of dairy cows. Adv. anim. Physiol. anim. Nutr., 7, 5-26.

KRONFELD D. S., 1982. Major metabolic determinants of milk volume, mammary efficiency, and spontaneous ketosis in dairy cows. J. Dairy Sci, 65, 2204-2212.

KRONFELD D. S., RAGGI F., 1964. Glucose kinetics in normal, fasting and insulin-treated cows. Am. J. Physiol., 206, 109-112.

KRONFELD D. S., RAGGI F., RAMBERG C. F., 1968. Mammary blood flow and ketone body metabolism in normal, fasted and ketotic cows. Am. J. Physiol., 215, 218-227.

KRONFELD D. S., MAYER G. P., ROBERTSON J. Mc D., RAGGI F., 1963. Depression of milk secretion during insulin administration. J. Dairy Sci., 46, 559-563.

KUNZ P. L., BLUM J. W., 1985. Relationships between energy balances and blood levels of hormones and metabolites in dairy cows during late pregnancy and early lactation. Z. Tierphysiol. Tierernaehrg. Futtermittelkde, 54, 239-248.

KUNZ P. L., BLUM J. W., HART I. C., BICKEL H., LANDIS J., 1985. Effects of different energy intake before and after calving on feed intake, performance and metabolic parameters in dairy cows. Anim. Prod., 40, 219-231.

LAARVELD B., CHRISTENSEN D. A., BROCKMAN R, P., 1981. The effect of insulin on net metabolism of glucose and amino acids by the bovine mammary gland. Endocrinology, 108, 2217-2221.

LAARVELD B., DELORME B., KERR D. E., 1982. Lipotropic effect of estradiol-17- $\beta$ in fed and fasted lactating cows. J. Dairy Sci., 65, 920-926.

LAFONTAN M., 1986. Physiologie et pharmacologie de la mobilisation des lipides : aspects actuels et futurs. Cah. Nutr. Diét., 21, 19-46.

LAND C., LEAVER J. D., 1981. The effect of body condition at calving on the production of Friesian cows and heifers. Anim. Prod., 32, 362-363.

LANGLANDS J. P., SUTHERLAND H. A. M., 1968. An estimate of the nutrients utilized for pregnancy by Merino sheep. Br. J. Nutr., 22, 217-227.

LARNICOL S., REMOND B., CHILLIARD Y., 1984. Etat d'engraissement des vaches laitières à la mise-bas : effets sur quelques paramètres zootechniques selon le niveau d'alimentation en début de lactation. Résultats préliminaires. In LARNICOL S., 1984, Thèse Doc. Ing., Lab. Lactation (INRA-Theix), E.N.S.A. Montpellier.

LARSEN T., 1985. Regulatory aspects of adipose tissue metabolism in reindeer - seasonal interactions. Thèse Université de Tromso (Norvège).

LEAT W. M. F., 1974. Variation in plasma glucose and free fatty acid concentrations in sheep associated with season, pregnancy and lactation. J. agric. Sci., Camb., 82, 181-184.

LEAT W. M. F., FORD E. J. H., 1966. Utilisation of free fatty acids by starved and pregnant sheep. Biochem. J., 101, 317-322.

LEAT W. M. F., HARRISON F. A., 1975. Digestion, absorption and transport of lipids in the sheep, 481-495. In : I. W. McDONALD, A.C.I. WARNER. Digestion and metabolism in the ruminant. The Univ. New England Publ. Unit. Australia.

LEE V., RAMACHANDRAN J., LI C. H., 1974. Does bovine growth hormone possess rapid lipolytic activity? Arch. Biochem. Biophys., 161, 222-226.

LENG R. A., 1965. Ketone body metabolism in normal and underfed pregnant sheep and in pregnancy toxaemia. Res. vet. Sci., 6, 433-441.

LENKEIT W., 1972. Der muetterliche Stoffwechsel waehrend der Graviditaet. In W. LENKEIT, K. BREIREM, E. CRASEMAN, Handbuch der Tierernaehrung, Vol. 2, 115-142, Verlag Paul Parey Hamburg, Berlin.

LEON M., WOODSIDE B., 1983. Energetic limits on reproduction : maternal food intake. Physiol. Behav., 30, 945-957.

LIEPA G. U., BEITZ D. C., LINDER J. R., 1978. Fatty acid synthesis in ruminating and nonruminating goats. J. Nutr., 108, 1733-1739.

LINDSAY D. B., 1971. Changes in the pattern of glucose metabolism in growth, pregnancy and lactation in ruminants. Proc. Nutr. Soc., 30, 272-277. 
LINDSAY D. B., 1978. The effect of feeding pattern and sampling procedure on blood parameters. In The use of blood metabolites in animal production, Brit. Soc. anim. Prod., occasional Publ. $n^{\circ} 1,99-120$.

LINDSAY D. B., 1979. Metabolism in the whole animal. Proc. Nutr. Soc., 38, 295-301.

LINDSAY D. B., 1981. Characteristics of the metabolism of carbohydrate in ruminants compared with other mammals. Curr. Top. vet. Med. anim. Sci. 10, 101-121.

LINZELL J. L., 1974. Mammary blood flow and methods of identifying and measuring precursors of milk. In B. L. LARSON, V. R. SMITH, Lactation, a comprehensive treatise, Vol. I, 143225. Acad. Press, N. Y.

LITTLE W., 1974. An effect of the stage of lactation on the concentration of albumin in the serum of dairy cows. Res. vet. Sci., 17, 193-199.

LODGE G. A., FISHER L. J., LESARD J. R., 1975. Influence of prepartum feed intake on performance of cows fed ad libitum during lactation. J. Dairy Sci., 58, 696-702.

LODGE G. A., HEANEY D. P., 1973a. Composition of weight change in the pregnant ewe. Can. J. anim. Sci., 53, 95-105.

LODGE G. A., HEANEY D. P., 1973b. Energy cost of pregnancy in single - and twin-bearing ewes. Can. J. anim. Sci, 53, 479-489.

LOMAX M. A., BAIRD G. D., 1983. Blood flow and nutrient exchange across the liver and gut of the dairy cow. Effect of lactation and fasting. Br. J. Nutr., 49, 481-496.

LOMAX M. A., BAIRD G. D., MALLINSON C. B., SYMONDS M. W., 1979. Differences between lactating and non-lactating dairy cows in concentration and secretion rate of insulin. Biochem. J., 180, 281-289.

LOMAX M. A., DONALDSON I. A., POGSON C. I., 1983. The control of fatty acid metabolism in liver cells from fed and starved sheep. Biochem. J., 214, 553-560.

LUICK J. R., SMITH L., 1963. Fatty acid synthesis during fasting and bovine ketosis. J. Dairy Sci., 46, 1251-1255.

LUTHMAN J., HOLTENIUS P., 1972. Norepinephrine-induced fatty liver and hypocalcemia in sheep. Acta vet. scand., 13, 31-41.

LUTHMAN J., JONSON G., 1972a. Short term hormonal effects on blood glucose and non-esterified fatty acids in female sheep. Acta vet. scand., 13, 112-127.

LUTHMAN J., JONSON G., 1972b. The relationship between serum calcium and plasma nonesterified fatty acids in normal and hypocalcemic cows and sheep. Acta vet. scand., 13, $42-55$.

LUTHMAN J., JONSON G., JACOBSSON S. O., 1972. The effects of estrogen and progesterone on the blood levels of glucose, non-esterified fatty acids and cholesterol in ovariectomized sheep. Acta vet. Scand., 13, 242-250.

LUTHMAN J., PERSSON J., 1975. Lipid mobilization in parturient cows. Acta vet. scand., 16. 63-75.

MACKIE W. S., CAMPBELL R. M., 1972. Effects of pregnancy and lactation on the activities of some gluconeogenic and urea-cycle enzymes in sheep liver. J. agric. Sci., Camb., 79, 423-429.

MACKIE W. S., FELL B. F., 1971. The half-life of serum albumin in relation to liver hypertrophy in the lactating ewe. Res. vet. Sci., 12, 54-58.

MACRAE J. C., EGAN A. R., 1983. Threonine metabolism in sheep. 2. Threonine catabolism and gluconeogenesis in pregnant ewes. Br. J. Nutr., 49, 385-393.

MAGDUS M., GALAMBOS L., HUSVETH F., 1985. Studies on the lipid metabolism of ewes in the periparturient period. Acta. vet. hung., 33, 89-100.

MALTERRE C., 1986a. Production de viande de génisses, 201-246. In D. MICOL, Production de viande bovine. I.N.R.A., Paris.

MALTERRE $C_{1}, 1986 \mathrm{~b}$. Production de viande de vaches de réforme, 247-269. In D. MICOL, Production de viande bovine. I.N.R.A., Paris.

MAMO J. C. L., SNOSWELL A. M., TOPPING D. L., 1983. Plasma triacylglycerol secretion in sheep. Paradoxical effects of fasting and alloxan diabetes. Biochim. Biophys. Acta, 753, 272-275.

MANNS, J. G., BODA, J. M., 1965. Effects of ovine growth hormone and prolactin on blood glucose, serum insulin, plasma nonesterified fatty acids and amino nitrogen in sheep. Endocrinology, 76, 1109-1114. 
MARTAL J., DJIANE J., 1977. The production of chorionic somatomammotrophin in sheep. $J$. Reprod. Fert., 49, 285-289.

MARTIN R. A., EHLE F. R., 1986. Body composition of lactating and dry Holstein cows estimated by deuterium dilution. J. Dairy Sci., 69, 88-98.

MAYER L., 1970. Untersuchungen ueber die Veraenderungen des Milchfetts und des Koerperfetts von Milchtieren im Verlauf der Laktation. Thèse Fac. Agronom., Kiel (R.F.A.).

MAZUR A., AL-KOTOBE M., RAYSSIGUIER Y., 1987. Influence de la lipomobilisation sur la sécrétion des triglycérides par le foie, chez le mouton. Reprod. Nutr. Dévelop., 27, 317-318.

MAZUR A., BAUCHART D., CHILLIARD Y., DIDIER R., RAYSSIGUIER Y., 1986b. Teneur en lipides du foie chez la vache en début de lactation : comparaison des différentes techniques d'estimation des triglycérides hépatiques. Reprod. Nutr. Dévelop., 26, 355-356.

MAZUR A., GUEUX E., BAZIN S., RAYSSIGUIER Y., 1986c. Evolution du cholestérol lié aux lipoprotéines légères chez la vache en début de lactation et relation avec l'infiltration lipidique du foie. Reprod. Nutr. Dévelop., 26, 363-364.

MAZUR A., GUEUX E., CHILLIARD Y., RAYSSIGUIER Y., 1986a. Evolution des lipides et lipoprotéines plasmatiques chez la vache en début de lactation. Reprod. Nutr. Dévelop., 26, $357-$ 358.

MEPHAM T. B., LAWRENCE S. E., PETERS A. R., HART I. C., 1984. Effects of exogenous growth hormone on mammary function in lactating goats. Horm. Metabol. Res., 16, $248-253$.

MERSMANN H. J., HOUK J. M., PHINNEY G., UNDERWOOD M. C., 1973. Lipogenesis by in vitro liver and adipose tissue preparations from neonatal swine. Am. J. Physiol., 224, 11231129.

MESBAH M. M., BALDWIN R. L., 1983. Effects of diet, pregnancy, and lactation on enzyme activities and gluconeogenesis in ruminant liver. J. Dairy Sci., 66, 783-788.

METZ S. H. M., LOPES-CORDOZO M., VAN DEN BERGH S. G., 1974. Inhibition of lipolysis in bovine adipose tissue by butyrate and B-hydroxybutyrate. FEBS Lett., 47, 19-22.

METZ S. H. M., MULDER I., VAN DEN BERGH S. G., 1973. Regulation of lipolysis in bovine adipose tissue by the degree of saturation of plasma albumin with fatty acids. Biochim. Biophys. Acta, 306,42-50.

METZ S. H. M., VAN DEN BERGH S. G., 1972. Effects of volatile fatty acids, ketone bodies, glucose and insulin on lipolysis in bovine adipose tissue. FEBS Lett., 21, 203-206.

METZ S. H. M., VAN DEN BERGH S. G., 1977. Regulation of fat mobilization in adipose tissue of dairy cows in the period around parturition. Neth J. agric. Sci, 25, 198-211.

MILLER T. B., CHIGARU P., DOWNIE J. G., GALBRAITH H., Mc DONALD D. C., TOPPS J. H., 1978. Observations under field conditions. The suckler cow, 71-86. In The use of blood metabolites in animal production. Br. Soc. Anim. Prod. Occasional Publ. $\mathrm{n}^{\circ} 1$.

MILLS S. E., BEITZ D. C., YOUNG J. W., 1986a. Characterization of metabolic changes during a protocol for inducing lactation ketosis in dairy cows. J. Dairy Sci., 69, 352-361.

MILLS S. E., BEITZ D. C., YOUNG J. W., 1986b. Evidence for impaired metabolism in liver during induced lactation ketosis of dairy cows. J. Dairy Sci., 69, 362-370.

MOE P. W., 1981. Energy metabolism of dairy cattle. J. Dairy Sci., 64, 1120-1139.

MOORE J. H., CHRISTIE W. W., 1981. Lipid metabolism in the mammary gland of ruminant animals, 227-277. In CHRISTIE W. W., Lipid metabolism in ruminant animals (Pergamon Press).

MORROW D. A., 1976. Fat cow syndrome. J. Dairy Sci., 59, 1625-1629.

MOULTON C. R., TROWBRIDGE P. F., HAIGH L. D., 1923. Studies in animal nutrition V. Changes in the composition of the mature dairy cow during fattening. Missouri Agric. Exp. Stat. Res. Bull., ${ }^{\circ} 61,20 \mathrm{pp}$.

MULDER I., 1971. Concentration and composition of plasma free fatty acids in cattle at partus. Z. Tierphysiol. Tierernaehr. Futtermittelk., 27, 190-192.

MURASE T., YAMADA N., MATSUZAKI F., 1981. The in vitro effect of growth hormone on adipose tissue lipoprotein lipase in rats. Life Sci., 28, 199-201.

Mc CANN J. P., REIMERS T. J., 1985. Glucose response to exogenous insulin and kinetics of insulin metabolism in obese and lean heifers. J. anim. Sci., 61, 612-618.

Mc CANN J. P., REIMERS T. J., 1986. Effects of obesity on insulin and glucose metabolism in cyclic heifers. J. anim., Sci., 62, 772-782. 
MC CLYMONT G. L., VALLANCE S., 1962. Depression of blood glycerides and milk fat synthesis by glucose infusion. Proc. Nutr. Soc., 21, XLI.

Mc CUTCHEON S. N., BAUMAN D. E., 1986. Effect of chronic growth hormone treatment on responses to epinephrine and thyrotropin-releasing hormone in lactating cows. J. Dairy Sci, 69, 44-51.

Mc DOWELL G. H., 1983. Hormonal control of glucose homoeostasis in ruminants. Proc. Nutr. Soc., 42, 149-167.

Mc DOWELL G. H., HART I. C., 1984. Responses to infusion of growth hormone into the mammary arteries of lactating sheep. Can. J. anim. Sci., 64 (Suppl.) 306-307.

Mc FARLAND D. C., McNAMARA J. P., 1985. Lipoprotein lipase activity in bovine adipose tissue before, during and after lactation. J. Dairy Sci, 68, supplt 1, 168 (Abstr.).

Mc NAMARA J. P., DAVIS S. R., COLLIER R. J., 1983. Effect of growth hormone and thyroxine on plasma lipids, mammary lipid uptake and milk fat in Jersey cows. J. Dairy Sci., 66, supplt 1 (Abstract $n^{\circ}$ P. 311).

MC NAMARA J. P., HILLERS J. K., 1986. Adaptations in lipid metabolism of bovine adipose tissue in lactogenesis and lactation. J. Lipid Res., 27, 150-157.

Mc NAMARA J. P., HILLERS J. K., McFARLAND D. C., CRONRATH J. D., 1985, Effect of diet and genetic selection for milk production on lipogenesis and lipolysis in bovine adipose tissue. J. Dairy Sci., 68, supplt 1, 143 (Abstr.).

Mc NAMARA J. P., McFARLAND D. C., HILLERS J. K., 1986. Epinephrine responsiveness of bovine adipose tissue increases during the periparturient period. J. Dairy Sci., 69, supplt 1 . 154 (Abstr.).

Mc NIVEN M. A., 1984. Effect of body fatness on blood metabolites and insulin insensivity in adult sheep. Can. J. anim., Sci., 64, 1049-1053.

N'GUEMA EMANE M., DELOUIS C., KELLY A., DJIANE J., 1986. Evolution of prolactin and placental lactogen receptors in ewes during pregnancy and lactation. Endocrinology, 118, 695-700.

NOBLE R. C., STEELE W., MOORE J. H., 1970. The composition of ewe's milk fat during early and late lactation. J. Dairy Res., 37, 297-301.

NOBLE R. C., STEELE W., MOORE J. H., 1971. The plasma lipids of the ewe during pregnancy and lactation. Res. vet. Sci., 12, 47-53.

O'HEA E. K., LEVElLLÉ G. A., 1969. Significance of adipose tissue and liver as sites of fatty acid synthesis in the pig and the efficiency of utilization of various substances for lipogenesis. J. Nutr., 99, 338-344.

ODDY V. H., GOODEN J. M., HOUGH G. M., TELENI E., ANNISON E. F., 1985. Partitioning of nutrients in Merino ewes. II. Glucose utilization by skeletal muscle, the pregnant uterus and the lactating mammary gland in relation to whole body glucose utilization. Aust. J. biol. Sci., 38, 95-108.

OLDHAM J. D., 1984. Protein-energy interrelationships in dairy cows. J. Dairy Sci., 67, 1090-1114.

OLDHAM J. D., LINDSAY D. B., 1983. Interrelationships between protein-yielding and energyyielding nutrients. Int. Symp. Protein metabolism and nutrition, Clermont-Ferrand (France), Ed. I.N.R.A. Publ., Vol. I, 183-209 (EAAP Publ. $n^{\circ} 31$ ).

OPSTVEDT J., BALDWIN R. L., RONNING M., 1967. Effect of diet upon activities of several enzymes in abdominal adipose and mammary tissue in the lactating dairy cow. J. Dairy Sci., 50. 108-109.

OPSTVEDT J., RONNING M., 1967. Effect upon lipid metabolism of feeding alfalfa hay or concentrate ad libitum as the sole feed for milking cows. J. Dairy Sci, 50, 345-354.

DRSKOV E. R., GRUBB D. A., KAY R. N. B., 1977. Effect of postruminal glucose or protein supplementation on milk yield and composition in Friesian cows in early lactation and negative energy balance. Br. J. Nutr., 38, 397-405.

PALMQUIST D. L., 1972. Palmitic acid as a source of endogenous acetate and beta-hydroxybutyrate in fed and fasted ruminants. J. Nutr., 102, 1401-1406.

PALMQUIST D. L., CONRAD H. R., 1971. Origin of plasma fatty acids in lactating cows fed high grain or high fat diets. J. Dairy Sci., 54, 1025-1033.

PALMQUIST D. L., DAVIS C. L., BROWN R. E., SACHAN D. S., 1969. Availability and metabolism of various substrates in ruminants. $V$. Entry rate into the body and incorporation into milk fat of D(-)B-hydroxybutyrate. J. Dairy Sci., 52, 633-638. 
PARKER B. N. J., LEWIS G., 1978. The effect of dietary energy level on body condition and some blood compounds in the dairy cow, 121-132. In The use of blood metabolites in animal production, Br. Soc. Anim. Prod. Occasional Publ. $n^{\circ} 1$.

PATTERSON D. S. P., 1966. Depot fat mobilization and liver lipogenesis and ketogenesis in ovine pregnancy toxaemia and the eftects of corticotrophin administration. Res. vet. Sci., 7. 484-492.

PATTERSON D. S. P., BURNS K. N., CUNNINGHAM N. F., HERBERT C. N., SABA N., 1964. Plasma concentration of glucose and non esterified fatty acids (NEFA) in the pregnant and lactating ewe and the effect of dietary restriction. J. agric. Sci. Camb., 62, 253-262.

PATTERSON J. Y. F., LINZELL J. L., 1974. Cortisol secretion rate, glucose entry rate and the mammary uptake of cortisol and glucose during pregnancy and lactation in dairy cows. $J$. Endocrinol., 62, 371-383.

PAYNE E., MASTERS C. J., 1971. The in vitro incorporation of 14C-labelled fatty acids into ovine liver and omental adipose tissue. Int. J. Biochem., 2, 623-643.

PAYNE E., RATTRAY P. V., 1980. The effect of restricted grazing on the fatty acid composition of ovine milk fat during early lactation. Br. J. Nutr., 44, 47-52.

PEART J. N., 1967. The effect of different levels of nutrition during late pregnancy on the subsequent milk production of Blackface ewes and on growth of their lambs. J. agric. Sci. Camb., 68, 365-371.

PEART J. N., 1968a. Lactation studies with Blackface ewes and their lambs. J. agric. Sci. Camb., 70, 87-94.

PEART J. N., 1968b. Some effect of live weight and body composition on the milk production of Blackface ewes. J. agric. Sci. Camb., 70, 331-338.

PEART J. N., 1970. The influence of live weight and body condition on the subsequent milk production of Blackface ewes following a period of undernourishment in early lactation. $J$. agric. Sci. Camb., 75, 459-469.

PEART J. N., EDWARDS R. A., DONALDSON E., 1972. The yield and composition of the milk of Finnish-Landrace $\times$ Blackface ewes. J. agric. Sci. Camb., 79, 303-313.

PEEL C. J., BAUMAN D. E., GOREWIT R. C., SNIFFEN C. J., 1981. Effect of exogenous growth hormone on lactational performance in high yielding dairy cows. J. Nutr., 111, 1662-1671.

PEEL C. J., FRONK T. J., BAUMAN D. E., GOREWIT R. C., 1982. Lactational response to exogenous growth hormone and abomasal infusion of a glucose-sodium caseinate mixture in high yielding dairy cows. J. Nutr., 112, 1770-1778.

PEEL C. J., FRONK T. J., BAUMAN D. E., GOREWIT R. C., 1983. Effect of exogenous growth hormone in early and late lactation on lactational performance of dairy cows. J. Dairy Sci., 66, 776-782.

PEEL C. J., SANDLES L. D., QUELCH K. J., HERINGTON A. C., 1985. The effects of long-term administration of bovine growth hormone on the lactational performance of identical-twin dairy cows. Anim. Prod., 41, 135-142.

PEETERS G., HOUVENAGHEL A., ROETS E., MASSART-LEËN A. M., VERBEKE R., DHONDT G., VERSCHOOTEN F., 1979. Electromagnetic blood flow recording and balance of nutrients in the udder of lactating cows. J. anim. Sci, 48, 1143-1153.

PEHRSON B., 1971. Studies of the blood lipid pattern in healthy dairy cows. Acta vet. scand., 12, 230-242.

PENZHORN E. J., MEINTJES J. P., 1972. Influence of pregnancy and lactation on the voluntary feed intake of afrikaner heifers and cows. Agroanimalia, 4, 83-92.

PÉRIER A., BOCQUIER F., KANN G., MARTINET J., 1986. Influence de la photopériode et des apports énergétiques pendant la gestation sur les taux plasmatiques de la prolactine, de l'hormone de croissance et de l'hormone placentaire lactogène puis sur la production laitière de la brebis traite. Reprod. Nutr. Dévelop., 26, 391-392.

PERKINS B. L., SMITH R. D., SNIFFEN C. F., 1983. Effects of body condition on liver fat content and performance in dairy cows (Abstr.). J. Dairy Sci, 66 (supplt 1) 220.

PETERS R. R., CHAPIN L. T., EMERY R. S., TUCKER H. A., 1981. Milk yield, feed intake, prolactin, growth hormone, and glucocorticoid response of cows to supplemented light. J. Dairy Sci. 64, 1671-1678.

PETHES G., BOKORI J., RUDAS P., FRENYO V. L., FEKETE S., 1985. Thyroxine, triiodothy- 
ronine, reverse-triiodothyronine, and other physiological characteristics of periparturient cows fed restricted energy. J. Dairy Sci., 68, 1148-1154.

PETHICK D. W., LINDSAY D. B., 1982a. Metabolism of ketone bodies in pregnant sheep. Br. J. Nutr., 48, 549-563.

PETHICK D. W., LINDSAY D. B., 1982b. Acetate metabolism in lactating sheep. Br. J. Nutr., 48, 319-327.

PETHICK D. W., LINDSAY D. B., BARKER P. J., NORTHROP A. J., 1983. The metabolism of circulating non-esterified fatty acids by the whole animal, hind limb muscle and uterus of pregnant ewes. Br. J. Nutr., 49, 129-143.

PETIT M., 1978. Vaches nourrices, 377-402. In Alimentation des Ruminants, Ed. I.N.R.A. Publ., Versailles.

PETIT M., REEMOND B., 1977. Note sur les variations du taux d'acides gras non estérifiés plasmatiques chez la vache à la fin de la gestation. Ann. Zootech., 26, 131-138.

PIKE B. V., ROBERTS C. J., 1980. The metabolic activity of bovine adipocytes before and after parturition. Res. vet. Sci., 29, 108-110.

PIKE B. V., ROBERTS C. J., 1981. Comparison of glucose and acetate as substrates for lipid synthesis in bovine adipocytes. Res. vet. Sci, 30, 390-391.

PIKE B. V., ROBERTS C. J., 1984. Size and lipolytic capacity of bovine adipocytes from subcutaneous and internal adipose tissue. Vet. Res. Commun., 8, 61-64.

PLAUT K., BAUMAN D. E., AGERGAARD N., 1985. Effect of exogenous prolactin on lactational performance of dairy cows. J. Dairy Sci., 68, supplt 1, 170 (Abstr.).

POCIUS P. A., HERBEIN J. H., 1986. Effects of in vivo administration of growth hormone on milk production and in vitro hepatic metabolism in dairy cattle. J. Dairy Sci., 69, 713-720.

PRIOR R. L., 1978. Effect of level of feed intake on lactate and acetate metabolism and lipogenesis in vivo in sheep. J. Nutr., 108, 926-935.

PRIOR R. L., CHRISTENSON R. K., 1976. Influence of dietary energy during gestation on lambing performance, and glucose metabolism in Finn-cross ewes. J. anim. Sci., 43, 11141124.

PRIOR R. L., CHRISTENSON R. K., 1978. Insulin and glucose effects on glucose metabolism in pregnant and nonpregnant ewes. J. anim. Sci., 46, 201-210.

PRIOR R. L., SMITH S. B., 1982. Hormonal effects on partitioning of nutrients for tissue growth : role of insulin. Fed. Proc., 41, 2545-2549.

PRIOR R. L., SMITH S. B., SCHANBACHER B. D., MERSMANN H. J., 1983. Lipid metabolism in finishing bulls and steers implanted with oestradiol-17/3-dipropionate. Anim. Prod., 37, 81-88.

PUPPIONE D. L., 1978. Implications of unique features of blood lipid transport in the lactating cow. J. Dairy Sci., 61, 651-659.

PURROY-UNANUA A., TISSIER M., THÉRIEZ M., 1978. Mesure de la composition corporelle des brebis à différents stades du cycle de reproduction par la méthode des espaces de diffusion. Résultats préliminaires. In PURROY-UNANUA A., Thèse Doc. $3^{e}$ cycle. Lab. Prod. Ovine (I.N.R.A.-Theix), Univ. Clermont-Fd.

RADLOFF H. D., SCHULTZ L. H., 1966. Hormonal regulation of plasma free fatty acid concentration in ruminants. J. Dairy SCi., 49, 971-975.

RADLOFF H. D., SCHULTZ L. H., HOEKSTRA W. G., 1966. Relationship of plasma free fatty acids to other blood components in ruminants under various physiological conditions. $J$. Dairy Sci, 49, 179-182.

RAO D. R., HAWKINS G. E., 1976. Acetate contribution to the synthesis of milk fat fractions by dairy cows fed different levels of concentrates. Nutr. Rep. Int., 13, 403-411.

RAO D. R., HAWKINS G. E., SMITH R. C., 1973. Effect of glucose and insulin on lipoprotein lipase activity in adipose tissue and milk. J. Dairy Sci, 56, 1415-1419.

RAPHAEL B. C., DIMICK P. S., PUPPIONE D. L., 1973. Lipid characterization of bovine serum lipoproteins throughout gestation and lactation. J. Dairy Sci., 56, 1025-1032.

RATTRAY P. V., GARRETT W. N., EAST N. E., HINMAN N., 1974b. Growth, development and composition of the ovine conceptus and mammary gland during pregnancy. J. anim. Sci., 38, 613-626.

RATTRAY P. V., GARRETT W. N., HINMAN N., EAST N. E., 1974a. Effects of level of nutrition, 
pregnancy and age on the composition of the wool-free ingesta-free body and carcass of sheep. J. anim. Sci., 39, 687-693.

RATTRAY P. V., TRIGG T. E., URLICH C. F., 1980. Energy exchanges in twin-pregnant ewes. In L. E. MOUNT, Energy Metabolism, 325-328, Butterworths, London, EAAP. Publ. $n^{\circ} 26$.

RAYSSIGUIER Y., MAZUR A., REID I. M., ROBERTS C. J., GUEUX E., 1986a. Modifications des lipoprotéines plasmatiques associées à la stéatose hépatique chez la vache en début de lactation. Reprod. Nutr. Dévelop., 26, 361-362.

RAYSSIGUIER Y., MAZUR A.; REMOND B., CHILLIARD Y., GUEUX E., 1986b. Influence de l'état corporel au vêlage et du niveau d'alimentation en début de lactation sur la stéatose hépatique chez la vache laitière. Reprod. Nutr. Dévelop., 26, 359-360.

REFSAL K. R., NACHREINER R. F., ANDERSON C. R., 1984. Relationship of season, herd, lactation, age, and pregnancy with serum thyroxine and triiodothyronine in Holstein cows. Dom. Anim. Endocrinol., 1, 225-234.

REID I. M., 1980. The incidence and severity of fatty liver in dairy cows. Vet. Rec., 107, $281-284$.

REID I. M., COLLINS R. A., BAIRD G. D., ROBERTS C. J., SYMONDS H. W., 1979. Lipid production rates and the pathogenesis of fatty liver in fasted cows. J. agric. Sci. Camb., 93, 253-256.

REID I. M., COLLINS R. A., DEW S. M., HILL A. W., WILLIAMS M. R., 1983b. Immune competence of dairy cows with fatty liver, 191-194. In Proc. 5th. int. Conf. on Production diseases in farm animals. Uppsala, Sweden.

REID I.M., DEW S. M., COLLINS R. A., DUCKER J. M., BLOOM-FIELD J. A., MORANT S. C., 1983a. The relationship between fatty liver and fertility in dairy cows : a farm investigation. J. agric. Sci. Camb., 101, 499-502.

REID I. M., ROBERTS C. J., 1982. Fatty liver in dairy cows. In Practice, 4, 164-169.

REID I. M., ROBERTS C. J., 1983. Subclinical fatty liver in dairy cows. Current research and future prospects. Irish Vet. J., 37, 104-110.

REID I. M., ROBERTS C. J., BAIRD G. D., 1980. The effects of underfeeding during pregnancy and lactation on structure and chemistry of bovine liver and muscle. J. agric. Sci. Camb., 94, 239-245.

REID I. M., ROBERTS C. J., TREACHER R. J., WILLIAMS L. A., 1986. Effect of body condition at calving on tissue mobilization, development of fatty liver and blood chemistry of dairy cows. Anim. Prod., 43, 7-15.

REID I. M., ROWLANDS G. J., DEW A. M., COLLINS R. A., ROBERTS C. J., MANSTON R., 1983. The relationship between post-parturient fatty liver and blood composition in dairy cows. $J$. agric. Sci., Camb., 101, 473-480.

REID R. L., 1951. Studies on the carbohydrate metabolism of sheep. III. The blood glucose during insulin hypoglycaemia. Austr. J. agric. Res., 2, 132-145.

REID R. L., 1952. Studies on the carbohydrate metabolism of sheep. V. The effect of hyperglycaemia and of insulin on the rate of extrahepatic glucose assimilation. Austr. J. agric. Res., 3. 160-167.

REID R. L., 1963. The nutritional physiology of the pregnant ewe. J. Aust. Inst. agric. Sci., 29, 215-223.

REID R. L., 1968. The physiopathology of undernourishment in pregnant sheep, with particular reference to pregnancy toxemia. Adv. vet. Sci, 12, 163-238.

REID R. L., HINKS N. T., 1962a. Studies on the carbohydrate metabolism of sheep. XVII. Feed requirements and voluntary feed intake in late pregnancy, with particular reference to prevention of hypoglycemia and hyperketonemia. Austr. J. agric. Res., 13, 1092-1111.

REID R. L., HINKS N. T., 1962b. Studies of carbohydrate metabolism of sheep. XVIII. - The metabolism of glucose, free fatty acids, ketones, and amino acids in late pregnancy and lactation. Austr. J. agric. Res., 13, 1112-1123.

REID R. L., HINKS N. T., 1962c. Studies on the carbohydrate metabolism of sheep. XIX. The metabolism of glucose, free fatty acids, and ketones after feeding and during fasting or undernourishment of non-pregnant, pregnant, and lactating ewes. Aust. J. agric. Res., 13. 1124-1136.

RÉMĖSY C., CHILLIARD Y., AROEIRA L., MAZUR A., FAFOURNOUX P., DEMIGNÉ C., 1984. Les déviations du métabolisme des lipides chez le ruminant durant la gestation et la lactation. Bull. tech. CRZV Theix, I.N.R.A., 55, 53-71. 
RÉMÉSY C., CHILLIARD Y., RAYSSIGUIER Y., MAZUR A., DEMIGNÉ C., 1986. Le métabolisme hépatique des glucides et des lipides chez les ruminants : principales interactions durant la gestation et la lactation. Reprod. Nutr. Dévelop., 26, 205-226.

RÉMESY C., DEMIGNÉ C., 1976. Variation in some plasma metabolites from neoglucogenesis and ketogenesis in pregnant ewes in relation to diet. Ann. Rech. vét., 7, 887-895.

RÉMESY C., DEMIGNE C., 1979. Effects of undernutrition during late pregnancy on gluconeogenesis and ketogeneșis in twin-pregnant ewes. Ann. Biol. anim. Biochim. Biophys., 19, 241 250.

RÉMOND B., JOURNET M., 1970. Influence de l'état nutritionnel des vaches laitières au début de la lactation sur la mobilisation des réserves lipidiques et la sécrétion des matières grasses du lait. $18^{e}$ Congr. int. Laiterie, Sydney, Vol. 1F, 619.

RÉMOND B., JOURNET M., 1971. Alimentation des vaches laitières avec des rations à forte proportion d'aliments concentrés. 1. Quantités ingérées et production laitière. Ann. Zootech., 20, 169-184.

RÉMOND B., TOULLEC R., JOURNET M., 1973. Evolution chez la vache laitière des teneurs de différents constituants du sang à la fin de la gestation et au début de la lactation. Relations avec la sécrétion des matières grasses du lait. Ann. Biol. anim. Biochim. Biophys., 13, 363380.

REYNAERT R., DE PAEPE M., MARUS S., PEETERS G., 1975. Influence of serum free fatty acid-levels on growth hormone secretion in lactating cows. J. Endocr., 66, 213-224.

REYNAERT R., TOP W., PEETERS G., 1977. Bovine serum growth hormone levels in clinical ketosis. Vet. Rec., 101, 36-37.

RICHARD A. L., McCUTCHEON S. N., BAUMAN D. E., 1985. Responses of dairy cows to exogenous bovine growth hormone administered during early lactation. J. Dairy Sci., 68, 23852389.

ROBELIN J., 1982. A note on the estimation in vivo of body fat in cows using deuterium oxide or adipose-cell size. Anim. Prod., 34, 347-350.

ROBELIN J., CHILLIARD Y., 1983. Composition corporelle de la vache adulte en début de lactation ou en cours d'engraissement, mesurée par analyse chimique du corps entier. Résultats non publiés, cités par CHILLIARD et al., 1983.

ROBELIN J., CHILLIARD Y., 1984. Cellularité et activité LPL des différents dépôts adipeux chez la vache adulte en cours d'engraissement. $\eta^{\text {re }}$ Conférence annuelle sur l'Obésité (AFERO), Paris, 23 Mars 1984. p. 8.

ROBERTS C. J., 1982. Fat mobilisation of high-yielding dairy cows in early lactation. Proc. 12th World Congr. Diseases of cattle, Amsterdam, Vol. 1, 501-507.

ROBERTS C. J., REID I. M., DEW S. M., STARK A. J., BAIRD G. D., COLLINS R., MATHER D., 1978. The effects of underfeeding for 6 months during pregnancy and lactation on blood constituents, milk yield and body weight of dairy cows. J. Agric. Sci. Camb., 90, 383-394.

ROBERTS C. J., REID I. M., PIKE B. V., TURFREY B. R., 1979. Tissue mobilization in dairy cows in early lactation. Proc. Nutr. Soc., 38, 68A.

ROBERTS C. J., REID I. M., ROWLANDS G. J., PATTERSON A., 1981. A fat mobilization syndrome in dairy cows in early lactation. Vet. Rec., 108, 7-9.

ROBERTS C. J., TURFREY B. A., BLAND A. P., 1983. Lipid deposition in different fiber types of skeletal muscle of periparturient dairy cows. Vet. pathol., 20, 23-31.

ROBINSON J. J., 1973. Some aspects of ewe nutrition. Vet. Rec., 92, 602-606.

ROBINSON J. J., FRASER C., GILL J. C., MCHATTIE I., 1974. The effect of dietary crude protein concentration and time of weaning on milk production and body-weight change in the ewe. Anim. Prod., 19, 331-339.

ROBINSON J. J., FRAZER C., BENNETT C., 1971. An assessment of the energy requirements of the pregnant ewe using plasma free fatty acid concentrations. J. agric. Sci., Camb., 77, 141-145.

ROBINSON J. J., MCDONALD I., McHATTIE I., PENNIE K., 1978. Studies on reproduction in prolific ewes. 4. Sequential changes in the maternal body during pregnancy. J. agric. Sci., Camb., 91, 291-304.

ROOK J. A. F., 1979. The role of carbohydrate metabolism in the regulation of milk production. Proc. Nutr. Soc., 38, 309-314.

ROSSO P., 1977. Maternal nutrition, nutrient exchange, and fetal growth. Curr. Conc. Nutr., 5, 3-25. 
ROWLANDS G. J., 1978. Changes in concentrations of serum albumin in dairy cows at calving and their possible significance in relation to milk vield and fertility during lactation, 59-70. In The use of blood metabolites in animal production, Br. Soc. Anim. Prod., Occasional Publ. $\mathrm{n}^{\circ} 1$.

RULQUIN H., 1983. Effets sur la digestion et le métabolisme des vaches laitières d'infusions d'acides gras volatils dans le rumen et de caséinate dans le duodénum. II. - Métabolisme général et mammaire. Reprod. Nutr. Dévelop., 23, 1029-1042.

RUSSEL A. J. F., 1978. The use of measurements of energy status in pregnant ewes, 31-40. In The use of blood metabolites in animal production, $\mathrm{Br}$. Soc. Anim. Prod., Occasional Publ. $\mathrm{n}^{\circ} 1$.

RUSSEL A. J. F., DONEY J. M., GUNN R. G., 1971. The distribution of chemical fat in the bodies of Scottish Blackface ewes. Anim. Prod., 13, 503-509.

RUSSEL A. J. F., DONEY J. M., REID R. L., 1967. The use of biochemical parameters in controlling nutritional state in pregnant ewes and the effect of undernourishment during pregnancy on lamb birth weight. J. agric. Sci. Camb., 68, 351-358.

RUSSEL A. J. F., GUNN R. G., DONEY J. M., 1968. Components of weight loss in pregnant hill ewes during winter. Anim. Prod., 10, 43-51.

RUSSEL A. J. F., WRIGHT I. A., 1983. The use of blood metabolites in the determination of energy status in beef cows. Anim. Prod., 37, 335-343.

SALAMAN M. R., 1972. Discrepancies in the fat mobilizing activities of bovine growth hormone fractions determined in vivo and in vitro. J. Endocrinol., 55, 459-460.

SASAKI Y., MORIYA K., HAMADA H., 1981. Effects of glucocorticoid-treatment and/or adrenalectomy on the changes of plasma glucose and NEFA levels after insulin injection in sheep. Jap. J. zootech. Sci., 52, 780-788.

SATO H., 1977. Fat mobilization and glycogenolysis by norepinephrine in dairy cows. Jap. J. Zootech. Sci., 48, 610-616.

SAUL G. R., 1983. The composition, fat distribution and yield of carcass beef from steers and heifers when entire, spayed, pregnant or fitted with an intravaginal device. Aust. J. Exp. Agric. anim. Husb., 23, 354-360.

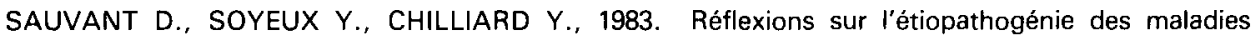
de la nutrition. Bull. Tech. CRZV Theix, INRA, 53, 117-121.

SCHIEMANN R., HENSELER G., JENTSCH W., WITTENBURG H., 1974. Die Verwertung der Futterenergie fur die Milchproduktion. 8. Mitteilung : Energieumsatz-messungen an Hochleistungskuhen im Fruhstadium der Laktation. Arch. Tierernahr., 24, 105-137.

SCHOENLE E., ZAPF J., FROESCH E. R., 1982. Glucose transport in adipocytes and its control by growth hormone in vivo. Am. J. Physiol., 242, E368-E372.

SCHREINER R. L., LEMONS J. A., GRESHAM E. L., 1981. Metabolic and hormonal response to chronic maternal fasting in the ewe. Ann. Nutr. Metab., 25, 38-47.

SCHULTZ L. H., 1974. Ketosis. In B. L. LARSON, V. R. SMITH, Lactation, a comprehensive treatise, vol. II, 317-353 Acad. Press, New York.

SCHWALM J. W., SCHULTZ L. H., 1976. Relationship of insulin concentration to blood metabolites in the dairy cow. $J$. Dairy Sci, 59, 255-261.

SCHWALM J. W., WATERMAN R., SHOOK G. E., SCHULTZ L. H., 1972. Blood metabolite interrelationships and changes in mammary gland metabolism during subclinical ketosis. $J$. Dairy Sci, 55, 58-64.

SENSENIG S. C., DAWES D. J., HEITMANN R. N., 1985. Energy metabolite concentrations and net fluxes across splanchnic and peripheral tissues in pregnant ewes. J. anim. Sci., 61, supplt 1 , 454 (Abstr.).

SHIRLEY J. E., 1973. Regulatory aspects of trig/yceride uptake by bovine adipose and mammary tissues. Ph. D. thesis, Michigan State Univ., East Lansing (U.S.A.).

SHIRLEY J. E., EMERY R. S., CONVEY E. M., OXENDER W. D., 1973a. Enzymatic changes in bovine adipose and mammary tissue, serum and mammary tissue hormonal changes with initiation of lactation. J. Dairy Sci, 56, 569-574.

SHIRLEY J. E., MORROW D., EMERY R. S., 1973b. Mammary and adipose lipoprotein lipase and glyceride synthetase as regulators of blood fat uptake. $J$. Nutr., 103, XXII (Abstr.).

SIDHU K. S., EMERY R. S., 1972. Regulation of blood fatty acids and glycerol in lactating cows. J. Dairy Sci., 55, 926-930. 
SIDHU K. S., EMERY R. S., 1973. Blood fatty acids and glycerol response to diet and norepinephrine. J. Dairy Sci., 56, 258-260.

SKARDA J., URBANOVA E., BECKA S., HOUDEBINE L. M., DELOUIS C., PICHOVA D., PICHA J., BILEK J., 1982. Effect of bovine growth hormone on development of goat mammary tissue in organ culture. Endrocrinol. exp., 16. 19-31.

SMITH J. A. B., DASTUR B. N., 1938. Studies on the secretion of milk fat. II. The effect of inanition on the yield and composition of milk fat. Biochem. J., 32, 1868-1876.

SMITH N. E., BALDWIN R. L., 1974. Effects of breed, pregnancy, and lactation on weight of organs and tissues in dairy cattle. J. Dairy Sci, 47, 1055-1060.

SMITH R. D., PERKINS B. L., SNIFFEN C. J., PEARSON E. G., 1983a. Body condition and fatty liver in dairy cows - Is there a relationship with reproductive performance ? Cornell Nutr., Conf. Feed. Manuf., 20-25.

SMITH R. D., HANSEL W., COPPOCK C. E., 1976. Plasma growth hormone and insulin during early lactation in cows fed silage based diets. J. Dairy Sci, 59, 248-254.

SMITH R. W., KNIGHT R. A., WALSH A., 1981a. Effect of lactation on the concentrations of protein, lipids and nucleic acids in ovine skeletal muscle. Res. vet. Sci, 30, 253-254.

SMITH R. W., KNIGHT R. A., WALSH A., 1982. Activities of some enzymes of glucose metabolism in bovine liver and kidney cortex at three stages of lactation. Res. vet. Sci., 33, 287-289.

SMITH R. W., WALSH A., 1975. The composition of the liver lipids of the ewe during pregnancy and lactation. Res. vet. Sci, 19, 230-232.

SMITH R. W., WALSH A., 1982. Effects of pregnancy and lactation on the activities in sheep liver of some enzymes of glucose metabolism. J. agric. Sci. Camb., 98, 563-565.

SMITH R. W., WALSH A., 1984. Effect of lactation on the metabolism of sheep adipose tissue. Res. Vét. Sci, 37, 320-323.

SMITH R. W., WALSH A., KNIGHT A., 1981b. Metabolism of bovine adipose tissue in vitro. Nat. Inst. Res. Dairying, Rep. 1980, 56 (Abstr.).

SMITH S. B., CROUSE J. D., 1984. Relative contributions of acetate, lactate and glucose to lipogenesis in bovine intramuscular and subcutaneous adipose tissue. J. Nutr., 114, 792-800.

SMITH S. B., PRIOR R. L., MERSMANN H. J., 1983b. Interrelationships between insulin and lipid metabolism in normal and alloxan-diabetic cattle. J. Nutr., 113. 1002-1015.

SNOSWELL A. M., COSTA N. D., McCLEAN J. G., BAIRD G. D., LOMAX M. A., SYMONDS H. W., 1978. Interrelationships between acetylation and the disposal of acetyl groups in the livers of dairy cows. J. Dairy Res., 45, 331-338.

SODERHOLM C. G., OTTERBY D. E., EHLE F. R., LINN J. G., HANSEN W. P., ANNEXSTAD R. J., 1986b. Effects of different doses of recombinant bovine somatotropin (rbSTH) on milk production, body composition, and condition score in lactating cows. J. Dairy Sci., 69, supplt 1 , 152 (Abstr.).

SODERHOLM C. G., OTTERBY D. E., LINN J. G., WHEATON J. E., HANSEN W. P., ANNEXSTAD R. J., 1986a. Effects of different doses of recombinant bovine somatotropin (rbSTH) on circulating metabolites, hormones, and physiological parameters in lactating cows. J. Dairy Sci., 69, Supplt 1, 152 (Abstr.).

SOLER-ARGILAGA C., INFANTE R., RENAUD G., POLONOVSKI J., 1974. Factors influencing free fatty acid uptake by the isolated perfused rat liver. Biochimie, 56, 757-761.

STEEL J. W., LENG R. A., 1973. Effects of plane of nutrition and pregnancy on gluconeogenesis in sheep. 1. The kinetics of glucose metabolism. Br. J. Nutr., 30, 451-473.

STERN D., ADLER J. H., TAGARI H., EYAL E., 1978a. Responses of dairy ewes before and after parturition to different nutritional regimes during pregnancy. II. - Energy intake, bodyweight changes during lactation and milk production. Ann. Zootech., 27, 335-346.

STERN D., ADLER J. H., TAGARI H., EYAL E., 1978b. Responses of dairy ewes before and after parturition, to different nutritional regimes during pregnancy. I. - Ewe body weight, uterine contents, and lamb birth weight. Ann. Zootech., 27, 317-333.

STERN D., ADLER J. H., TAGARI H., EYAL E., 1979. Responses of dairy ewes before and after parturition to different nutritional regimes during pregnancy. III. - The concentration of some metabolites in the blood during pregnancy. Ann. Zootech., 28, 239-250.

STOBBS T. H., BRETT D. J., 1974. Milk yield and composition of milk and blood as indicators of energy intake by Jersey cows. Aust. J. agric. Res., 25, 657-666. 
STORRY J. E., BURMBY P. E., HALL A. J., JONHSON V. W., 1974. Responses in rumen fermentation and milk fat secretion in cows receiving low-roughage diets supplemented with protected tallow. J. Dairy Res., 41, 165-173.

STORRY J. E., BRUMBY P. E., TUCKLEY B., WELCH V. A., STEAD D., FULFORD R. J., 1980. Effect of feeding protected lipid to dairy cows in early lactation on the composition of blood lipoproteins and secretion of fatty acids in milk. J. agric. Sci. Camb., 94, 503-516.

SUTTON J. D., 1981. Concentrate feeding and milk composition, 35-48. In HARESIGN W., Recent advances in animal nutrition. Butterworths, London.

SUTTON J. D., OLDHAM J. D., HART I. C., 1980. Products of digestion, hormones and energy utilization in milking cows given concentrates containing varying proportions of barley or maize, 303-306. In L. E. MOUNT, Energy metabolism, EAAP Publ. $\mathrm{n}^{\circ}$ 26, Butterworths, London.

SWAN H., 1976. The physiological interrelationship of reproduction, lactation and nutrition in the cow, 85-102. In H. SWAN, W. H. BROSTER, Principles of cattle production, Butterworths, London.

SYKES A. R., FIELD A. C., 1972. Effects of dietary deficiencies of energy, protein and calcium on the pregnant ewe. I. Body composition and mineral content of the ewes. J. agric. Sci. Camb., 78, 109-117.

SYKES A. R., FIELD A. C., GUNN R. G., 1974. Effects of age and state of incisor dentition on body composition and lamb production of sheep grazing hill pastures. J. agric. Sci., Camb., 83, $135-143$.

SYMONDS M. E., BRYANT M. J., LOMAX M. A., 1985. The effect of shearing on body tissue mobilization in pregnant sheep. Proc. Nutr. Soc., 44, 53A.

SYRSTAD O., STANDAL N., KARIJORD O., 1982. Concentration of various fatty acids in milk. Z. Tierzuechtg. Zuechtgsbiol., 99, 94-100.

TERQUI M., 1978. Contribution à l'étude des astrogènes chez la brebis et la truie. Thèse Doct. Etat ès-Sci., Univ. Paris 6, France.

TERQUI M., DELOUIS C., 1975. Les oestrogènes au cours de la gestation et de la parturition chez la brebis, 332-341. 1re Journ. Rech. ovine caprine, I.N.R.A. ITOVIC.

THILSTED S. H., 1983. The relationship between plasma glucose concentration, glucose utilization rate and partition of absorbed nutrients in the dairy cow. Diss. Abstr. Int., 44, 332.

THILSTED S. H., 1985a. Plasma glucose concentration and glucose turnover rate in the dairy cow in late pregnancy and early lactation. Z. Tierphysiol. Tierenaehrg. Futtermittelkde, 53, 1-9.

THILSTED S. H., 1985b. Regulation of the partition of nutrients in the dairy cow in late pregnancy and early lactation. Z. Tierphysiol. Tierenaehrg. Futtermittelkde, 53, 10-18.

THORDARSON G., McDOWELL G. H., FORSYTH I. A., SMITH S. V., 1984. Metabolic effects of placental lactogen in sheep. Nat. Inst. Res. Dairying, Rep. 1983, $94-95$ (Abstr.).

THYE F. W., WARNER R. G., MILLER P. D., 1970. Relationship of various blood metabolites to voluntary feed intake in lactating ewes. J. Nutr., 100, 565-572.

TISSIER M., BRELURUT A., 1979. Utilisation d'un ensilage d'herbe de qualité médiocre par la brebis à la fin de la gestation et au début de la lactation. Bull. Tech. CRZV Theix, I.N.R.A., 35, 59-65.

TISSIER M., MATHIEU C., THÉRIEZ M., 1980b. Effet du niveau d'apport énergétique et de la saison d'agnelage sur les performances des brebis allaitantes. Utilisation des réserves corporelles. Résultats préliminaires. In MATHIEU C., Mémoire Lab. Prod. Ovine (I.N.R.A.-Theix), ENSFA Rennes.

TISSIER M., THÉRIEZ M., 1978. Ovins, 403-448. In Alimentation des ruminants, Ed. I.N.R.A. Publ., 78000 Versailles, France.

TISSIER M., THÉRIEZ M., MOLÉNAT G., 1975. Evolution des quantités d'aliment ingérées par les brebis à la fin de la gestation et au début de la lactation. Incidences sur leurs performances. I. Etude de deux rations à base de foin de qualité différente. Ann. Zootech., 24, 711-727.

TISSIER M., THÉRIEZ M., MOLÉNAT G., 1977. Evolution des quantités d'aliment ingérées par la brebis à la fin de la gestation et au début de la lactation. Incidences sur leurs performances. II. Ration à base d'ensilage de maïs et de foin distribuée à volonté. Ann. Zootech., 26. 149-166. 
TISSIER M., THÉRIEZ M., PURROY A., BRELURUT A., 1980a. Energy utilization by ewes during pregnancy and lactation, 329-333. In L. E. MOUNT, Energy metabolism, Butterworths, London, EAAP Publ. $n^{\circ} 26$.

TREACHER R. J., 1978. Dietary protein levels and blood composition of dairy cattle, 133-142. In The use of blood metabolites in animal production, Br. Soc. Anim. Prod., Occasional Publ. $n^{\circ} 1$.

TREACHER R. J., REID I. M., ROBERTS C. J., 1986. Effect of body condition at calving on the health and performance of dairy cows. Anim. Prod., 43, 1-6.

TREACHER T. T., 1970. Effects of nutrition in late pregnancy on subsequent milk production in ewes. Anim. Prod., 12, 23-36.

TREACHER T. T., 1971. Effects of nutrition in pregnancy and in lactation on milk yield in ewes. Anim. Prod., 13, 493-501.

TRENKLE A., 1981. Endocrine regulation of energy metabọlism in ruminants. Fed. Proc., 40, 25362541.

TRENKLE A. H., 1969. The mechanisms of action of estrogens in feeds on mammalian and avian growth, 150-164. In The use of drugs in animal feeds. Nat. Acad. Sci., Washington, D.C.

TRIGG T. E., JURY K. E., BRYANT A. M., PARR C. R., 1980. The energy metabolism of dairy cows underfed in early lactation, 345-349. In L. E. MOUNT, Energy metabolism, Butterworths, London, EAAP Publ. $n^{\circ} 26$.

TRIGG T. E., PARR C. W., 1981. Aspects of energy metabolism of Jersey cows differing in breeding index. Proc. N. Z. Soc. anim. Prod., 41, 44-47.

TRIGG T. E., TOPPS J. H., 1981. Composition of body weight change during lactation in Hereford X British Friesian cow. J. agric. Sci., Camb., 97, 147-157.

TULLOH N. M., 1966. Physical studies of the alimentary tract of grazing cattle: IV. Dimensions of the tract in lactating and non-lactating cows. N. Z. J. agric. Res., 9, 999-1008.

TYRRELL H. F., BROWN A. C., REYNOLDS P. J., HAALAND G. L., PEEL C. J., BAUMAN D. E., STEINHOUR W. C., 1982. Effect of growth hormone on utilization of energy by lactating Holstein cows, 46-47. In A. EKERN, F. SUNDSTOL, Energy metabolism of farm animals, EAAP. Publ. $n^{\circ} 29$.

TYRRELL H. F., HAALAND G. L., 1983. A note on the body composition of dry, just calved, and mid-lactating Holstein cows. J. Dairy Sci, 66, supplt 1 (Abstr. p. 136).

VAN DER WALT J. G., 1984. Metabolic interactions of lipogenic precursors in the ruminant, 571-593. In F. M. C. GILCHRIST, R. I. MACKIE, Herbivore nutrition in the subtropics and tropics. The Sci. Press.

VAN DER WALT J. G., PROCOS J., LABUSChAGNE F. J., 1980. Glucose turnover, tolerance and insulin response in wethers, ewes and pregnant ewes in the fed and fasted state. Onderstepoort J. vet. Res., 47, 173-178.

VAN ES A. J. H., 1975. Feed evaluation for dairy cows. Livest. Prod. Sci, 2, 95-107.

VAN SOEST P. J., 1963. Ruminant fat metabolism with particular reference to factors affecting low milk fat and feed efficiency. A review. J. Dairy Sci., 46, 204-216.

VANDERMEERSCHEN-DOIZE F., PAQUAY R., 1984. Effects of continuous long-term intravenous infusion of long-chain fatty acids on feeding behaviour and blood components of adult sheep. Appetite, 5, 137-146.

VARMAN P. N., SCHULTZ L. H., 1968. Blood lipids of cows at different stages of lactation. J. Dairy Sc., 51, 1971-1974.

VARMAN G. C. E., JEACOCK M. K., SHEPHERD D. A. L., 1978. Hepatic ketone-body metabolism in developing sheep and pregnant ewes. Br. J. Nutr., 40, 359-367.

VASILATOS R., 1982. Nutritional and physiological aspects of growth hormone and insulin action in the bovine. Ph. D. Thesis, The Pennsylvania State University, USA.

VASILATOS R., WANGSNESS P. J., 1980. Changes in concentrations of insulin, growth hormone and metabolites in plasma with spontaneous feeding in lactating dairy cows. J. Nutr., 110, 1479-1487.

VASILATOS R., WANGSNESS P. J., 1981. Diurnal variations in plasma insulin and growth hormone associated with two stages of lactation in high producing dairy cows. Endocrinology, 108 , 300-304. 
VÉRITÉ R., JOURNET M., 1977. Utilisation des tourteaux traités au formol par les vaches laitières. II. Effets sur la production laitière du traitement des tourteaux et du niveau d'apport azoté au début de la lactation. Ann. Zootech., 26, 183-207.

VÉRITÉ R., JOURNET M., 1978. Vaches laitières, 345-376. In Alimentation des ruminants, I.N.R.A. Publ., 78000 Versailles.

VERMOREL M., BOCQUIER F., VERNET J., BRELURUT A., 1985. Mobilization and reconstitution of body reserves in dairy ewes studied by indirect calorimetry and D20 dilution technique. Comm. 10th int. Symp. Energy metabolism, Airlie, Virginia, USA, September 1985, $4 \mathrm{pp}$.

VERMOREL M., RÉMOND B., VERNET J., HART I. C., LIAMADIS D., 1982. Utilization of body reserves by high-producing cows in early lactation. Effects of crude protein and amino acid supply, 18-21. In A. EKERN, F. SUNDSTOL, Energy metabolism of farm animals, EAAP Publ. $n^{\circ} 29$.

VERMOREL M., VERNET J., MASSELIN S., THÉRIEZ M., 1984. Mobilisation des réserves corporelles chez la brebis en début de lactation. C. R. ATP-I.N.R.A. (non publié).

VERNON R. G., 1978. Lipogenesis in sheep adipose tissue maintained in tissue culture : effects of insulin and growth hormone. Biochem. Soc. Trans., 6, 988-990.

VERNON R. G., 1979. Lipogenesis in ovine adipose tissue in tissue culture. Ann. Rech. vét., 10. 399-400.

VERNON R. G., 1980. Lipid metabolism in the adipose of ruminant animals. Progr. Lipid. Res., 19, 23-106.

VERNON R. G., 1982. Effects of growth hormone on fatty acid synthesis in sheep adipose tissue. Int. J. Biochem., 14, 255-258.

VERNON R. G., 1984. Adenosine : a local modulator of adipose tissue metabolism. Hannah Res. Inst., Rep. 1983, 85-94.

VERNON R. G., 1986. The response of tissues to hormones and the partition of nutrients during lactation. Hannah Res. Inst., Rep. 1985, 115-121.

VERNON R. G., CLEGG R. A., FLINT D. J., 1981. Metabolism of sheep adipose tissue during pregnancy and lactation. Adaptation and regulations. Biochem. J., 200, 307-314.

VERNON R. G., CLEGG R. A., FLINT D. J., 1985a. Adaptations of adipose tissue metabolism and number of insulin receptors in pregnant sheep. Comp. Biochem. Physiol., 81B, 909-913.

VERNON R. G., CLEGG R. A., FLINT D. J., 1986. Adipose tissue metabolism in sheep: response to season and its modulation by reproductive state. Horm. Metabol. Res., 18, 308 312.

VERNON R. G., FINLEY E., 1985. Regulation of lipolysis during pregnancy and lactation in sheep. Response to noradrenaline and adenosine. Biochem. J., 230, 651-656.

VERNON R. G., FINLEY E., 1986. Endocrine control of lipogenesis in adipose tissue from lactating sheep. Biochem. Soc. Trans., 14, 635-636.

VERNON R. G., FINLEY E., TAYLOR E., FLINT D. J., 1985b. Insulin binding and action on bovine adipocytes. Endocrinology, 116, 1195-1199.

VERNON R. G., FLINT D. J., 1983. Control of fatty acids synthesis during lactation. Proc. Nutr. Soc., 42. 315-331.

VERNON R. G., FLINT D. J., 1984. Adipose tissue : metabolic adaptation during lactation. Symp. Zool. Soc. Lond, 51, 119-145.

VERNON R. G., TAYLOR E., FAULKNER A., 1984. Regulation of glucose metabolism in tissue of the sheep hindlimb : response to lactation. Can. J. amin. Sci., 64 (suppl.), 302-303.

VERNON R. G., TAYLOR E., 1986. Enzymes of adenosine metabolism of sheep adipose tissue : changes in activity with season, pregnancy and lactation. Horm. Metabol. Res., 18, 369-373.

VÉZINHET A., 1973. Influence de l'hypophysectomie et de traitements à I'hormone somatotrope bovine sur la croissance relative de l'agneau. Ann. Biol. anim. Bioch. Biophys., 13, 51-73.

VÉZINHET A., 1976. Etude du tissu adipeux chez l'agneau et le lapin après la naissance: développement, lipolyse, lipogenèse; influence de l'hypophysectomie et de l'hormone de croissance. Thèse Dr. ès Sci., Acad. Montpellier.

VÉZINHET A., KHERIF J. P., BOUTHIER E., 1974. Effet lipolytique in vivo de l'hormone somatotrope chez des agneaux normaux et hypophysectomisés soumis ou non à un jeûne. Ann. Biol. anim. Bioch. Biophys., 14, 781-791. 
VINCENT R., LINDSAY D, B., 1985. Effect of pregnancy and lactation on muscle protein metabolism in sheep. (Abstr.). Proc. Nutr. Soc., 44, 77A.

VINES D. T., CONVEY E. M., TUCKER H. A., 1977. Serum prolactin and growth hormone responses to thyrotropin releasing hormone in postpubertal cattle. J. Dairy Sci., 60, 19491957.

WAGHORN G. C., 1983. Modeling analyses of bovine mammary and liver metabolism. Diss. Abstr. Int., 44, 2B-3B.

WALKER C. K., ELLIOT J. M., 1973. Effect of roughage restriction on serum insulin in the dairy cow. J. Dairy Sci, 56, 375-377.

WALLACE L. R., 1948a. The growth of lambs before and after birth in relation to the level of nutrition. Part I. J. agric. Sci., 38, 93-153.

WALLACE L. R., 1948b. The growth of lambs before and after birth in relation to the level of nutrition. Part II and III. J. agric. Sci., 38, 243-302.

WALLACE L. R., 1948c. The growth of lambs before and after birth in relation to the level of nutrition. Part III. J. agric. Sci., 38, 367-401.

WALSH D. S., VESELY J. A., MAHADEVAN S., 1980. Relationship between milk production and circulating hormones in dairy cows. J. Dairy Sci, 63, 290-294.

WARRINGTON B. G., BYERS F. M., SHELLING G. T., BAKER J. F., FORREST D. W., GREENE L. W., 1985. Body composition changes during gestation in large and small mature size heifers receiving demarcated energy intakes. J. anim. Sci, 61, supplt 1, 458 (Abstr.).

WASTNEY M. E., WOLFF J. E., BICKERSTAFFE R., 1983. Glucose turnover and hepatocyte glucose production of starved and toxaemic pregnant sheep. Aust. J. biol. Sci., 36, 271-284.

WEST C. E., ANNISON E. F., 1964. Metabolism of palmitate in sheep. Biochem. J., 92, 573-578.

WIKTORSSON H., 1979. General plane of nutrition for dairy cows, 148-170. In W. H. BROSTER, H. SWAN, Feeding strategy for the high yielding dairy cow, Granada Publ. Ltd.

WILLIAMS W. F., LEE S. D., HEAD H. H., LYNCH J., 1963. Growth hormone effects on bovine blood plasma fatty acid concentration and metabolism. J. Dairy Sci., 46, 1405-1408.

WILSON S., 1983. Apparent re-esterification of fatty acids during lipolysis in pregnant ewes. Proc. Nutr. Soc., 42, 130A.

WILSON S., 1984. The metabolism of fatty acids in undernourished pregnant ewes. Can. J. anim. Sci., 64 (suppl.), 246-247.

WILSON S., MACRAE J. C., BUTTERY P. J., 1983. Glucose production and utilization in nonpregnant, pregnant and lactating ewes. Br. J. Nutr., 50, 303-316.

WITTENBURG H., HENSELER G., HOFFMAN L., 1974. Die Verwertung der Futterenergie fuer die Milchproduktion. 9. Mitteilung. Untersuchen ueber die chemische Zusammensetzung der Milch von Hochleistungskuehen im Fruehstadium der Laktation. Arch. Tierernaehr., 24, 139-148.

WRENN T. R., WEYANT J. R., MILLER R. W., BITMAN J., 1971. Alterations in blood and milk lipids produced by administration of Triton WR-1339. J. Dairy Sci., 54, 266-270.

YAMDAGNI S., SCHULTZ L. H., 1969. Metabolism of 1-14C palmitic acid in goats in various metabolic states. J. Dairy Sci., 52, 1278-1288.

YANG Y. T., BALDWIN R. L., 1973a. Lipolysis in isolated cow adipose cells. J. Dairy Sci., 56, 366-374.

YANG Y. T., BALDWIN R. L., 1973b. Preparation and metabolism of isolated cells from bovine adipose tissue. J. Dairy Sci, 56, 350-365.

YOUNG J. W., 1977. Gluconeogenesis in cattle: significance and methodology. J. Dairy Sci., 60, 1-15.

YOUSEF I. M., EMERY R. S., ASKEW E. W., BENSON J. D., THOMAS J. W., HUBER J. T., 1969. Comparison of several enzymes and components of milk, blood and tissues between cows and ewes. J. Dairy Sci, 52, 1577-1581.

ZANARTU D., POLAN C. E., FERRERI L. E., McGILLIARD M. L., 1983. Effect of stage of lactation and varying available energy intake on milk production, milk composition, and subsequent tissue enzymic activity. J. Dairy Sci., 66, 1644-1652. 